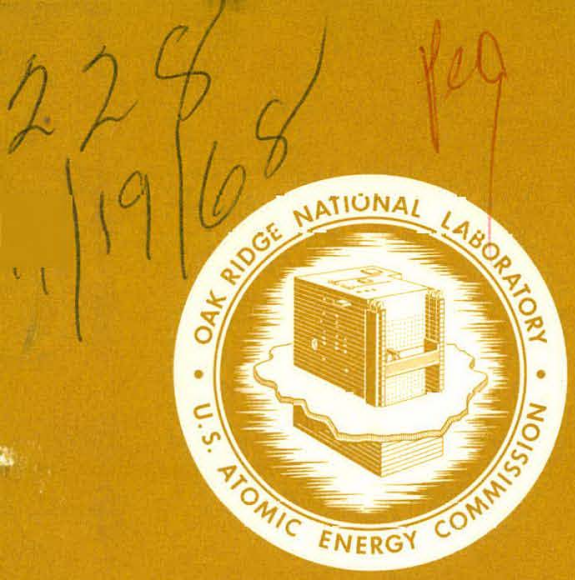

OAK RIDGE NATIONAL LABORATORY

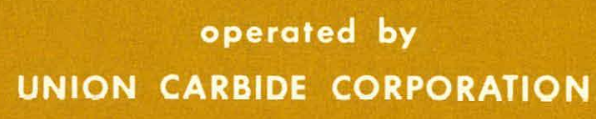

for the

U.S. ATOMIC ENERGY COMMISSION

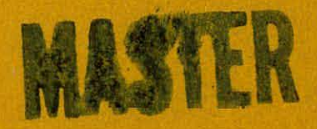

ORNL-NSIC-24

UC-80 - Reactor Technology

\title{
EMERGENCY CORE-COOLING SYSTEMS FOR LIGHT-WATER-COOLED POWER REACTORS
}

C. G. Lawson

NUCLEAR SAFETY INFORMATION CENTER

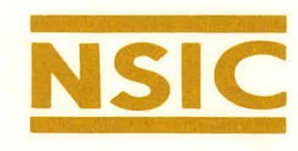




\section{DISCLAIMER}

This report was prepared as an account of work sponsored by an agency of the United States Government. Neither the United States Government nor any agency Thereof, nor any of their employees, makes any warranty, express or implied, or assumes any legal liability or responsibility for the accuracy, completeness, or usefulness of any information, apparatus, product, or process disclosed, or represents that its use would not infringe privately owned rights. Reference herein to any specific commercial product, process, or service by trade name, trademark, manufacturer, or otherwise does not necessarily constitute or imply its endorsement, recommendation, or favoring by the United States Government or any agency thereof. The views and opinions of authors expressed herein do not necessarily state or reflect those of the United States Government or any agency thereof. 


\section{DISCLAIMER}

Portions of this document may be illegible in electronic image products. Images are produced from the best available original document. 


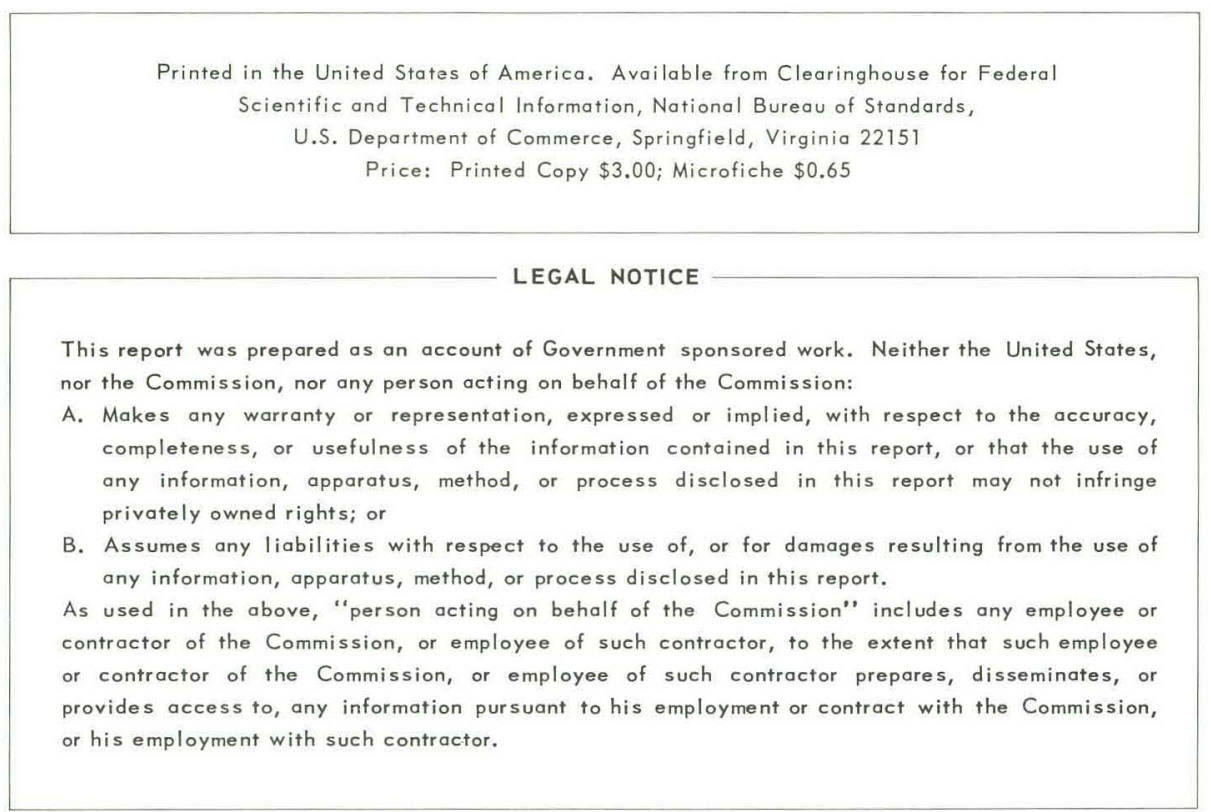


Contract No. W-7405-eng-26

Nuclear Safety Information Center

\title{
EMERGENCY CORE-COOLING SYSTEMS FOR LIGHT-WATER- COOLED POWER REACTORS
}

\author{
C. G. Lawson
}

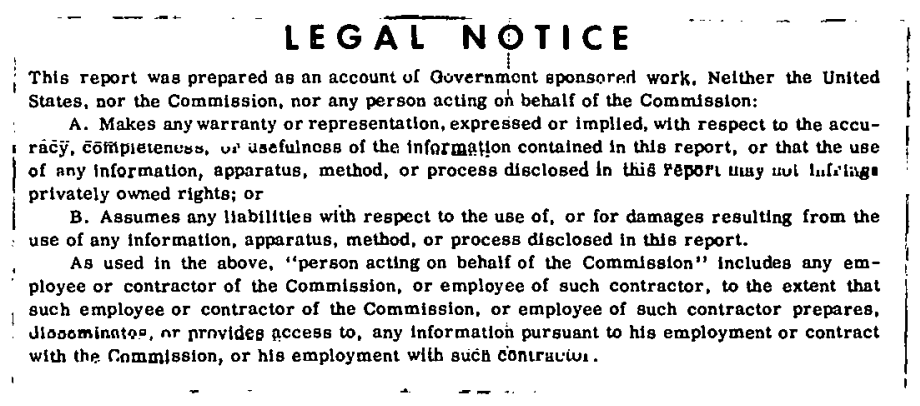

OCTOBER 1968

OAK RIDGE NATIONAL LABORATORY

Oak Ridge, Tennessee

operated by

UNION CARBIDE CORPORATION

for the

U.S. ATOMIC ENERGY COMMTSSION 
THIS PAGE

\section{WAS INTENTIONALLY LEFT BLANK}


FOREWORD

The recent surge in the building of large nuclear power plants, particularly with the projected desirability of using urban sites for such installations, has focused attention on many aspects of the AEC's responsibilities for licensing reactors and insuring the public safety. Since the industry is "young," meaningful, long-term operating experience is sparse and the definition of the possible accident spectrum, as well as a set of firm design requirements, is subject to a largely analytical. approach that necessarily involves conservative judgments. As plant designs become standardized and operating experience on the newer large reactors is gained, the inevitable process of refinement and of acquiring confidence in the operation of the plants will occur. This relatively slow evolutionary approach to acquiring firm design standards and criteria is not felt to be conducive to achieving the great national benefits of atomic energy within a reasonable time, in terms of the conservation of resources, combating air pollution, and the multitude of gains resulting from low-cost electricity.

As part of the effort to improve on this approach, the Regulatory Review (Mitchell). Panel recommended the formation by the AEC of a Steering Commititee on Reactor Safety Research to coordinate the needs of the Regulatory Program with the direction of the safety research and development programs. This committee, in turn, recommended that several studies be undertaken to provide guidance for the research and development projects, and this was, in turn, implemented by the AEC Division of Reactor Development and Technology into the series of discussion reports herein described. It was intended that these reports provide a comprehensive assessment of the present status of specific aspects of nuclear safety and, by identifying accepted technology and the technology needing further experimental verification, that they enhance the understanding and confidence in this new. industry.

Accordingly a number of the safety aspects of large light-water power reactors were selected by the $\mathrm{AEC}^{*}$ as subjects for detailed study to

*Ietter from Milton Shaw (Director, AEC Division of Reactor Development and Technology) Lu ORNL, March 20, 1066. 
ascertain whether gaps in knowledge exist and where a research and development program could be of benefit. The subjects selected cover many of the areas for which inadequate factual bases exist and in which research that duplicates expected conditions is very difficult to perform. In general the subjects are in areas considered critical in the safety analysis of power reactor installations. Eight subjects were identified and a state-of-technology type of discussion report was prepared on each. The reports, which are directed primarily toward a technical-management audience, generally compare existing or planned plant applications with what is capable of being done at this time. Such comparisons have helped to identify inadequacies in assumptions, available data, or general basic knowledge so that, together with the opinions of experts in a particular field, areas of meaningful research and development have been identified. This report is one of the series of eight companion reports listed below:

\section{Title}

Missile Generation and Protection in Light-Water-Cooled Power Reactor Plants

Potential Metal-Water Reactions in Light-Water-Cooled Power Reactors

Emergency Core-Cooling Systems for Light-Water-Cooled Power Reactors

Air Cleaning as an Engineered Safety Heature in Light-Water-Cooled Power Reactors

Testing of Containment Systems Used with Light-Water-Cooled Power Reactors

Review of Methods of Mitigating Spread of Radioactivity from a Failed Containment System

Earthquakes and Nuclear Power Plant Design

Protection Instrumentation Systems in Light-Water-Cooled Power Reactor Plants
Author

ORNL-NSIC

No.

R. C. Gwaltney

22

H. A. McLain

23

C. G. Lawson

24

G. W. Keilholtz,

C. E. Guthrie, and

G. C. Battle, Jr.

F. C. Zapp

26

R. C. Robertson

27

T. F. Lomenick and

28

C. G. Bell

C. S. Walker

29 
Although not specifically one of this series, a related discussion report on reactor pressure vessels, ORNL-NSIC-2l, edited by G. D. Whitman, G. C. Robinson, and A. W. Savolainen, has also been prepared at ORNL.

The general approach in the preparation of these reports was to select a primary author-investigator knowledgeable in the subject area and to establish committees of experts to review the work at several stages during its preparation. Review groups were formed both from within ORNL and outside. The external review committee members were drawn principally from other national laboratories, universities, and private research institutes - in a.1.], 52 individuals participated and are identified in the reports. In some cases, part of the material used was developed and/or written by a subcontractor, who is similarly identified. In all cases, correspondence and/or visits were made to many sources of information, particularly to reactor operators, suppliers, architect-engineers, and public utilities, as well as to the appropriate national laboratories. This wide use of acknowledged experts was made in an attempt to include their opinions and knowledge toward the ultimate goal of achieving, through intensive research and development programs, well-defined design criteria to insure the public health and safety and to maintain a viable nuclear power industry. However, in all instances the authors have expressed conclusinns and recommendations that reflect their own judgment and not that of any particular group, such as the AEC, reactor designers, or utilities.

In most subject areas more information was developed than it has been possible to include in the body of the reports prepared in this series. In some instances, such information has been included in the appendices and in other instances this information will be included in more technically oriented reports to be published in the near future. In addition, it is expected that additional discussion reports will be written on some of the many other safety aspects of large water-cooled reactors, as well as other types of reactors as they come into wider usage.

J. W. Michel

Coordinator, Discussion Papers

Oak Ridge National Laboratory

Wm. B. Cottrell

Director, Nuclear Safety Program

Oak Ridie National Laboratory 
THIS PAGE

\section{WAS INTENTIONALLY LEFT BLANK}


The Nuclear Safety Information Center was established in March 1963 at the Oak Ridge National Laboratory under the sponsorship of the U.S. Atomic Energy Commission to serve as a focal point for the collection, storage, evaluation, and dissemination of nuclear safety information. A system of keywords is used to index the information cataloged by the Center. The title, author, installation, abstract; and keywords for each document reviewed is recorded on magnetic tape at the central computer facility in Oak Ridge. The references are cataloged according to the following categories:

1. General Safety Criteria

2. Siting of Nuclear Facilities

3. Transportation and Handling of Radioactive Materials

4. Aerospace Safety

5. Accident Analysis

6. Reactor Transients, Kinetics, and Stability

7. Fission Product Release, Transport, and Removal

8. Sources of Energy Release Under Accident Conditions

9. Nuclear Instrumentation, Control, and Safety Systems

10. Electrical Power Systems

11. Containment of Nuclear Facilities

12. Plant Safety Features

13. Radiochemical Plant Safety

14. Radionuclide Release and Movement in the Environment

15. Environmental Surveys, Monitoring and Radiation Exposure of Man

16. Meteorological consideraliuns

17. Operational Safety and Experience

18. Safety Analysis and Design Reports

19. Bibliographies

Computer programs have been developed that enable NSIC to (1) produce a quarterly indexed bibliography of its accessions. (issued with ORNL-NSIC report numbers); (2) operate a routine program of selective Dissemination of Information (SDI) to individuals according to their particular profile of interest; and (3) make retrospective searches of the references on the tapes.

Other services of the Center include principally (1) preparation of state-of-the-art reports (issued with ORNL-NSIC report numbers); (2) cooperation in the preparation of the bimonthly technical progress review, Nuclear Safety; (3) answering technical inquiries as time is available, and (4) providing counsel and guidance on nuclear safety problems. 
Services of the NSIC are available without charge to government agencies, research and educational institutions, and the nuclear industry. Under no circumstances do these services include furnishing copies of any. documents (except NSIC reports), although all documents may be examined at the Center by qualified personnel. Inquiries concerning the capabilities and operation of the Center may be addressed to

J. R. Buchanan, Assistant Director Nuclear Safety Information Center Oak Ridge National Laboratory

Post Office Box Y Oak Ridge, Tennessee 37830 Phone 615-483-8611; Ext. 3-7253 FTS 615-483-7253 


\section{ACKINOWLEDGMENTS}

The author wishes to acknowledge the helpful discussions with the staff members of the AEC; the General Electric Company at San Jose; Westinghouse Atomic Power Division; Combustion Engineering Company at Windsor Locks; Babcock \& Wilcox at Lynchburg, Virginia; the LOFT program, Plant Applications and Test Engineering, and the Water Reactor Safety Planning Office at the Phillips Petroleum Company, NRTS; the chairman of the Industrial Advisory Committee on Power Reactor Emergency Core Coolant Systems; members of the Oak Ridge National Laboratory Internal Review Committee; and Mr. A. E. Dukler, P. Lottes, Gil Brown, Dave Morrison, W. B. Cottrell, and John Michel. These staffs and individuals contributed immeasurably in discussions and information. In addition, the staff of the Nuclear Safety Information Center was indispensable in supplying documents and suggestions. 
THIS PAGE

\section{WAS INTENTIONALLY \\ LEFT BLANK}




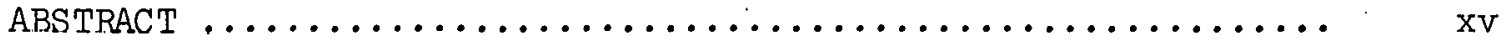

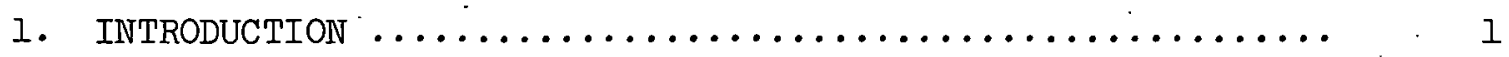

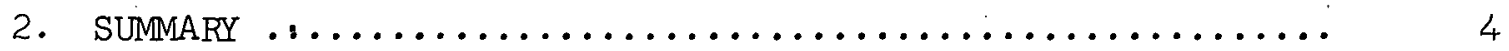

3. STATE OF CURREINT DESIGN TECHNOLOGY $\ldots \ldots \ldots \ldots \ldots \ldots \ldots \ldots \ldots$

3.1 Description of Boiling-Water Reactor Core and Emergency Core-Cooling System .............. 11

3.1.1 Core Design ....................... Il

3.1.2 Emergency Core-Cooling System Design ......... 14

3.1.3 Primary System Automatic Relief valves ....... 23

3.1.4 Condensate Pumping System ............... 24

3.1.5 Operation of Emergency Core-Cooling

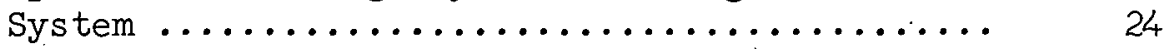

3.2 Descriptions of Pressurized-Water Reactor Cores

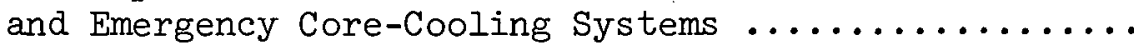

3.2.1 Sequence of Events Following Pipe

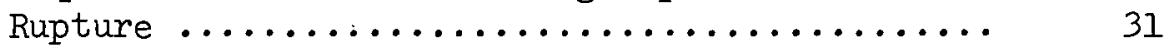

3.2.2 Emergency Cooling of Turkey Point Reactor .......................... 40

3.2.3 Emergency Cooling of Palisades Reactor ....... 43

3.2.4 Emergency Cooling of Oconee Rcactorc ......... 45

3.3 Special Considerations for Pressurized-Water

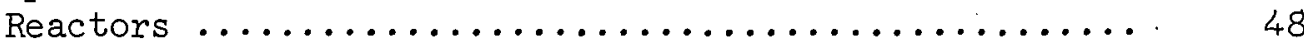

3.3.1 Damage from Blowdown Forces ............ 48

3.3.2 Distribution of Emergency Coolant Within Core ........................ 4.9

3.3.3 Heat Sources Within Core Following Pipe Rupture ....................... . 49

3.4 Considerations Common to PWR's and BWR's .......... 50

3.4.1 Thermal Conditions of the Fuel Elements and Pressure Vessel After Blowdown .......... 50

3.4.2 Core Heat Sources ................. 52

3.4.3 Heat Transfer Coefficients Required to

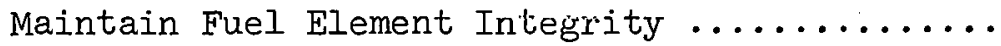


3.4.4 Heat Sinks for Emergency Cooling System ......

3.4.5 Reliability of Emergency Core-Cooling

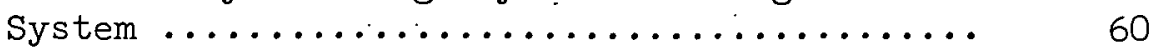

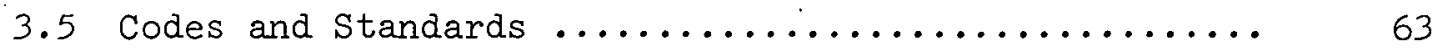

4. EXPERIMENTAL DATA AND ANALYSES AVAILABLE FOR

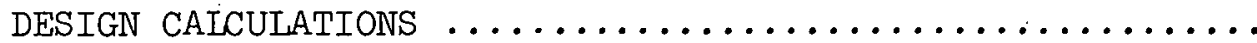

4.1 Computer Programs for Calculating Consequences of Emergency In-Core Cooling Situations ..........

4.2 Heat Sources .......................... 67

4.3 Heat Transfer and Cooling of Fuel Rods ........... 70

4.3.1 Effect of Blowdown History on Cladding Temperature ........................ 70

4.3.2 Effect of Cladding Temperature on Heat Transfer Rates in Spray Cooling .......... 75

4.4 Heat Transfer by Flooding ................... 84

4.4.1 Effectiveness ..................... 84

4.4.2 Limits. on Steam and Heat Removal............ 86

4.5. Heat Transfer by Radiation.- Minimum. Flow

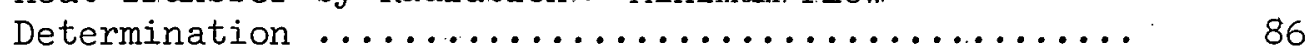

5. CONCLUSION AND RECOMMENDATIONS ................. 88

5.1 Removal of Energy Sources ................. 88

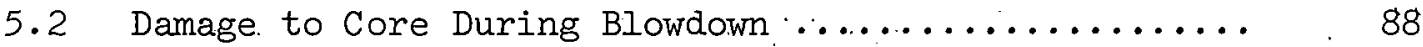

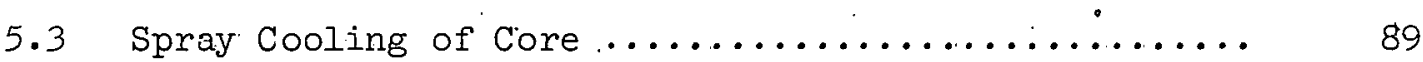

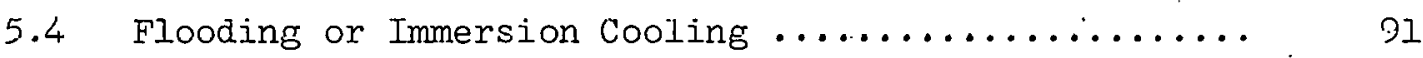

5.5 Structural Integrity of Core During Heatup ......... 91

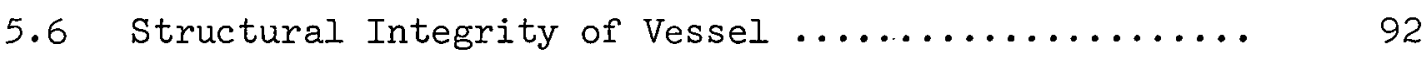

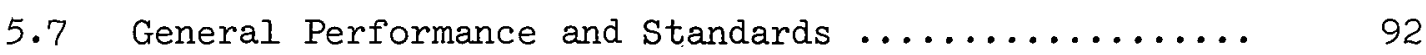

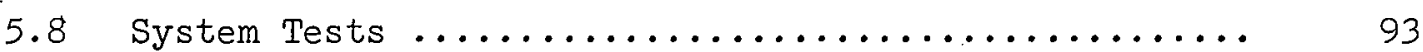

5.9 Design Improvements ...................... 94

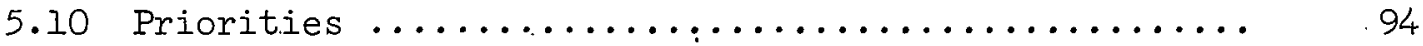

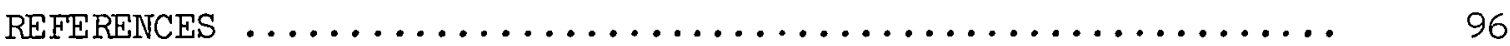

APPENDIX A. PERTINENT AEC GENERAL DESIGN CRITERIA .......... 103

APPENDIX B. THE LOSS-OF-COOLANT ACCIDENT ANALYSIS FOR OCONEE NUCLEAR STATION $\ldots \ldots \ldots \ldots \ldots \ldots \ldots \ldots \ldots \ldots$

APPENDIX C. DESCRIPTION OF CALCULATIONAL METHODS AND DIGITAL COMPUTER CODES FOR ANALYZING COOLANT BLOWDOWN AND CORE HEATUP PHENOMENA ........... 137 
APPENDIX D. COMPANIES, INSTALIATIONS, AND PERSONS VISITED 
THIS PAGE

\section{WAS INTENTIONALLY LEFT BLANK}




\begin{abstract}
The emergency water-injection and core-cooling systems of four lightwater-cooled reactors are described and reviewed. The designer's bases for establishing system parameters, such as pump flow rates and startup times, are discussed, and data available on these systems are compared with the design bases. It is concluded that the systems now being designed require that extrapolations be made of the existing information to prove adequate performance of the emergency systems for the most severe accident considered; that is, an instantaneous rupture of the largest primary coolant circulating line.

The Atomic Energy Commission and the, nuclear industry have initiated both experimental and analytical programs to obtain data for proving the effectiveness of the systems now being designed and those contemplated for future plants. Also, programs are under way to establish industrywide codes and standards to assure the quality of the nuclear power plants designed, built, and operated in the United States.
\end{abstract}




\section{INTRODUCTION}

The achievement of economic nuclear power has been primarily due to technological developments that permitted significant increases in specific power, burnup of fuel, and individual plant capacity. These advances rendered isolation by distance an impractical means of assuring safety of the public in the event of a reactor accident and consequently magnified the importance of engineered safety features for preventing accidental release of radioactivity from within the reactor core. Emergency core cooling is an engineered safety feature that is extensively employed because of its postulated effectiveness in mitigating the consequences of a loss-ofcoolant accident.

Emergency core-cooling systems are installed in commercial power reactors to assure heat removal from the fuel during and after reactor shutdown in the event that some accident occurs that results in the rupture of the primary cooling system and loss of the reactor coolant. The large range of possible rupture sizes and the need for assured cooling result in a number of subsystems for each reactor. These subsystems may include core spray systems, water storage or accumulator turiks, high-volume low-head pumps, low-volume high-head pumps, storage tanks for water boronated for reactivity control, and other heat-removal systems. These loops are often installed in duplicate (redundant systems), and the active components, such as valves, pumps, and instruments, may be installed in parallel (redundant active components) to improve both availability and overall reliability.

The emergency core-cooling systems now being designed for reactors wi.th power levels in the 1000-Mw(e) range will have the ability to control afterheat-generation rates greater than $100 \mathrm{Mw}(\mathrm{th})$ for the first few minutes after the control rods are inserted or the reactor core is shut down by some other mechanism. During the first hour after the reactor is subcritical, about $60 \mathrm{Mw}-\mathrm{hr}$ of decay heat and an additional $60 \mathrm{Mw}-\mathrm{hr}$ of stored thermal energy must be removed from the fuel elements to return the core to the ambient temperature of the stored emergency coularit. The uncontrolled release of this thermal energy could lead to penetration of 
the reactor containment vessel and release of fission products. In recognition of this situation, the Advisory Committee on Reactor Safeguards of the Atomic Energy Commission has recommended a vigorous and accelerated effort to test the effectiveness of emergency core-cooling systems, understand the conditions under. which they are required to function, and if necessary, to improve their effectiveness and reliability.

Data and standards are needed to guide the Atomic Energy Commission's Regulatory Staff and the nuclear industry in assuring the adequacy of the engineered safety features, first, to survive the accident and, then, to function in the variety of accident environments to which they may be exposed. These data and standards must be sufficiently general to apply to future reactors as well as those currently being designed. Pertinent general design criteria for nuclear power plant construction permits, as proposed by the AEC, are presented in Appendix A, and this report discusses some of the information required. to prepare. the more specific performance standards that are needed.

A report entitled "Emergency Core Cooling" 1 was prepared recently for the AEC by an advisory task force. This report also discusses the response of the emergency core-cooling system to a loss-of-coolant accident and some research and development needs.

The iossmfoconlant accident is a hypothetical referelice accilent used in discussing emergency core-cooling system response and capabilities. This assumed accident is a primary system rupture of any size up to an instantaneous double-ended rupture of the largest pipe attached to the reactor pressure vessel. Should this large break occur, the emergency core-cooling system must respond in a manner that will protect the health and safety of the public.

This report discusses four typical light-water-cooled reactors currently being designed to determine the state-of-the-art relating to the design of their emergency core-cooling systems. Discussions were held with the staff's of each of the reactor manufacturers concerning their design of the emergency core-cooling system and with the individuals of the Phillips Petroleum Company at the National Reactor Testing Station involved in research on the consequences of a loss-of-coolant accident. 
The emphasis in this report is on the manufacturers stated design capabilities of the intended emergency core-cooling systems, the extent to which these capabilities have been established, examinations of pertinent information, and attempts to determine where new information may increase understanding of the capabilities of these systems for preventing release of radioactivity during loss-of-coolant situations.

Published information available in late 1967 is presented. This information will be increased greatly in the near future because of the cfforts by the $\mathrm{AEC}$ and industry to improve reliability of emergency corecooling systems through analysis, design, development, and testing. 


\section{SUMMARY}

The emergency core-cooling systems now being designed for commercial light-water-cooled and -moderated power reactors and information available on their performance have been reviewed and analyzed from the viewpoint of reliability, testability, and effectiveness. Based on these analyses, areas are delineated where additional experimental and design effort may improve the understanding and performance of emergency corecooling systems.

Emergency core-cooling systems are engineered safety features of nuclear reactors. In the event of an improbable, but possible, primary system rupture, the emergency core-cooling system is designed to reduce the temperature of the core materials and the pressure and temperature of the containment atmosphere to levels that will assure containment vessel. integri.ty. If the emergency system failed to remove the energy stored in the fuel and the fission-product decay energy, the core might melt. As the molten mass dropped it would contact water remaining in the pressure vessel and release large quantities of energy in a period of about $1 / 2$ to $1 \mathrm{hr}$ that might rupture the pressure vessel.1,2 Upon rupture of the pressure vessel, the molten mass might contact additional water in the containment vessel and thus increase the likelihnnd nf ripture of the containment vessel and leakage of fission products to the environment.

The loss-of-coolant design accident with the emergency cooling system operating as designed includes the following four chronological steps:

1. System depressurization (which takes about $10 \mathrm{sec}$ in a PWR and about 30 sec in a BWR for the largest rupture considered).

2. Fuel and cladding heatup (until the emergency cooling system becomes effective).

3. Addition of emergency coolant and the resulting cooldown of the fuel elements.

4. Continued cooling of the reactor until recovery operations are completed.

If all the emergency cooling equipment operated as designed, the quenching of the core could be accomplished in 2 min or less in the event 
of the postulated design-basis accident; which is a double-ended rupture of the largest single pipe attached to the reactor core with only onsite emergency power available.

The primary requirements of an emergency core-cooling system are

1. To provide reliable cooling in the event of any pipe breaks within the design range by rapidly adding and distributing large amounts of emergency coolant to the core and throughout the fuel bundles to remove stored energy and decay heat and thereby to reduce the core temperature to that of the coolant. A number of subsystems are provided that operate at different flow rates and pump heads to meet this requirement. In addition, identical subsystems are installed in parallel to assure operation in the event accidents cause failure of active components or damage to passive components. The larger the pipe break, the more rapid would be the primary coolant leakage and the greater and sooner the need for the emergency coolant. For the larger design break, BWR systems with the Browns Ferry type of core would provide coolant to the core in the form of a spray at a flow rate of at least $1.8 \mathrm{gpm}$ per rated thermal megawatt within $30 \mathrm{sec}$ and, in addition, they would reflood the core in less than 2 min after the recirculation break. The most recent PWR systems, which include pressurized water-filled gas-activated storage tanks or accumulators, are designed to ad, enough boronated water to cover the core at least halfway up the active fuel elements within $30 \mathrm{sec}$ after the design break occurs. The use of water storage tanks or accumulators provides a substantial margin in the time required to start an emergency diesel-generator and pump (about $30 \mathrm{sec}$ ) by rapid.l.y injecting coolant and removing thermal energy initially stored in the fuel. In both types of reactor the cladding of 50 to over 90\% of the fuel rods may be perforated or ruptured, even with the emergency systems operating properly.

2. To supply long-term continuity of cooling by operating reliably for months after a large break, although not at the high initial flows. Equipment such as motors, pumps, and valves should therefore be designed for long-term operation, which implies accessibility for maintenance and testing. 
3. To provide a reliable power source for all equipment associated with * the emergency core-cooling system. The emergency power supply should therefore be tested under design load and operated at frequent intervals for a sufficient length of time to assure its long-term availability. In addition, prototype tests should be performed under environmental conditions simulating the design accident to assure the water delivery capability and effectiveness of the emergency cooling system. In anticipation of future reactors with higher performance fuel, the need should be determined for emergency power sources capable of more rapid starting.

The assumptions made by reactor designers in computing the temperature-time behavior of the fuel following a loss-of-coolent accident are generally conservative in that the calculated rate of temperature rise is based on assumptions that overestimate the stored energy of the fuel. The underlying assumption that the physical: state of the coolant, cladding, and fuel may be calculated. up to the melting temperature of the cladding. has not been. substantiated because of the unusual materials. problems and the expense involved in obtaining experimental data at temperatures approaching the melting points.of Zircaloy and uranium dioxide. Tests of emergency: cooling equipment have never been performed in the environmental conditions: of the dynamic pressure, temperature; and humidity that might prevail in a loss-of-coolant accident. Accordingly, tests of prototypes should be performed to demonstrate that the emergency equipment can survive and deliver conlant to the reactor pressure vessel under the transient conditions. System analyses should be conducted to assure that the emergency core-cooling system is completely independent of other reactor systems and that it is an asset to plant safety in all operational modes. These analyses and tests would supplement the current work on pressure vessel blowdown and core heatup for determining system effectiveness.

The capability for water to enter and distribute among the hot fuel elements, either upon spraying or flooding, should be demonstrated. For cores with Zircaloy-clad fuel elements, the demonstration should be carried out at temperatures from $2500^{\circ} \mathrm{F}$ up to the melting temperature of 
Zircaloy. Data should be obtained so that the physical as well as chemical interactions of Zircaloy and water at these temperatures are understood. Such data will permit determination and evaluation of the margin of safety existing in a design and the adequacy of the phenomenological models used in the analysis. Considerable analytical support is clearly needed to assure interpretation of test data in a manner applicable to reactor systems.

From the review of emergency cooling systems presented in safety analysis reports on boiling- and pressurized-water reactors, it is clear that these two types of reactor have different systems for securing emergency core cooling; yet both may be "equally safe." The emergency systems of both are designed to cope with the conditions existing as a consequence of a pipe rupture. The BWR operates at about 1100-psig saturated boiling and has a relatively small ratio of potential break size to pressure vessel cross section. This results in a depressurization process that is calculated to take at least $30 \mathrm{sec}$ for the largest break. The specific power of the BWR fuel is about $20 \%$ lower than that of PWR fuel, and hence the decay heat would not increase the fuel temperature as rapidly. The calculated time required to reach melting of the cladding with no emergency cooling and a conservative model is $2 \mathrm{~min}$. Thus the emergency cooling system is designed to add water to the pressure vessel through a spraying system and a flooding system even it emergency onsite power is required. The operation of either the spraying or flooding system is designed to prevent cladding melting. For small leaks the system pressure may not fall rapidly enough for the flooding and spraying systems to inject water. Thus there is a steam-turbine-driven pump that injects coolant to the reactor vessel at system pressure and an automaticpressure-relief system that depressurizes the pressure vessel and permits earlier coolant injection by the spraying and flooding systems.

- The spraying and flooding principles have been tested at atmospheric conditions with stainless steel-clad simulated fuel rods not pressurized to simulate fission gas. These test's need to be carried out with materials and thermodynamic conditions of pressure and temperature more closely simulating the reactor design-basis accident. Insufficient data exist to discrimiriate realistically among the poscible occurrences if 
an array of hot, pressurized Zircaloy-clad rods is sprayed or inundated with water in a confined vessel. Consequently, the selection of "cladding melting" as a part of the design-basis criteria for the safety margin may be considered tentative and arbitrary. However, the data that are available appear to support the capability of the emergency cooling system to perform its function unless the accident destroys both the spray and the flooding systems.

Pressurized-water reactors operate at about 2100 psig with subcooled water as the coolant moderator. For the largest potential pipe rupture the loss of coolant occurs in about $10 \mathrm{sec}$. This is more rapid than the BWR blowdown because of the higher initial pressure, the lower coolant inventory, and the larger ratio of pipe size to vessel volume. The very rapid blowdown requires a rapid addition of coolant because of the higher levels of stored thermal energy, the higher decay heat levels, and the higher operating specific power. Consequently, the PWR emergency corecooling system includes pressurized-water-storage tanks' designed to "reflood" the core inside the pressure vessel within $30 \mathrm{sec}$ after an assumed instantaneous large pipe break. In addition to the pressurized-storage tanks, the emergency cooling system includes two sets of pumps. One set of high-head low-flow pumps is designed to maintain coolant inventory for small breaks until an oxderly reactor shutdown is achiever. The second set of pumps consists of low-head high-flow pumps designed to add water to the pressure vessel continuously as part of the residual heat-removal system. Vapor venting of the higher temperature reactor coolant outlet lines without vapor binding the core during the reactor depressurization is achieved by venting through the pressurizer and by using check valves that prevent flow into the pressure vessel through the reactor vessel outlet lines. The PWR utilizes a flooding system because the core lies below all pressure vessel connecting lines of any size. The emergency cooling water is boronated for reactivity control.

$\mathrm{All}$ the light-water-cooled reactor emergency core-cooling systems are designed to limit peak cladding temperatures during the loss-ofcoolant accident to below $2400^{\circ} \mathrm{F} \cdot$ with only emergency power available. There exists at this time such a limited amount of information on the 
behavior during a loss-of-coolant accident of Zircaloy-clad fuel rods internally pressurized with fission gas that a positive conclusion of adequacy of these emergency systems would be speculative.

The extent to which an emergency core-cooling system performs its intended function may be evaluated in terms of the following conditions and critical temperatures.

Critical

Temperature

$\left({ }^{\circ} \mathrm{F}\right)$

Condition

$\sim 700$

Normal cladding temperature at power

$1500 \pm 300$

Cladding is perforated as a result of internal fission-gas pressure in the postaccident environment; some fission gases are released; eutectic formation between Zircaloy and stainless steels begin; flow blockage may occur from swelling

$2100 \pm 100 \quad$ Zircaloy-steam-reaction rate may produce energy in excess of decay heat if steam contacts Zircaloy; gas absorption embrittles Zircaloy

$2700 \quad$ Steel alloys melt

$\sim 2800 \cdot \quad$ Zircaloy-steam reaction may become autocatalytic unless Zircaloy is quenched by immersion

3400 Zircaloy melts; fission-product release from $\mathrm{UO}_{2}$ becomes increasingly significant above $3400^{\circ} \mathrm{F}$

$\sim 4800 \quad \mathrm{UO}_{2}$ and $\mathrm{ZrO}_{2}$ melt

Generally, the emergency cooling systems are designed to prevent cladding melting and to keep the total metal-water reaction at a level under $1 \%$ of the core Zircaloy based on a conservative calculational model. Specifically, the following matters need to be clarified to demonstrate the complete adequacy of these criteria:

1. Does the cracking, bulging, bowing, disintegration, or other deformation of the fuel rods that occur during blowdown, heating, or cooling in the loss-of-coolant accident with the emergency cooling system operating interfere with the effectiveness of the emergency core-cooling system? If so, does an acceptable design alternative exist? 
2. How much latitude exists in the design of the cooling system? What is the margin of safety. in (a) time to start, (b) maximum cladding temperature, (c) fuel specific power, and (d) load on core internals during blowdown? These questions should be answered by reference to experimental data obtained on a significant scale in which successful operation is demonstrated.

3. Experimental verification supported by analysis should continue to be required at all temperatures related to the loss-of-coolant accident to prove that the situation is controllable as opposed to the current process where the applicant's design is probed for faults.

4. The sequential meshing of the blowdown pressure and the injection of emergency coolant are critical in evaluating the course of the blowdown accident. The adequate meshing of process and equipment performance is extremely complicated and has been discussed analytically, but it has been largely ignored experimentally. Experimental demonstration is required to show that the blowdown-injection-cooling process reliably achieves recovery from a loss-of-coolant accident before the containment system is damaged.

The above items are all considered to be of prime importance in assuring the safety of a reactor plant in a loss-of-coolant accident. It is not possible, therefore, to establish a relative priority among them or an order of importance. 


\section{STATE OF CURRENT DESIGN TECHIOLOGY}

Designs that are typical of the most advanced of the current watercooled reactors were selected for study. These reactors include the Tennessee Valley Authority's Browns Ferry reactor as representative of a General Electric Company boiling-water reactor, the Turkey Point reactor of Florida Power and Light Company as a Westinghouse Electric Corporation pressurized-water reactor, the Oconee reactors of Duke Power Company as Babcock \& Wilcox Company pressurized-water reactors, and the Palisades plant of Consumers Electric Power Company as a Combustion Engineering Company pressurized-water reactor.

Much of the information on these designs is extracted and paraphrased directly from the preliminary safety analysis reports and the supplements to these reports, which are available in the AEC's Public Document Room. All these designs are currently being considered by the Division of Licensing and are subject to change.

The boiling-water reactor is discussed first because more information is available on the design and performance of its emergency corecooling system than for the other reactors. The pressurized-water reactor is discussed next, and at the end of this section, certain considerations common to both reactors are analyzed. The items common to both types of reactor include codes and standards, heat sources, emeryency power supplies, and other considerations.

\subsection{Description of Bolling-Waler Reactur Cure and Emergency Core-Cooling System}

\subsubsection{Core Design}

A schematic drawing of a boiling-water reactor is shown in Fig. 3.1. The enriched $\mathrm{UO}_{2}$ fuel is contained in a cylindrical assembly of square channels. Each fuel channel is a shrouded $7 \times 7$ square array of Zircaloyclad $\mathrm{UO}_{2}$ rods, as shown in Fig. 3.2. The control rods and sheets fit between the fuel channel shrouds. The reactor control rods are driven into the core from below the reactor. 


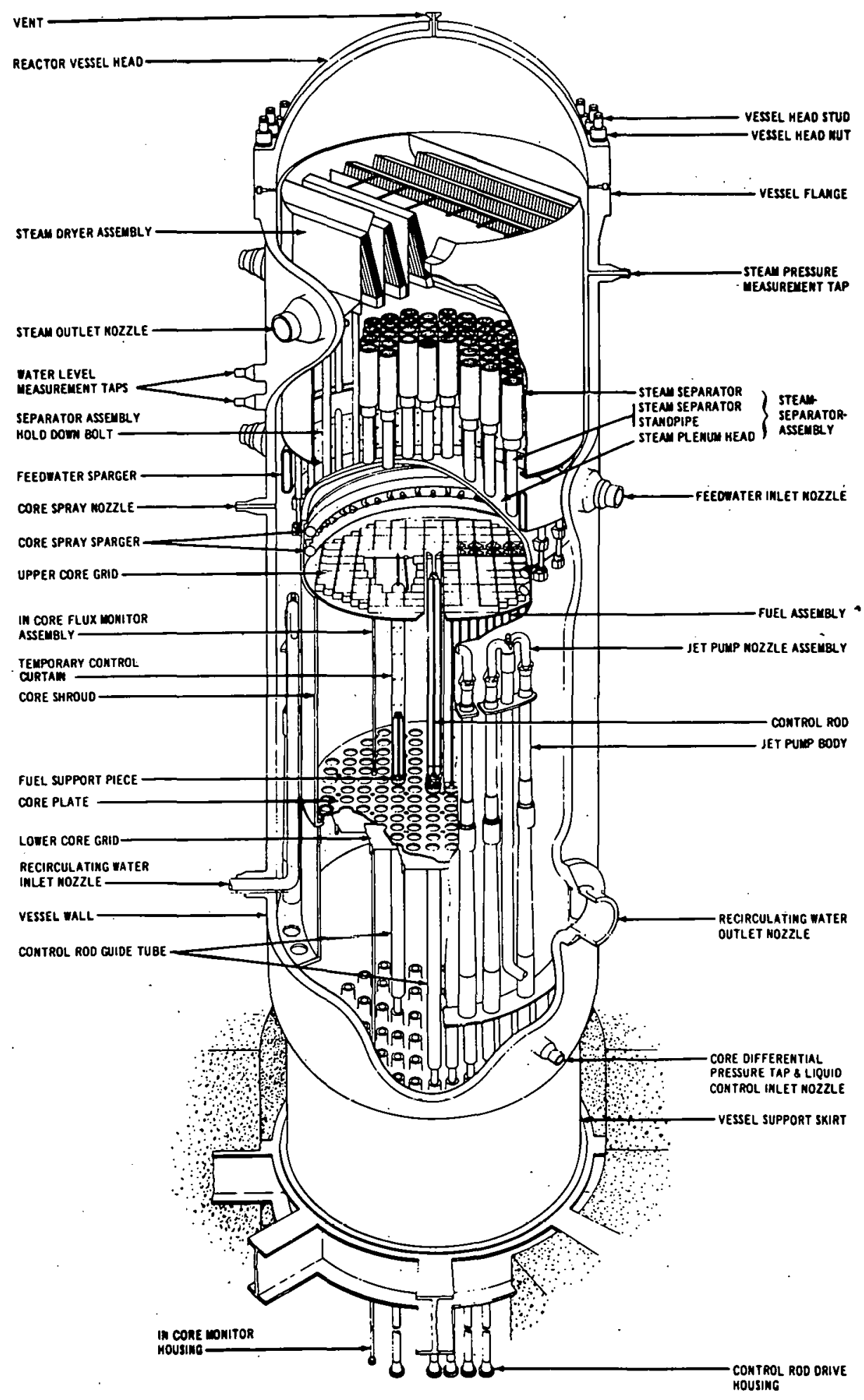

Fig. 3.1. Reactor Vessel and Internals for a General Electric Company Boiling-Water Reactor. (From Ref. 3) 


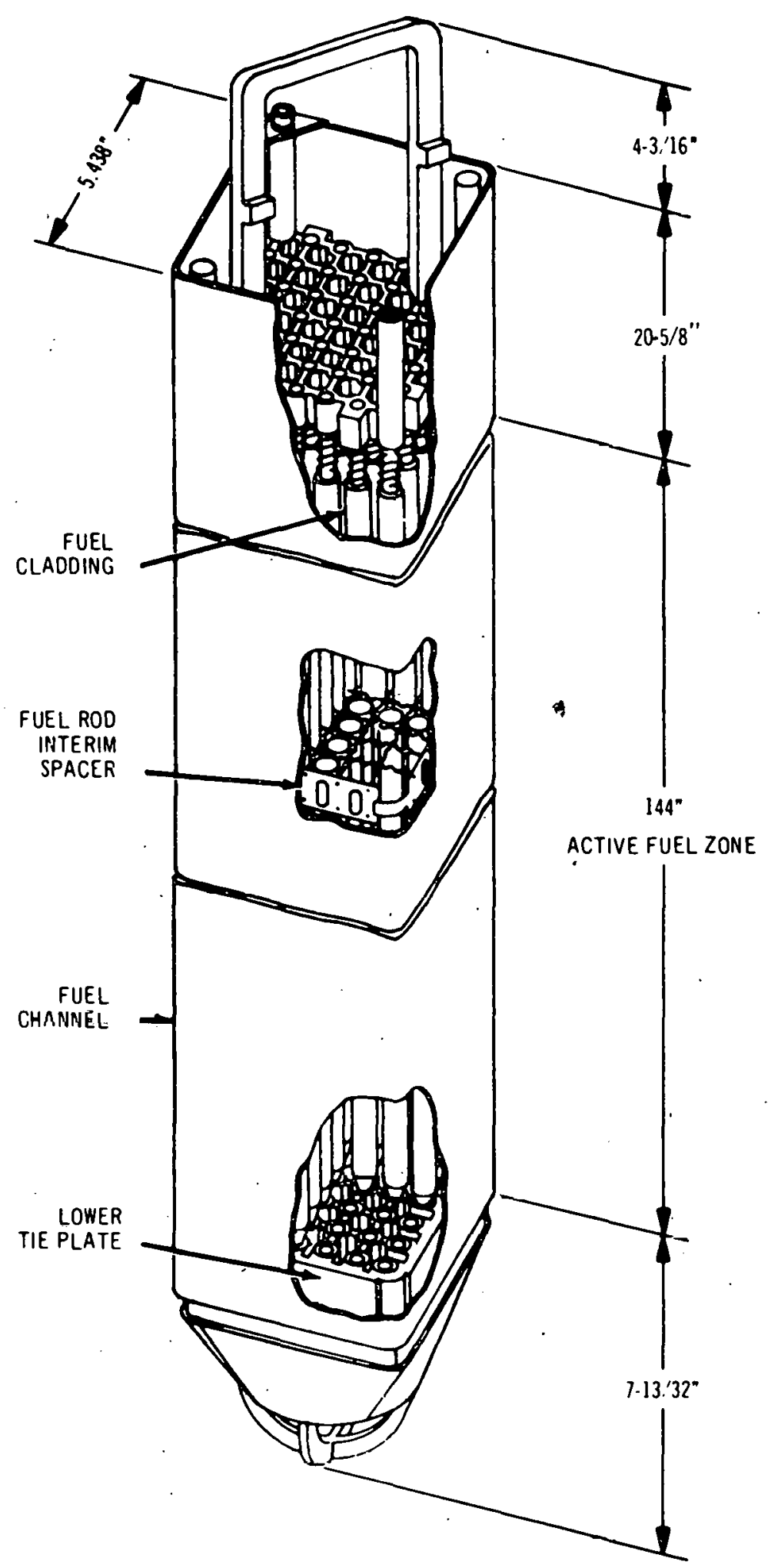

Fig. 3.2. BWR Fuel Assembly for a General Electric Company BoilingWater Reactor. (From Ref. 3) 
Condensate return from the turbine condensers is mixed with recirculated water from the steam separators and dryer. A portion of this subcooled mixture is removed from the reactor vessel through two recirculating-water outlet nozzles to the recirculating pumps and returned to the pressure vessel through a number of recirculating-water inlet lines. There are ten inlet nozzles per recirculating line. The returned recirculating water is used as the primary fluid in jet pumps to drive the remainder of the subcooled water mixture of condensate return and separator underflow through the reactor core. A shroud isolates the reactor core from the recirculated water and the jet pump assemblies. The exit end of the jet pump diffuser is welded to and penetrates the shroud. The fuel channels are supported and held in place by upper and lower core grids. Two core-spray sparger rings, part of the emergency core-cooling system, are located above the upper core grid for adding water to the core as a spray in the event of a loss-of-coolant accident.

The thermal characteristics of the core are listed in Table 3.1, and the cháracteristics of the emergency core-cooling system are listed in Table 3.2 .

\subsubsection{Emergency Core-Cooling System Design}

An emergency core-cooling system is required in a boiling-water reactor to maintain continuity of core cooling in the event of a rupture in the primary cooling system that causes leakage rates large enough for the coolant inventory and pressure to fall below some predetermined set point and to increase the pressure in the reactor containment chamber. The specifications of the emergency core-cooling system for the Browns Ferry reactor selected as representative for this study are listed in Table 3.2, and Fig. 3.3 presents a flow diagram of the system. The system includes a steam-driven high-pressure cold-water-injection pump, dual core-spray systems that are independent of each other and each is designed to prevent core melting, dual and independent heat-rejection systems that also serve to remove heat from the containment vessel atmosphere, and dual and independent low-pressure core flooding loops. On-site Diesel electric power is available for the pumps of one of each of these systems. 
Table 3.1. Thermal Specifications of Browns Ferry Boiling-Water Reactor

\begin{tabular}{|c|c|}
\hline Thermal power rating, $\mathrm{Mw}$ & 3,293 \\
\hline System pressure; psig & 1,000 \\
\hline Fuel assembly & $7 \times .7$ array \\
\hline Fuel diameter, in. & 0.488 \\
\hline Cladding outside diameter, in. & 0.562 \\
\hline Number of fuel rods & 37,436 \\
\hline Average fuel specific power & \\
\hline $\begin{array}{l}\mathrm{kw} / \mathrm{kg} \text { of } \mathrm{UO}_{2} \\
\mathrm{kw} / \mathrm{ft} \text { of } \mathrm{rod}\end{array}$ & $\begin{array}{l}19.5 \\
7.33\end{array}$ \\
\hline $\begin{array}{l}\text { Adiabatic heating rate of fuel at average } \\
\text { specific power, }{ }^{\circ} \mathrm{F} / \mathrm{sec}\end{array}$ & 92 \\
\hline Maximum-to-average rod power ratio & 1.74 \\
\hline Average rod power, $\mathrm{kw}$ & 88 \\
\hline \multicolumn{2}{|l|}{ Peak-to-average heat flux ratios } \\
\hline $\begin{array}{l}\text { Axial } \\
\text { Radial } \\
\text { Local } \\
\text { Total }\end{array}$ & $\begin{array}{l}1.5 \\
1.4 \\
1.24 \\
2.6\end{array}$ \\
\hline Average heat $f l u x, B t u / f^{2} \cdot h r$ & 163,200 \\
\hline $\begin{array}{l}\text { Average fucl temperatuxe it, hi.ghest heat } \\
\text { flux position, }{ }^{\circ} \mathrm{F}\end{array}$ & 2500 \\
\hline $\begin{array}{l}\text { Core average fuel temperature at full } \\
\text { power, }{ }^{\circ} \mathrm{F}\end{array}$ & 1100 \\
\hline
\end{tabular}

With interconnecting station or grid power, all systems are available for coolant injection in addition to the normal feedwater system. The emergency core-cooling systems are designed to control, by at least two methods, the thermal energy release from the fuel for any break size up to and including the double-ended rupture of either a single recirculating line or, the steam line leaving the top of the core. The steam line rupture results in the largest differential pressures (less than 50 psi) across the core internals during reactor depressurization. The pressure of the sleain dome eliminates the shock phenomenon. The recirculation 
Table 3.2. Characteristics of Emergency Cooling System of Browns Ferry Reactor

Systems injecting water at reactor pressure

Number of loops
Number of pumps
Number of valve actuators
Flow rate, gpm
Emergency power source (unde
trol only)
Emergency coolant source
Method of activating system
Time required for activation

Systems injecting water at intermediate pressure as core sprays ${ }^{a}$

Number of loops

Type

Pressure range of operation, psi

Number of pumps per loop

Number of valve actuators per pump

Flow rate per pump, gpm at 120 psig

Emergency power source

Time to activate with diesel power, sec

Emergency coolant source

Method of activating system

Heat sink

Systems injecting water at low pressure for core flooding $b$

Number of loops

Number of pumps per loop

Number of valves per pump

Flow rate per pump, gpm

At 200 psig

At 20 psig

Emergency coolant source

Method of activating system

Energency power source

Containment spray and continuous heat-rejection system

Number of loops

Number of pumps per loop

Numbcr of valves per loop

Flow rate per pump, gpm

Emergency power source

1

1

4,000

Reactor steam

Condensate storage tank and sup-

pression pool

Low liquid level

Time to open three valves after

sensing low liquid level

2

Spray

$<160$

1

1

6,250

Diesel for one spray pump; station

ac for both pumps

$\sim 30$

Suppression pool

Low water level, low reactor pressure, high drywell pressure.

Containment cooling system and river water

2

2

1

4,000

10,000

Suppression pool

Concurrent with activation of core spray

Diesel for three pumps and station ac for all four pumps

Emergency coolant source

Secondary heat sink

Residual heat removal

2

2

2

10,000

Diesel for two pumps and station ac

for all four pumps

Suppression pool

Service water system

Heat exchanger

${ }^{a}$ One spray loop pump and one containment cooling loop pump are necessary for continued cooling.

b If the sprays are inoperative, three purps are required during flooding; only one pump is required for long-term maintenance of level and cooling. 


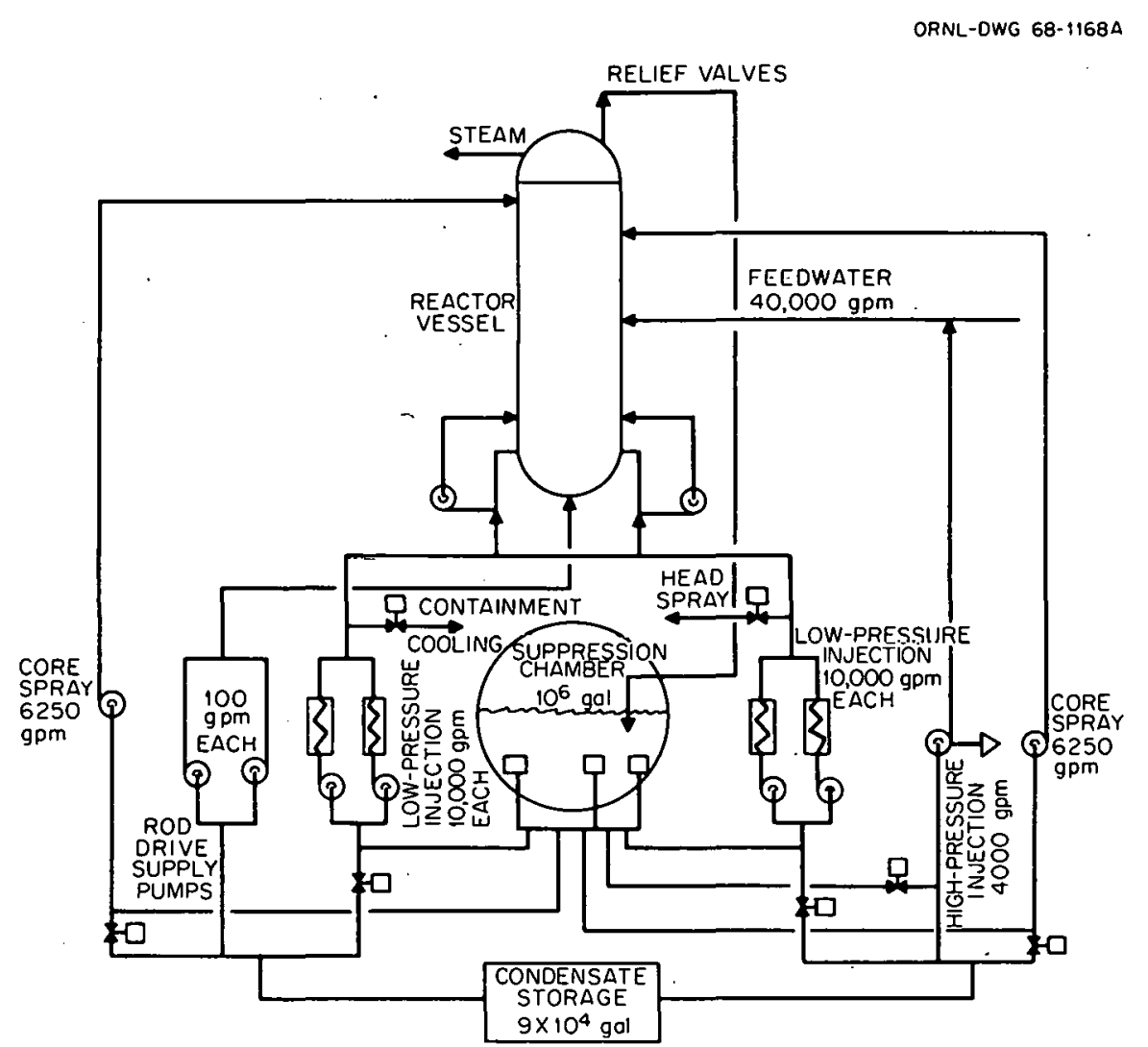

Fig. 3.3. Flow Diagram of Emergency Core-Cooling System for Browns Ferry BWR.

Ille supture resulto in the highest cladiing temperature. The reactor is depressurized in about $30 \mathrm{sec}$ following rupture of the recirculation line.

3.1.2.1 Core Spray Innps. For the Browns Ferry plant, two parallel cone spray loops are provided. Each of the loops draws suction from the suppression pool. A separate ring header for each loop is located inside the reactor vessel directly above the core to spray water through nozzles directly onto the fuel assembliẹs in a pattern preestablished from full-scale testing.

This syctcm is designed to rperate at a flow rate of $6250 \mathrm{gpm}$ at a reactor vessel pressure of 120 psig. Each of the core spray loops may be activated manually from the control room or automatically by the reactor protection system upon receipt of appropriate water level and pressure signals. The spray is activated when reactor pressure decreases 
below the spray pump discharge pressure, at which time a check valve opens and water is sprayed onto the top of the assemblies and flows down the fuel element channels.

For large breaks, such as the postulated rupture of the recirculation line with unobstructed flow from both ends of the pipe, the core spray is designed to deliver 6250-gpm flow within $30 \mathrm{sec}$ after the accident, even if startup of the standby Diesel power supply is required. To evaluate the thermal response of the core to a large depressurization accident and subsequent spray cooling, a core heatup digital computer code, TACTV, was utilized. Blowdown test data indicate that the core would be effectively cooled for the first few seconds (depending on bundle power) and that the heat transfer coefficients would then decrease to nearly zero at the end of the blowdown. The core spray heat transfer coefficients described in Appendix $E$ of the Browns Ferry design and analysis report ${ }^{3}$ and the heat transfer coefficients during the blowdown phase were input conditions to the core heatup code.

Radiation heat transfer between fuel rods in a bundle and between rods and the channel is included in the code. The digital computer code program also involves a continuous calculation of the extent and the current rate of metal-water reaction within the core. The model uses Baker and Just's correlation ${ }^{4}$ for the metal-water reaction of Zircaloy will an assumed unlimited steam supply.

The results for the core thermal response following a postulated recirculation-line break and with normal ac power available are given in Fig. 3.4. Both core spray loops and the low-pressure flooding loops would be activated within $30 \mathrm{sec}$ after the accident, and their cooling effect would quench the fuel rods within approximately 2 min after the accident, as shown in Fig. 3.4. The fuel rod cladding temperatures were calculated by taking into account spray cooling heat transfer coefficients based on the flow rate from only one pump and subsequent core flooding due to the accumulation of water in the vessel from the other core spray (flow rate of $6250 \mathrm{gpm}$ ) and the flooding loops (flow rate of 30,000 gpm). These cooling mechanisms would limit the extent of metal-water reaction in the core to approximately $0.2 \%$, which would result in a total concentration 


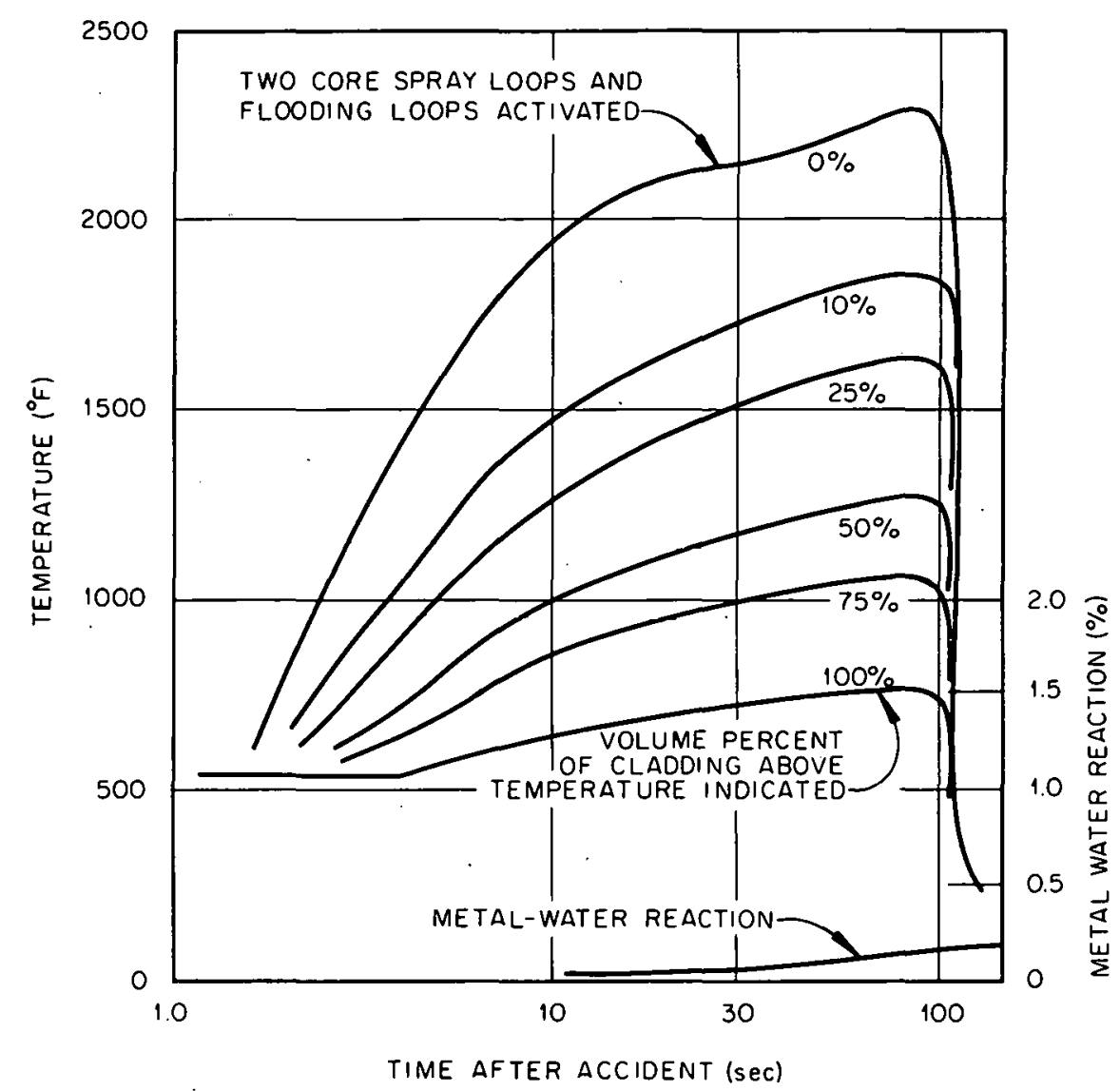

Fig. 3.4. Effect of Operation of Core Spray and Flooding Loops on Core Temperatures Following Rupture of Recirculation Line. (From Ref. 3)

of hydrogen in the containment vessel that would be below the flammability limit by a factor of 6 if released to an air atmosphere. If the radiolytic decomposition of water occurred unhampered, the flammability limit could be exceeded.

If one of the two core spray loops was not available, the core thermal response would be the same as in Fig. 3.4 , but the accumulation of - water to flood the core would take approximately $15 \mathrm{sec}$ longer. If no external ac power was available and thus one of the two core spray loops was unavailable, and if the entire flooding system was also unavailable, the core thermal response following a recirculation line break with only one spray loop operating would be as given in Fig. 3.5. As may be seen the peak temperature of the fuel rod cladding would reach $2350^{\circ} \mathrm{F}$ and $10 \%$ of the entixe core would be above $1850^{\circ} \mathrm{F}$. The sore would be flooded 


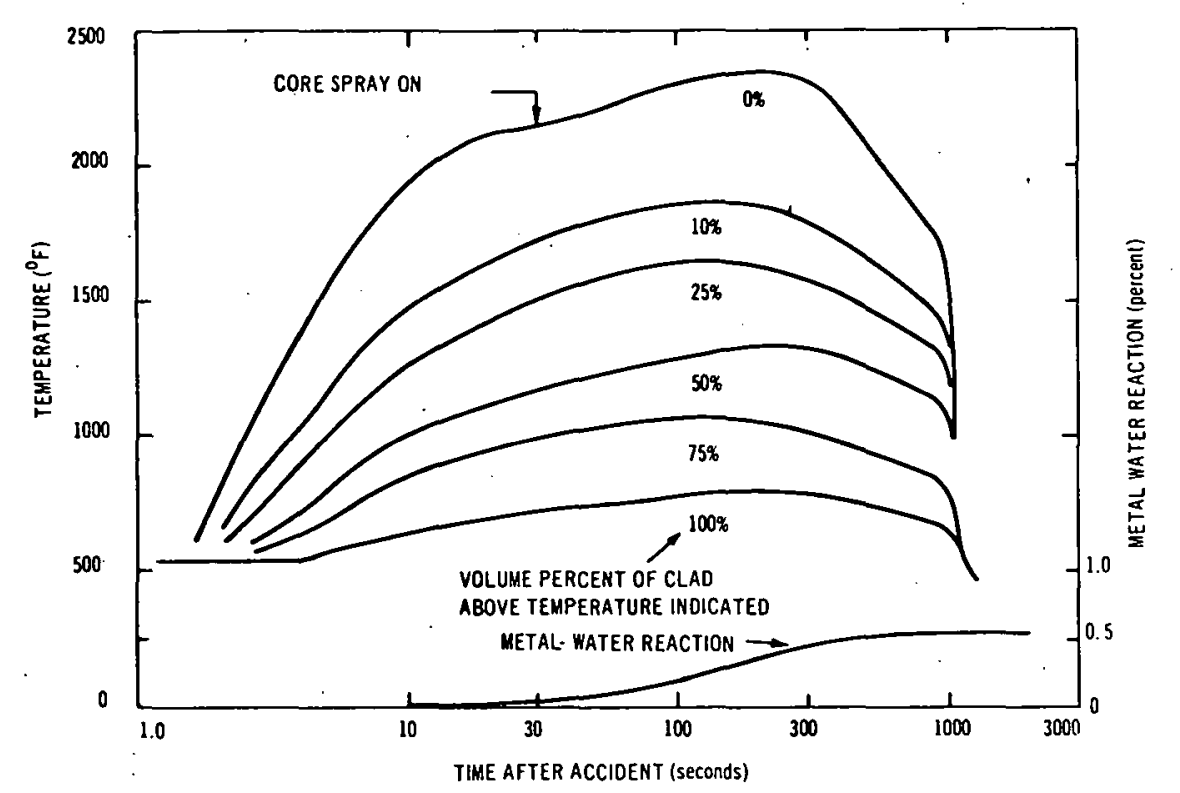

Fig. 3.5. Effect of Operation of Only One Core Spray on Core Temperatures Following Rupture of Recirculation Line. (From Ref. 3)

within 15 min after the accident due to the accumulation of water in the vessel. The calculations indicate that approximately $75 \%$ of the fuel rods in the core would experience cladding perforation based conservatively on a $1500^{\circ} \mathrm{F}$ perforation temperature without regard to time at temperature or burnup as shown in Fig. 3.6. Most of the rods would be perforated in the f'irst minute. The one core spray loop would limit the extent of metal-water reaction in the core to approximately $0.6 \%$, which would result in a total concentration of hydrogen in the containment vessel that would be below the flammability limit by a factor of 2 if released to an air atmosphere.

For intermediate and small breaks, the core would be more than onehalf covered, except possibly for about $1 / 2 \mathrm{~min}$, and the stored heat would therefore be removed from the core. The core cooling is assumed to be adequate until the core is one-half uncovered, at which time the core is. conservatively considered to be insulated for purposes of analysis. The basis for the assumption of adequate cooling until the core is one-half uncovered was established in tests on full-size fuel bundles. ${ }^{3}$ A parameter study of the Browns Ferry core resulted in the curve of Fig. 3.7, 


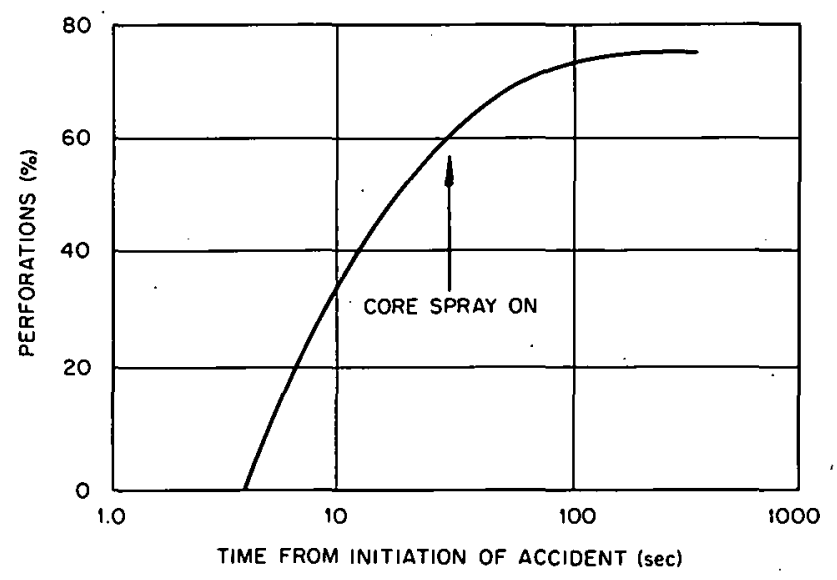

Fig. 3.6. Fuel Rod Perforation Following Break in Recirculation Line and Core Cooling with Only One Core Spray Operating.

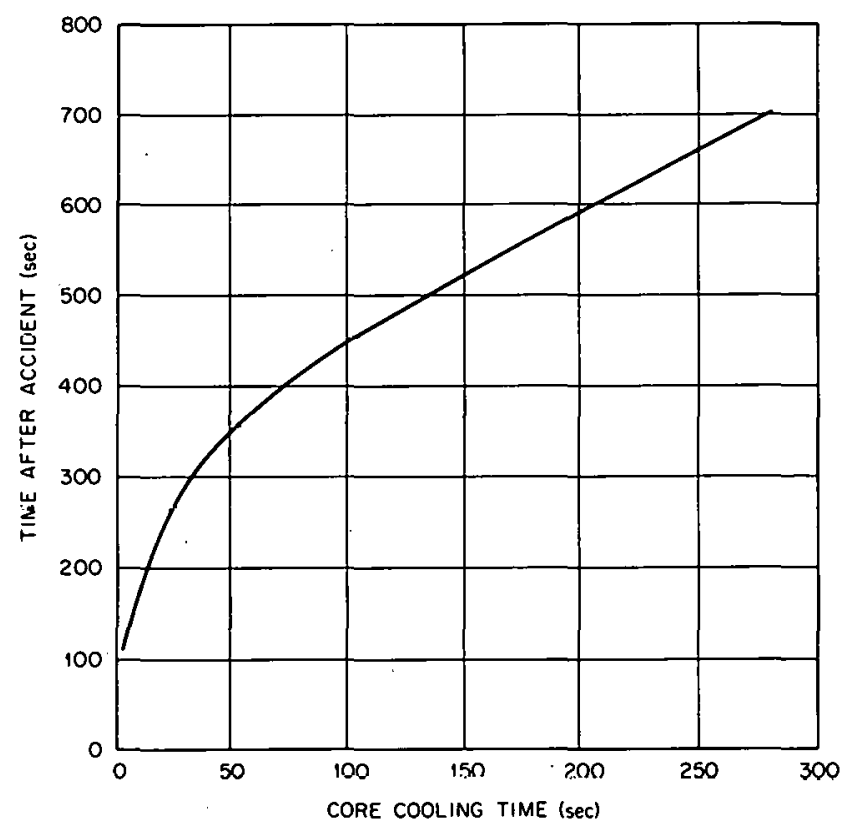

Fig. 3.7. Time to Reach Cladding Melting Temperatures with Core Uncovered as a Function of Core Cooling Time After Shutdown. (From Ref. 3)

which shows the allowable time the core could remain uncovered before local cladding melting after having been adequately cooled for various times after shutdown.

3.1.2.2 Low-Pressure Water-Injection Loops. The low-pressure waterinjestion loops are provided as additional, redundant means of removing 
decay heat and preventing fuel rod cladding damage, such as melting, for a spectrum of postulated loss-of-coolant accidents. These loops, which are designed to flood the core, would be automatically placed in service concurrently with the activation of the two core spray loops following a loss-of-coolant-accident. The loops are activated on the signal of reactor low water level. The flooding loops have four 10,000-gpm pumps, of which only three (without the spray loops operating) are required to reflood the core half way within sufficient time to prevent cladding melt over a range of break sizes, as shown in Fig. 3.8. The flooding loops are designed to pump the water directly from the suppression pool into the shroud of the pressure vessel through the recirculation loops. Basically, the low-pressure loops provide water so that the core can be flooded up to two-thirds of its height for an indefinite period. The recirculation line enters the pressure vessel at a level corresponding to two-thirds of the core height. The loops are designed to provide $30,000 \mathrm{gpm}$. within $30 \mathrm{sec}$ after the postulated recirculation line break, even if startup of the standby Diesel power supply is required. The

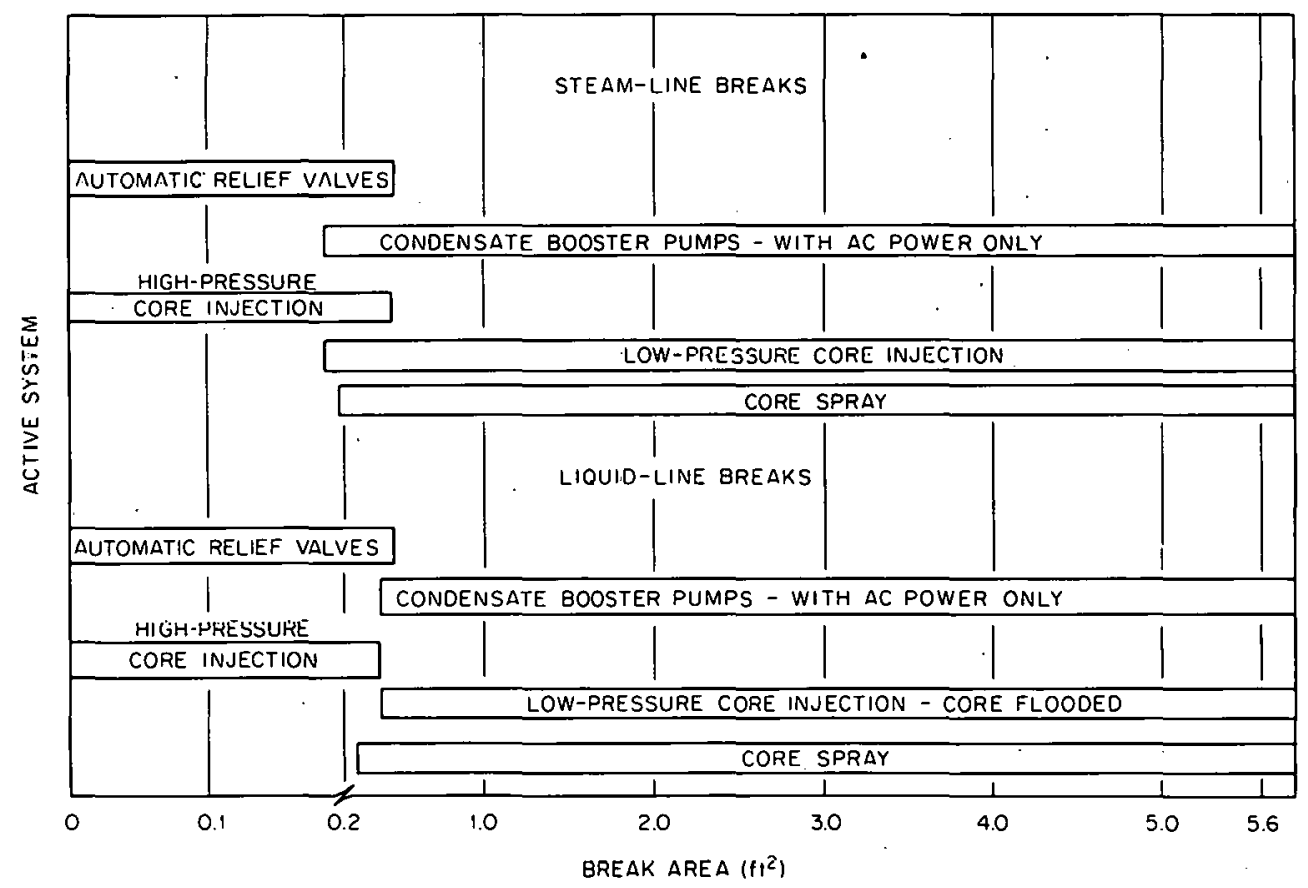

Fig. 3.8. Integrated Performance of Emergency Core-Cooling Systems of Browns Ferry Reactor. (From Ref.9) 
core would be half flooded within $100 \mathrm{sec}$ after the break. Therefore, the flooding loops can, without assistance from any other cooling mechanism or operator action, provide adequate cooling for the design-basis loss-of-coolant accident.

3.1.2.3 High-Pressure Water-Injection Loops. The high-pressure water-injection loop is designed to pump water into the reactor vessel under loss-of-coolant conditions associated with reactor vessel high pressure. This loop assures adequate coolant inventory in the reactor vessel for a spectrum of loss-of-coolant conditions smaller in magnitude than those provided for by the core spray and the low-pressure waterinjection loops. The high-pressure loop consists of a steam-turbinedriven makeup pump, valves, high-pressure piping, water sources, and instrumentation. The loop is designed to deliver water at a rate of 4000 gpm into the reactor pressure vessel within a pressure range of 1100 to $150 \mathrm{psig}$. The turbine is driven.with steam from the reactor via the main steam lines, and the steam goes to a condenser and condensate storage. Two sources of cooling water are available. The cooling water would be initially supplied from a condensate storage tank. When the water in the condensate storage tank had fallen to a predetermined level or the water in the suppression pool had been raised above a predetermined level, the pump suction supply would automatically be transferred to the suppression pool. The water would be pumped into the feedwater line and distributed within the reactor vessel through the feedwater sparger to obtain mixing with the hot water in the vessel.

Operation of the pump in the high-pressure loop would be independent of ac power and would require only steam extracted from the reactor to operate. A reactor low water level would start loop operation and a high water level would stop it. Electrical power would be required to operate the valves. The high-pressure loop is designed to depressurize the reactor vessel sufficiently by adding cold water for either the core spray or the low-pressure loops to be effective.

\subsubsection{Primary System Automatic Relief Valves}

The primary system relief valves will function as an automatic depressurizer to back up the high-pressure water-injection loop following 
a loss-of-coolant accident. The valves normally open automatically to the wetwell on reactor overpressure of approximately $100 \mathrm{psi}$ and then close at a lower preset pressure level. An additional function of these valves will be to open and remain open below this preset closing pressure, when signalled to do so, following a loss-of-coolant accident. This "remain open". signal would be based on simultaneous signals from high drywell pressure, low water level, and a signal indicating nonoperation of the feedwater system or high-pressure water-injection loop. A manual override could be effected by the operator within about 2 min after the last coincident signal. If no action were taken by the operator, the relief valves would open.

These valves would reduce the reactor pressure to the point where the low-pressure water-injection loops and/or the core sprays could ac'complish either reflooding of the core or spray cooling of the core before cladding melting occurred. Accidental opening of this valve system should be positively prevented, because it would cause a steam-line break.

\subsubsection{Condensate Pumping System}

It is probable that external ac power would be available in event of a break. Thus the condensate and sondensate hnoster pumps sould pro. vide essentially rated feedwater flow of apprnximately 28,000 gpm at a. reactor pressure of the order of $200 \mathrm{psig}$. This flow would be sufficient to provide adequate cooling of the core over approximately the same break spectrum as that provided for by the low-pressure water-injection loops. There is a cross connection to the condensate storage and the river to provide an infinite supply of water.

\subsubsection{Operation of Emergency Core-Cooling System}

It should be observed in Fig. 3.8 that. throughout the entire spectrum of breaks, there are always at least two processes for adequately cooling the core even under conditions of no external power supply. This was the basis for satisfying the emergency core-cooling design objective for the Browns Ferry plant. 
For the large break, it is assumed that the reactor is operating at the design thermal output and that the recirculation loop is instantly severed in a circumferential break. In the reactor vessel outlet leg of the recirculation loop, critical flow occurs at the break and at the ten jet-pump injection nozzles, the minimum area in the path to the break. Immediately following the break, the large increase in core void fraction due to depressurization sharply decreases reactor power. A scram is initiated in less than $1 \mathrm{sec}$ by high drywell pressure. Relative to the total blowdown time, the reactor steam pressure regulator quickly closes the turbine admission valves in an effort to maintain pressure. Hence, steam flow to the turbine would be a contributor to depressurization only during the first few seconds.

In about $4 \mathrm{sec}$, the subcooled liquid mass below the core would be flashing vigorously because of depressurization. This would tend to force a steam-water mixture up through the core, as well as backward through the jet-pump diffuser pipes, because the hydraulic resistance of the diffuser piping is significant relative to the series resistance through the core, grid plates, and separators.

Preliminary calculations indicate that it would take nearly $30 \mathrm{sec}$ to depressurize the vessel. During a fraction of this time, the bulk of the core would be cooled by a boiling two-phase mixture. The pump in the other recirculation line would continue to inject t'lu1d inlu lie ves= sel until the subcooled fluid began to flash. This would contribute to core flow momentarily. The mass of water-steam mixture in the vessel during the blowdown is shown in Fig. 3.9. It is assumed that the entire water inventory would be lost from the vessel during blowdown. A low water level in the reactor vessel should actuate the independent core spray loops, which would begin injecting water into the core when the pressure fell below 160 psig. The core spray loops would then spray water onto the top of the core, and the water would flow down the fuel channels and cool the fuel by radiation and steam convection.

One core spray loop would reflood the core up to the top of the jet pump diffusers in about $6 \mathrm{~min}$. Flooding of the core to the top of the jet pumps would be possible because the core shroud is sealed circumferentially arnund, the vessel wall and the vessel internals are designed to 


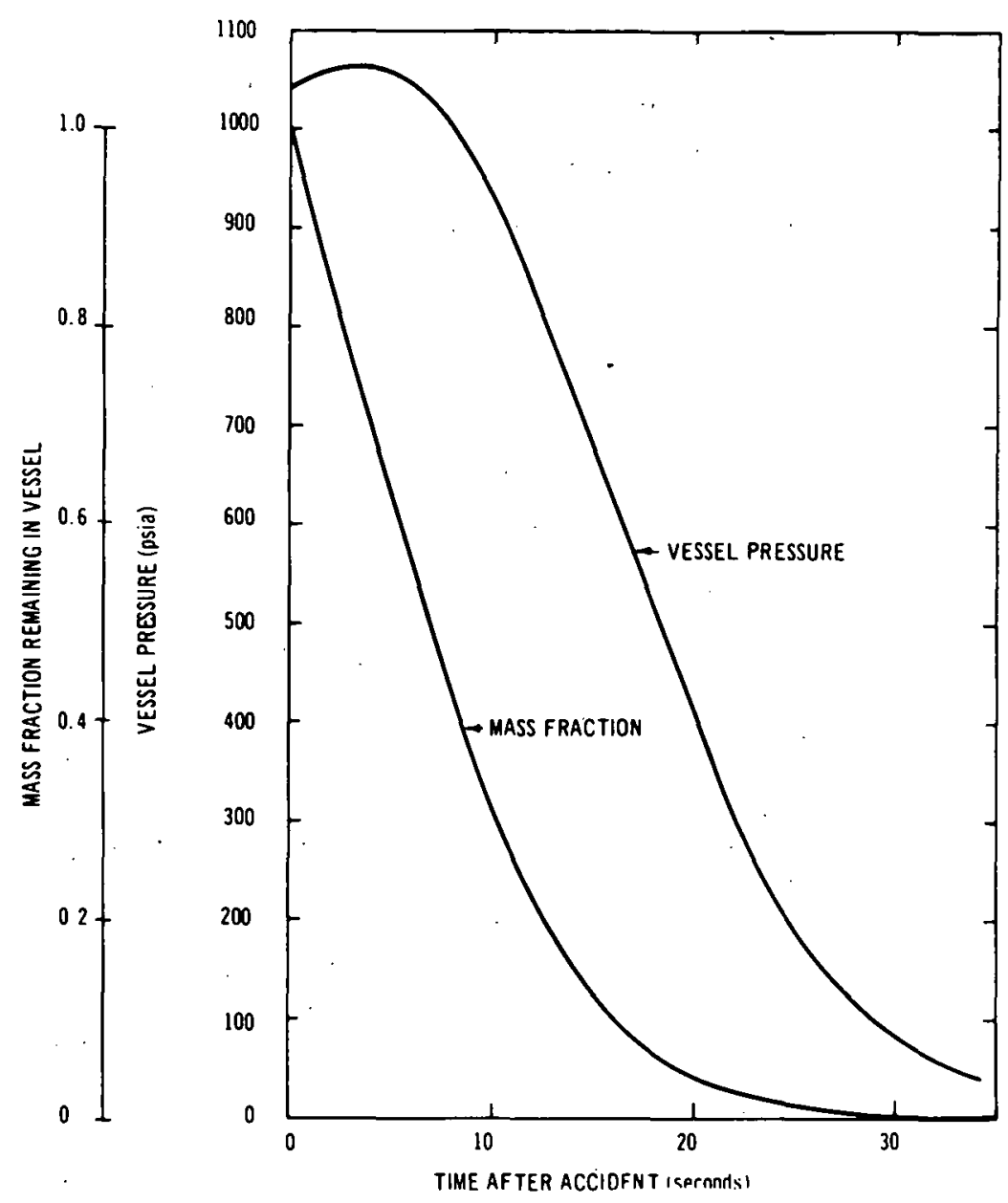

Fig. 3.9. Fiffect of Recirsulation Line Rupture and Dlüduwn un Vessel Pressure and the Amount of Water Remaining in the Vessel as a Function of Time. (From Ref. 3)

maintain their integrity during the blowdown. The tops of the jet pump diffusers are above the midplane of the core. When the core is half flooded with water, the voids formed in the flooded region from decay heat cause a steam-water mixture to flow up past the unflooded section of' f'uel and thereby cool it. This cooling has been substantiated by tests on full-scale heated fuel prototypes in which the maximum temperature in the unflooded portion was below $1300^{\circ} \mathrm{F}$ over a wide range of variables. These tests are discussed further in Chapter 4.

The effective time interval over which the core would be cooled during blowdown cannot be established precisely by calculation. Test 
data indicate, however; that a high boiling heat transfer coefficient would exist during the first 1 to $2 \mathrm{sec}$ of the blowdown and then diminish to approximately zero at the end of $24 \mathrm{sec}$. This time-variant heat transfer coefficient was used in the core heatup calculation described above. Figure 3.5 shows the fuel cladding temperature at various times following the pipe rupture with one core spray operating. The effective heat transfer coefficients determined by tests were used to obtain the cladding temperatures. The degree of metal-water reaction that would occur is also shown as a percentage of the total zirconium in the core. One of the core sprays would be activated within 1 min of the break, and the other core spray could be manually actuated if auxiliary power were available; however, only one operating spray would be required to cool the core. Approximately $75 \%$ of the fuel rods would experience cladding perforation, as shown in Fig. 3.6. This value is based on a $1500^{\circ} \mathrm{F}$ perforation temperature without regard to time at temperature or burnup. Some hydrogen would be produced from the metal-water reaction. (The metal-water reaction aspects of this accident are discussed in Ref. 5.) The double-ended recirculation line rupture results in the highest fuel and cladding temperatures, and in the event of rupture of smaller coolant lines, the consequences would depend on rupture size. Small leaks would be detected by drywell temperature rise, drywell sump level buildup, an increase in feedwater flow, and an apparent increase in the drywell leakage rate, as measured by the continuous leakage rate monitoring system. It is estimated that a $300-1 b / h r$ steam leak would be detected by a drywell temperature rise and that even smaller leakage rates could be detected from observation of sump level buildup. The reactor would be shut down upon evidence of significant leakage to reduce the chances of a small system failure progressing to a larger one.

The effects on the reactor core of a spectrum of coolant-loss accidents in excess of the feedwater capacity were investigated. The sequence of events for the assumed loss of coolant was the following: The loss of coolant would lower the water level in the vessel until scram, isolation, and core-cooling systems were activated by a low level indication. Even though it was activated, the core spray flow would not start until the reastrir pressure dropped below approximately 160 psig. The 
water level in the vessel would continue to fall. The active core would. be well cooled by the surrounding mixture until the water dropped below half of the core height. As the water level fell through the core, the cooling of the core would continue to be adequate due to the boiling associated with the vigorous flashing of the liquid in the core. After the net volume of liquid loss exceeded the liquid volume above the bottom of the core, the core would be considered void of liquid water and cooling would be inadequate.

For breaks larger than about $0.2 \mathrm{ft}^{2}$, the depressurization rate would be sufficiently rapid that the core spray would be activated, and the effects would be less severe than those for the largest break because the core would be cooled longer during the transient. Smaller breaks would result in coolant losses well within the capacity of the feed pumps, and the core spray would not be required to prevent fuel meltdown. The operator would have indications of a leak and many minutes in which to scram the reactor. The feedwater could then continue to make up the leakage and keep the core covered until the presisure dropped below the pressure at which the automatic relief valve or the core spray would be activated. Thus small breaks would also be much less severe than the break of the recirculation line.

\subsection{Descriptions of Pressurized-Water Reactor Cores and Emergency Core-Cooling Systems}

Pressurized-water reactors are cooled by nonboiling lifght water that flows upward through the fuel elements. A cut-away drawing of a PWR designed by Westinghouse Electric Corporation is shown in Fig. 3.10 (Ref. 6), and a typical fuel assembly is shown in Fig. 3.11. The pressure vessel coolant inlets are located above the top of the core. The coolant flows downward between a core shroud and the pressure vessel, enters a plenum below the core bottom, and flows upward through the core and outward to the steam generators.

The fuel assemblies consist of a $15 \times 15$ square array of Zircaloyclad $\mathrm{UO}_{2}$ fuel rods. The fuel rods are $12 \mathrm{ft}$ long and have a diameter of about 0.42 in. The fuel assemblies are designed with open channels; that 


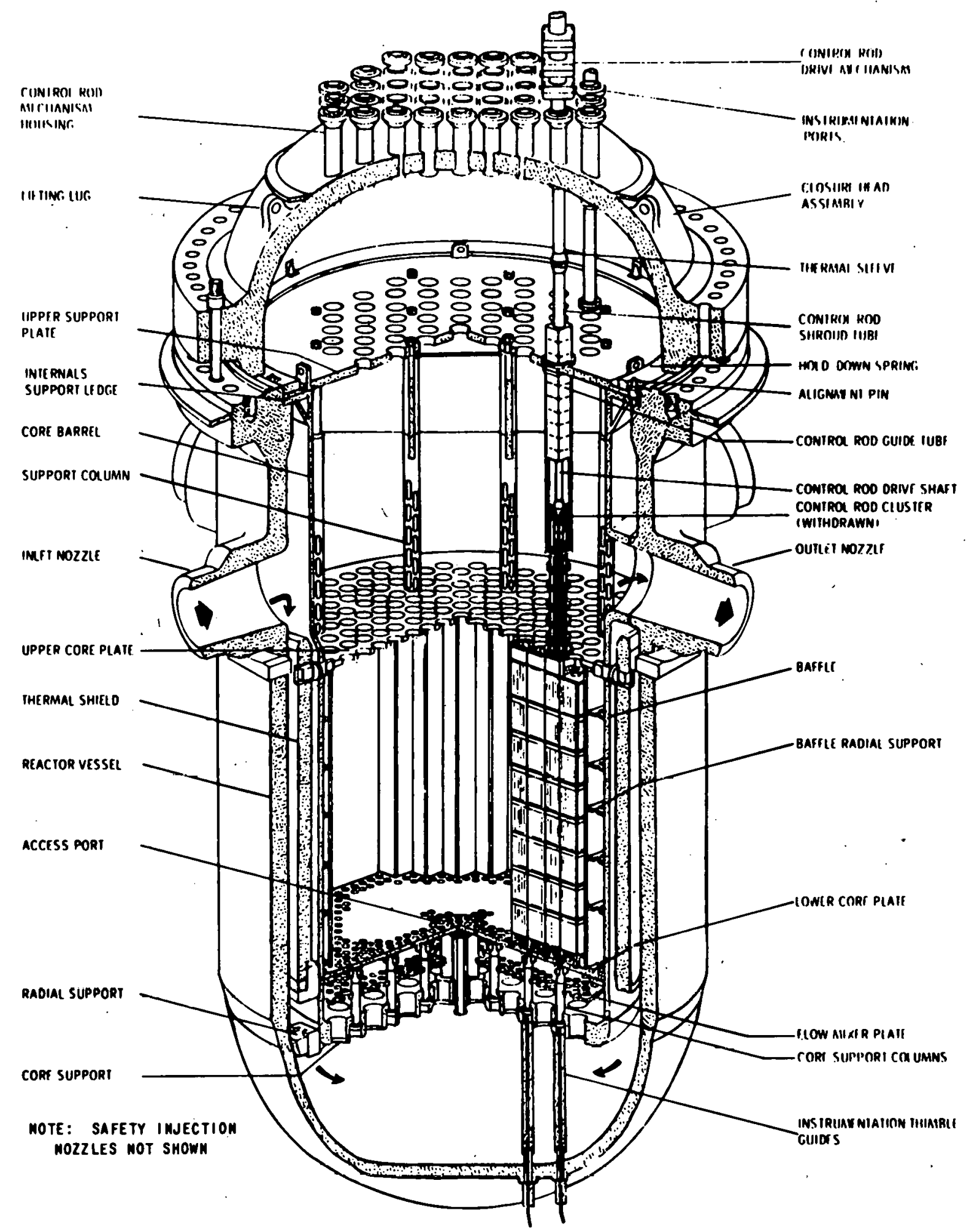

Fig. 3.10. PWR Reactor Vessel and Internals Designed by Westinghouse Electric Corporation. (From Ref. 6) 


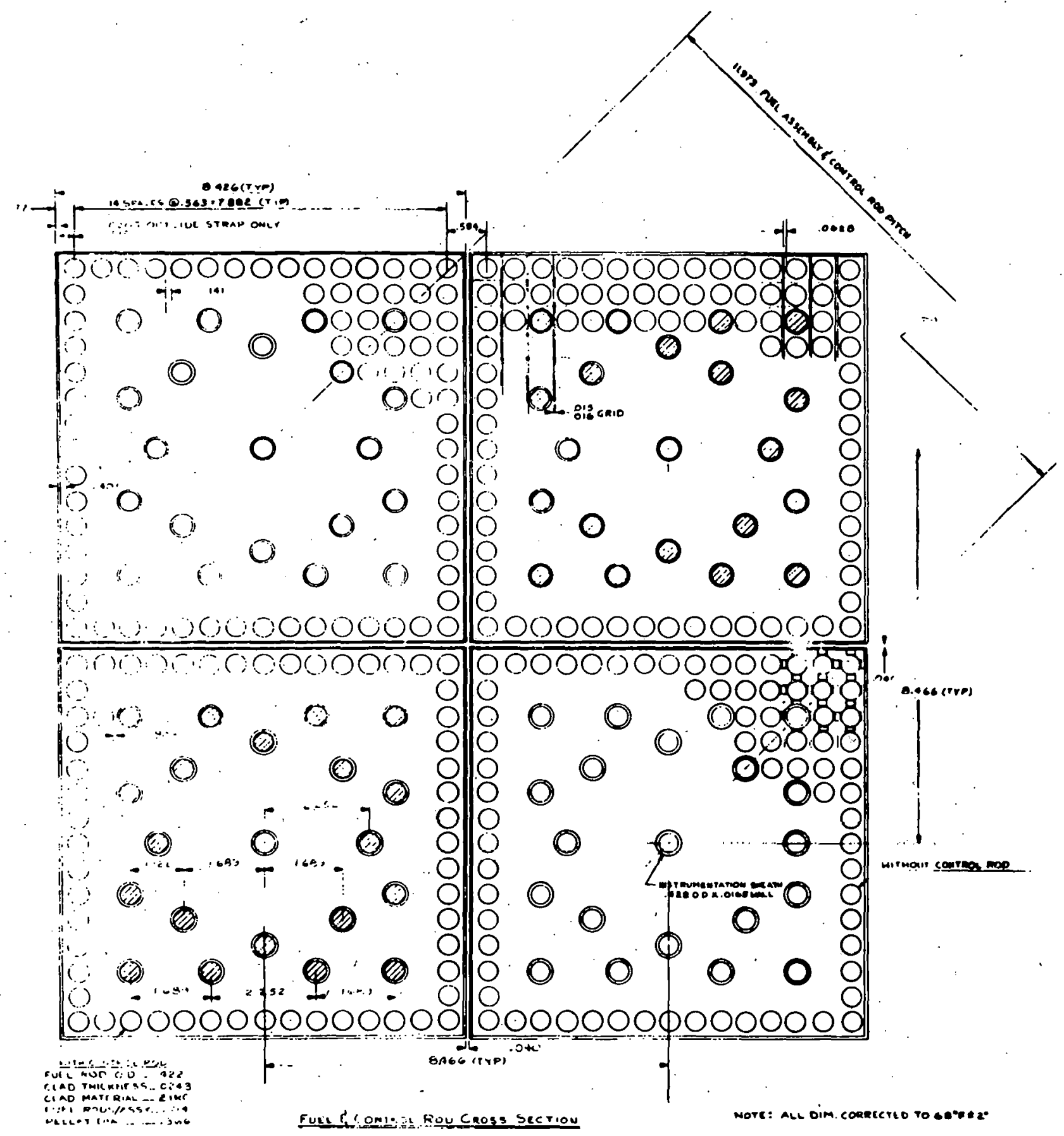

Fig. 3.1. PWR Fuel Assembly and Control-Cluster Cross Section. (From Ref. 6) 
is, there are openings to permit radial flow of coolant among adjacent fuel assemblies. The reactor control clusters are neutron-absorbing rods that are dispersed within the fuel assembly in place of fuel rods and are operated from above the reactor core.

The distribution of emergency cooling water within the core can be accomplished by gravity flow because of the "open channel" construction. Therefore the coolant may be added from above the core by a deluge system, as well as from below by a flooding system. The injection nozzles of the emergency cooling system may be located either on the primary coolant inlet or outlet lines. The emergency coolant may be added from gas-pressurized accumulator tanks, and it may be added by "charging" or makeup pumps that operate at reactor pressure or by large-volume intermediate- and low-pressure pumps for sustained afterheat removal.

The thermal design parameters for three typical PWR's are presented in Table 3.3. These three reactors $6,7,8$ were selected as representative of the current state of design. They are currently in the licensing process, and the designs are subject to change. The components of the emergency cooling systems are described in Tables 3.4, 3.5, and 3.6. Flow diagrams of the emergency cooling systems are shown in Figs. 3.12, 3.13, and 3.14. A typical analysis of postulated loss-of-coolant accidents and the performance of the various emergency cooling systems is reproduced in Appendix B, which was taken from the preliminary safety analysis report for the Oconee Nuclear Station.

The PWR emergency core-cooling system relies primarily on reflooding at least half way up the active region within a short period after the break. This is accomplished with high-pressure, intermediate-pressure, and low-pressure emergency water-injection systems to protect the core for any break size up to a double-ended rupture of the largest pipe attached to the pressure vessel.

\section{2 .1 Sequence of Events Hollowing Hipe Rupture}

This description of the sequence of events following a pipe rupture is generally applicable to all PWR's. A detailed discussion for one plant (Oconee Nuclear Station) is reproduced in Appendix B. 
Table 3.3. Thermal Parameters for Pressurized-Water Reactors Typical of Those Being Considered for Licensing.

\begin{tabular}{|c|c|c|c|}
\hline Reactor & Turkey Point & Palisades & Oconee \\
\hline Thermal power rating, $\mathrm{Mw}$. & 2,097 & 2,640 & $2,452^{a}$ \\
\hline $\begin{array}{l}\text { Number of fuel assemblies }(15 \times 15 \\
\text { square array) }\end{array}$ & 157 & 204 & \\
\hline Fuel rod diameter, in. & 0.367 & 0.359 & 0.362 \\
\hline Cladding outside diameter, in. & 0.422 & 0.413 & 0.420 \\
\hline Fuel pitch, in. & 0.563 & 0.553 & 0.558 \\
\hline Average fuel specific power & & & \\
\hline $\begin{array}{l}\mathrm{kw} / \mathrm{kg} \text { of } \mathrm{UO}_{2} \\
\mathrm{kw} / \mathrm{ft} \text { of } \operatorname{rod}\end{array}$ & $\begin{array}{l}25.8 \\
5.3\end{array}$ & $\begin{array}{l}24.7 \\
4.4\end{array}$ & $\begin{array}{l}26.9 \\
5.4\end{array}$ \\
\hline $\begin{array}{l}\text { Adiabatic heating rate of fuel at } \\
\text { average specific power, }{ }^{\circ} \mathrm{F} / \mathrm{sec}\end{array}$ & 125.5 & 122 & 128 \\
\hline Average rod power, kw & 59 & 58.5 & \\
\hline \multicolumn{4}{|l|}{ Peak-to-average heat flux ratios } \\
\hline $\begin{array}{l}\text { Axial } \\
\text { Radial } \\
\text { Total }\end{array}$ & $\begin{array}{l}1.78 \\
1.88 \\
3.12\end{array}$ & $\begin{array}{l}1.80 \\
1.83 \\
3.30\end{array}$ & $\begin{array}{l}1.70 \\
1.85 \\
3.15\end{array}$ \\
\hline Average heat flux, Btu/ft ${ }^{2} \cdot h r$ & 164,200 & 139,200 & 167,620 \\
\hline $\begin{array}{l}\text { Average fuel temperature at highest } \\
\text { heat t'Lux position, }{ }^{\prime} F\end{array}$ & 2300 & 2450 & 2600 \\
\hline $\begin{array}{l}\text { Core average fuel temperature at } \\
\text { full power, }{ }^{\circ} \mathrm{F}\end{array}$ & 1150 & 1100 & 1385 \\
\hline
\end{tabular}

\footnotetext{
In core.
}

The emergency cooling system is designed to prevent cladding melting and to limit the metal-water reaction to less than $1 \%$ metal reacted in the event of an instantaneous rupture of the primary coolant piping. The design accident is assumed to occur on the inlet line to the reactor vessel (cold leg) or on the outlet line (hot leg) between the pressurizer and the steam generator. The cold-leg break is the most severe from the thermal standpoint because the reactor would lose its coolant most rapidly for that break - in about. 8 to $13 \mathrm{sec}$. Accompanying these assumed 
I

Table 3.4. Summary Description of Turkey Point Reactor Emergency Cooling Systems

Systems injecting water at reactor pressure

Number of loops

Number of pumps ${ }^{a}$ on emergency power

Number of valve actuators per loop

Flow rate per pump, gpm

Emergency power source (under local control only)

Emergency coolant source

Method of activating system

Time required for activation (with emergency power), sec

Systems injecting water at intermediate pressure

Number of loops

Type

Pressure range of operation

Number of pumps per loop

Number of valve actuators per pump

Emergency power source

Emergency coolant source

Method of system activation

Recirculating system or coolant-injection system

Number of loops

Operating pressure

Number of pumps per loop

Number of valves per pump

Flow rate, gpm per pump

Emergency power source

Emergency coolant source

Secondary heat'sink

Containment, spray system

Number of loops

Pumps per loop

Flow rate per pump, spm

Design head, ft

Emergency power source

Emergency coolant source
1 on each of three cold and hot legs

1 Diesel, 3 ac

1

300

Diesel-generator

30, 000-gal boronated water (refueling water)

Low pressure and low level in coincidence 25

3.

Pressurized on-line accumulators

Up to $600 \mathrm{psi}$

1

None; check valves only

None required

9000 gal per accumulator

Check valve opens when. reactor pressure is less than 600 psia

2

Residual heat removal up to 500 psig

1

1

3000

1 pump on Diesel

Refueling tank

Service water through residual heat

2

1

1128

400

Diesel for one pump

Refueling water

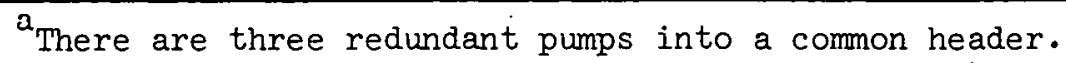


Table 3.5. Summary Description of Palisades Reactor

Emergency Cooling Systems

System injecting water at reactor pressure

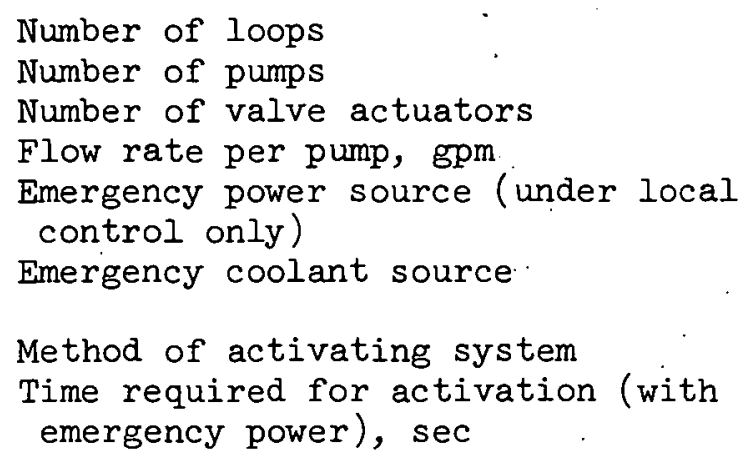

Pressurized accumulator

Number of loops
Type of water storage tank
Pressure range of operation
Number per loop
Number of valve actuators per loop
Capacity per accumulator, gal
Emergency power source
Method of activation

Systems injecting water at low-pressure

Number of loops

Type

Pressure range of operation, psig

Number of pumps per loop

Number of valve actuators per pump

Emergency power source

Emergency coolant source

Method of system activation

Heat sink

Heat rejection and containment spray system

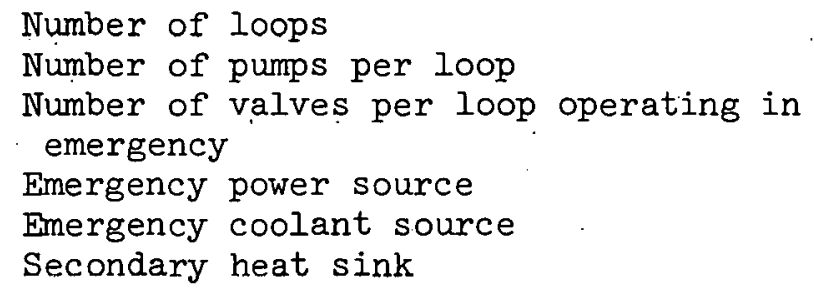

1

3

1 at each of four inject points 200

Diesel

250, 000-gal boronated-water storage tank

Low level and/or low pressure $\sim 30$

4

Gas pressurized, on line

Up to $600 \mathrm{psig}$.

1

1 check valve

7500

None required

Check valve opens when accumulator pressure exceeds system pressure

2

Pump injection

150

One of 4900-gpm capacity

One for two pumps

Diesel-generator for one pump 250, 000-gal boronated-water storage tank

Low level and/or low pressure Containment sump

1

3

2

Diesel for two pumps

Sump or refueling tank

Two containment heat exchangers in parallel with Dieselpowered service water supply pumps 
Table 3.6. Summary. Description of Oconee Reactor Emergency Cooling Systems

Systems injecting water at reactor pressure

Number of loops

Pressure range of operation

Number of pumps per reactor

Number of valve actuators per three pumps,

Flow'rate per pump, gpm

Emergency power source (local)

Emergency coolant source

Method of activating system

Time required for activation (with emergency power)

- Core flooding system

Number of loops

Fressure rangc of operation

Core flooding tanks

Total emergency coolant volume, $\mathrm{ft}^{3}$

Normal water volume, $\mathrm{ft}^{3}$

Check valves

Isolation valves

Method of activation

Systems injecting water at low pressure

Number of loops

Pressure range of operation

Number of pumps per reactor

Number of valve actuators per three pumps

Flow rate per pump, gpm

Emergency power s̀ource (local)

Emergency soolant source

Method of system activation

Heat sink

Time required for activation (with energy power)

Low-pressure service water system

Number of Jnops

Number of pumpe per loop

Flow water per pump, gpm

Number of automatic valves per three pumps

Energency power source (local)

Emergency coolant source

Secondary heat sink
2

Start at $1800 \mathrm{psig}$

3

$500(\max )$

Companion reactors if operating; Keowee hydrostation

Reactor building sump; boronated water storage tank

Low reactor coolant system pressure signal On the line in $25 \mathrm{sec}$ (including also lowpressure injection system)

2

Start of 600 psig

2

1410

940

Two in 14-in. flood line

One per flood line

Low reactor coolant system pressure

2

Start at $200 \mathrm{psig}$

3

4

3000 at $100 \mathrm{psig}$

Companion reactors if operating; Keowee hydrostation

Initially, boronated water storage tank;

later, reactor building sump

Low reactor coolant system pressure signal

Luw-pressue service water oyctom

On line in $25 \mathrm{sec}$ (including also the high-. pressure injection system)

2

Three for Units 1 and 2; two Ior Unlt 3 20,000

Four for Units , and 2; two for 2 pumps (Unit 3)

Companion units if operating; Keowee hydrostation

Turbine condenser intakes; high-pressure service water system

Turbine condenser circulating water discharge 


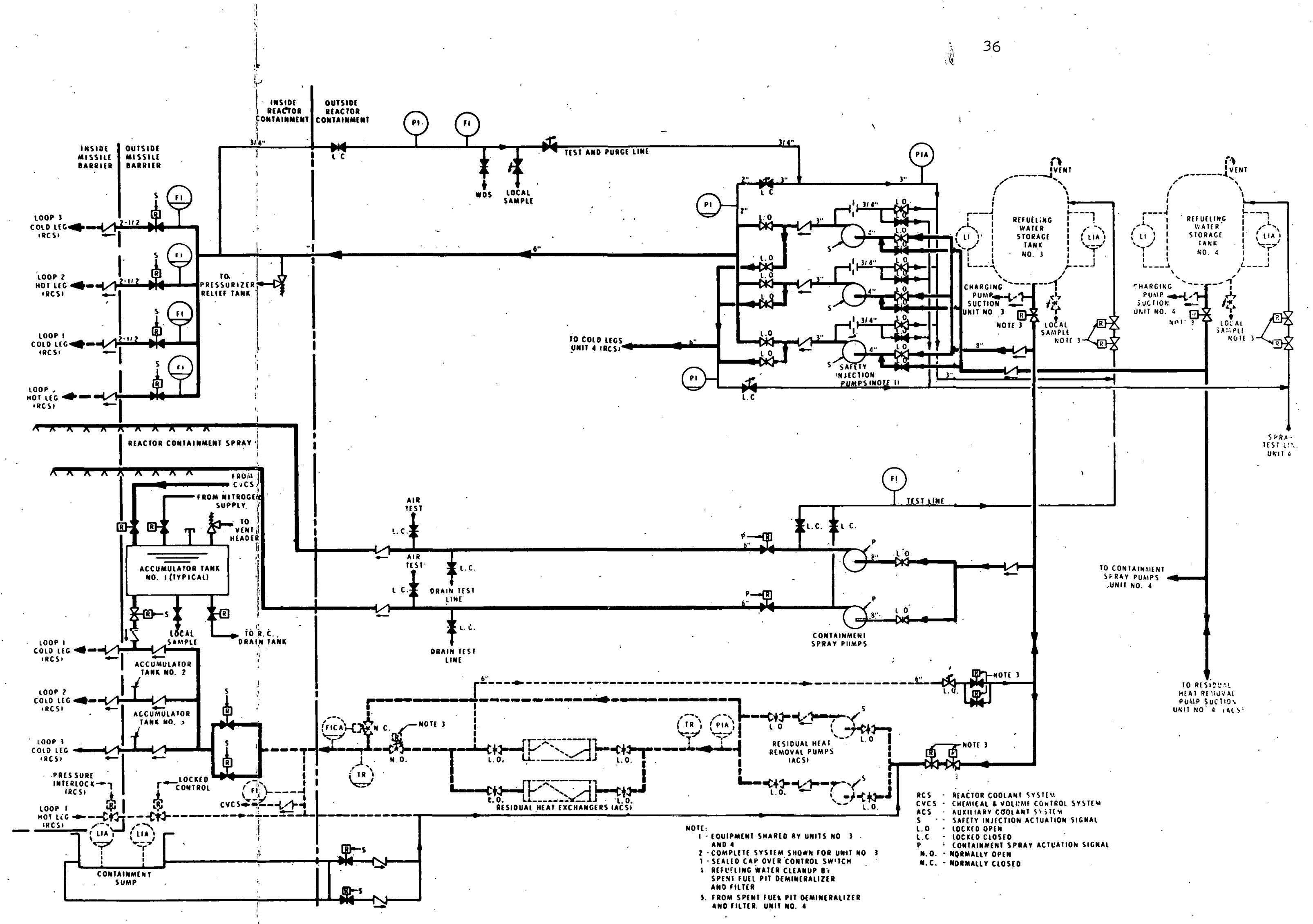

Fig. 3.12. Safety Injection and Spray System for Turkey Point Reac-
tor. (From Ref. 6) 


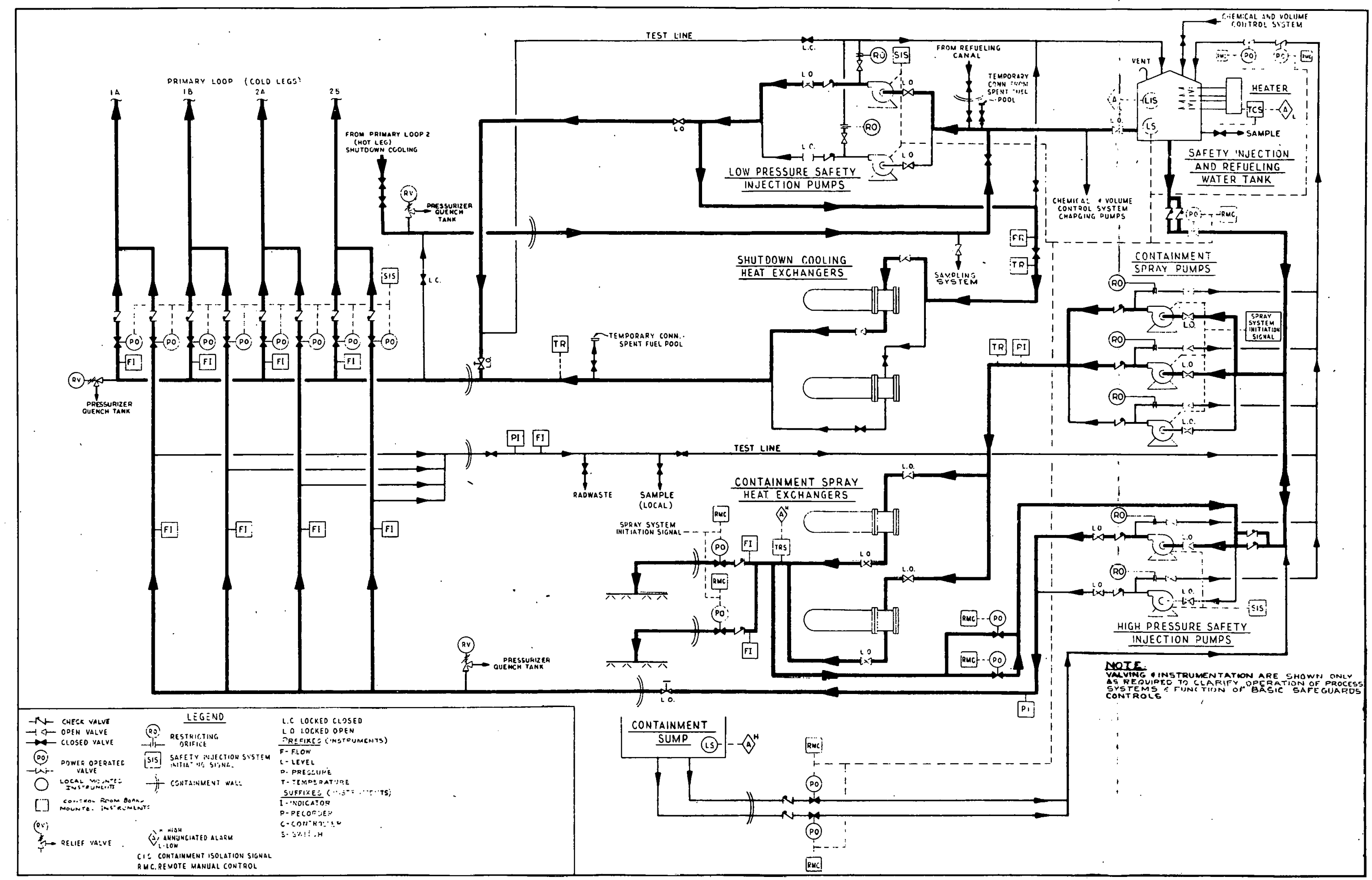

Fig. 3.13. Flow Diagram of Safety Injection and Containment Spray Systems of Palisades Reactor. (From Ref. 7) 


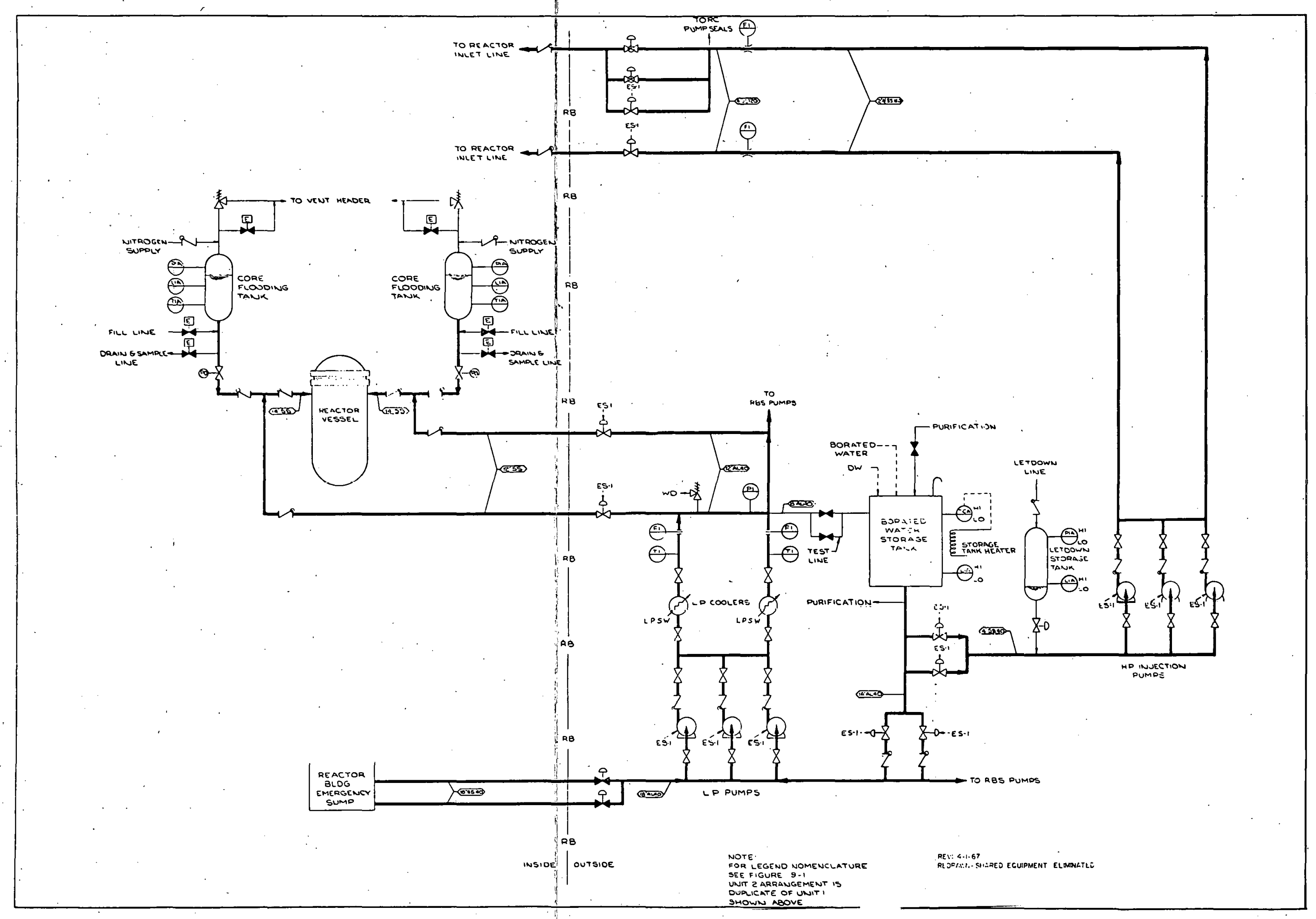

Fig. 3.14. Emergency Injection Systems of Oconee Reactors. (From Ref. 8). 
instantaneous large-pipe ruptures there would be large pressure differentials across the core internals. There might be acoustic shock loadings (due to the difference in saturation pressure) of up to about 600 psi axially across the core and radially across the top of the core barrel. ${ }^{9}$ The internals must be designed to take this loading without deforming to the point where the coolant inlet nozzles are blocked. The saturation pressure is reached in about $0.05 \mathrm{sec}$. The pressure difference generated across the shroud after saturation temperatures are reached. is up to $300 \mathrm{psi}$, and the core internals, including control rods and support structure, must be designed for this loading so that the emergency coolant injection system and control rods can work. The piping systems and all components in the area of the primary system must also be designed to take the reaction forces that result from pipe ruptures. These are discussed in a report in this series on missiles and internal projectiles. 10

In the case of the cold leg, or most severe break, the saturation pressure is first reached in the hot leg and in the pressure vessel exit. This event may destroy whatever natural circulation may exist in the primary circuit. If a flow reversal is caused in the core, cooling of the fuel rods may stop. Provision for venting the outlet line to the containment vessel for any break is therefore provided. As the pressure in the vessel falls, the cold leg reaches the saturation pressure, and the effluent becomes slightly supersaturated before flashing into steam. Some oscillation in pressure may occur for a few tenths of a second before the vessel internal pressure continues to fall monotonically toward atmospheric.

Sometime during the blowdown, the core is uncooled by water and the fuel rods and cladding begin to absorb decay heat, as well as to distribute the heat in the rods by thermal conduction. 'I'he smaller diameter of' the PWR rods and the open lattice design could result in better rod cools ing during blowdown than in BWR's, but the smaller blowdown time and the higher rod specific power will tend toward higher heatup rates. Thus the PWR fuel rods, like those of the BWR, will heat up and reach perforation temperatures. Fuel rod cladding failures for a recently designed large PWR corell following the double-ended main cold leg rupture and 
0.5 - and 3.0-ft ${ }^{2}$ pressurizer loop cold leg ruptures are plotted in Fig. 3.15 as a function of time after the rupture. The cladding temperature distribution is shown in Fig. 3.16 as a function of time after the accident based on design operation of the emergency core cooling system.

\subsubsection{Emergency Cooling of Turkey Point Reactor}

3.2.2.1 Description. The engineered safety features of the Turkey Point reactor ${ }^{6}$ include the high-pressure water injection system, the recirculation system for residual-heat removal, and a set of four accumulator tanks, one for each circulation loop. The operating flow sheet is shown in Fig. 3.12, and the pertinent reactor design and emergency cooling system data are given in Tables 3.3 and 3.4 , respectively. The engineered safety system power loads are arranged to operate from electrical buses supplied from normal outside ac power and on-site Diesel emergency power. Thus, if normal ac power is lost following a loss-of-coolant accident, power is available for the emergency cooling systems.

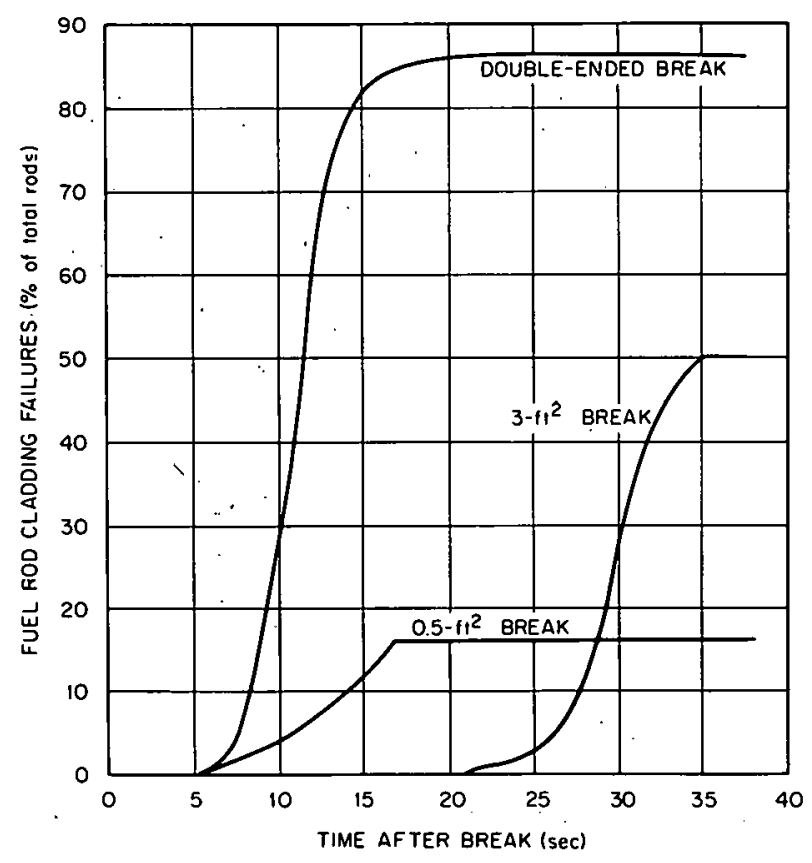

Fig. 3.15. Fuel Rod Cladding Failures After Ruptures in Diablo Canyon Reactor with Emergency Cooling System Operating. (From Ref. II) 


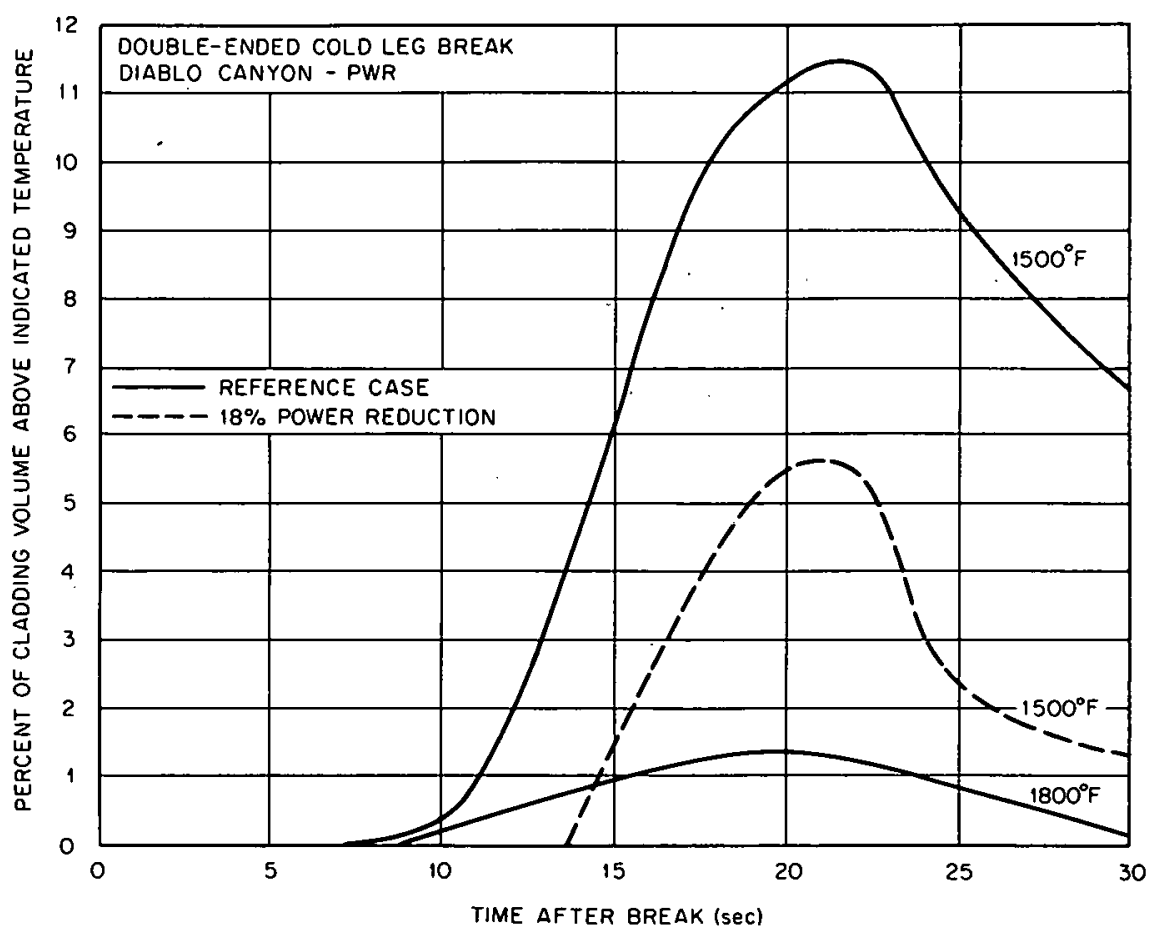

Fig. 3.16. Cladding Heatup Following Double-Ended Cold Leg Break in Diablo Canyon Reactor with Emergency Cooling System Operating. (From Ref: 11)

Routine periodic testing of the emergency cooling system components is intended. If one of the components required maintenance as a result of failure to perform during the test according to prescribed limits, the necessary corrections of minor maintenance would be made and the unit retested immediately. Satisfactory performance of the remaining redundant component(s) would be proof of the availability of that system, and it might not be necessary to adjust the plant load during the brief period that a component was out of service.

\subsubsection{Design Bases. The primary purpose of the emergency water-} injection system is to supply boronated water to the reactor cooling system to limit fuel rod cladding temperatures in the event of a loss of coolant. Operation of all components of the emergency system would prevent any melting of fuel cladding and limit the metal-water reaction to a negligible amount for reactor coolant piping ruptures up to and including the double-ended rupture of the largest pipe connected to the reactor pressure 
vessel. High containment vessel pressure is also being used as an additional and independent means of detecting the loss-of-coolant accident.

The safety circuits would be activated on a coincident low-level and low-pressure indication from two out of three indicating instruments, and high-pressure water-injection pumps would deliver boronated water from refueling water storage to the hot and cold legs of the reactor coolant loops. The pumps initially take suction from the refueling water storage tanks and switch to the containment sump when the refueling water storage tanks are low. Water flows to the sump by gravity from the pipe break.

The accumulator tanks are designed to operate at 600 psig through check valves and to refill the core through the pressure vessel cooling tubes with boronated water to a level at least half way up the core within about $1 / 2$ min following a large pipe break.

The residual-heat-removal system delivers boronated water to the reactor vessel cold legs at about 150 psig after the addition of water from the accumulator tanks has started and the pressure vessel is depressurized. The arrangement of the pumps in this system assures that the core will be covered at least to the level of the inlet lines, which are above the core.

The accumulators are designed to initiate action in about $10 \mathrm{sec}$ in the event of a large break, and with one high-pressure injection system pump and one residual-heat-removal system pump operating, the top of the core will be reflooded in $78 \mathrm{sec}$ after the break, even it pumping is not available the first $25 \mathrm{sec}$.

The total performance for a spectrum of break sizes is shown in Fig. 3.17, as calculated by Westinghouse Electric Corporation and reported in Supplement 5 of the preliminary safety analysis report for the Turkey Point reactor. ${ }^{6}$ This reactor has the capability of double coverage of each break size in pumping capacity. However, the piping systems are not completely independent.

Westinghouse Electric Corporation has developed a new emergency core-cooling system flowsheet for the Diablo Canyon Nuclear Power Station. In addition to a pressurized-water storage tank on each inlet line, this flowsheet shows two completely separate high-pressure water-injection 


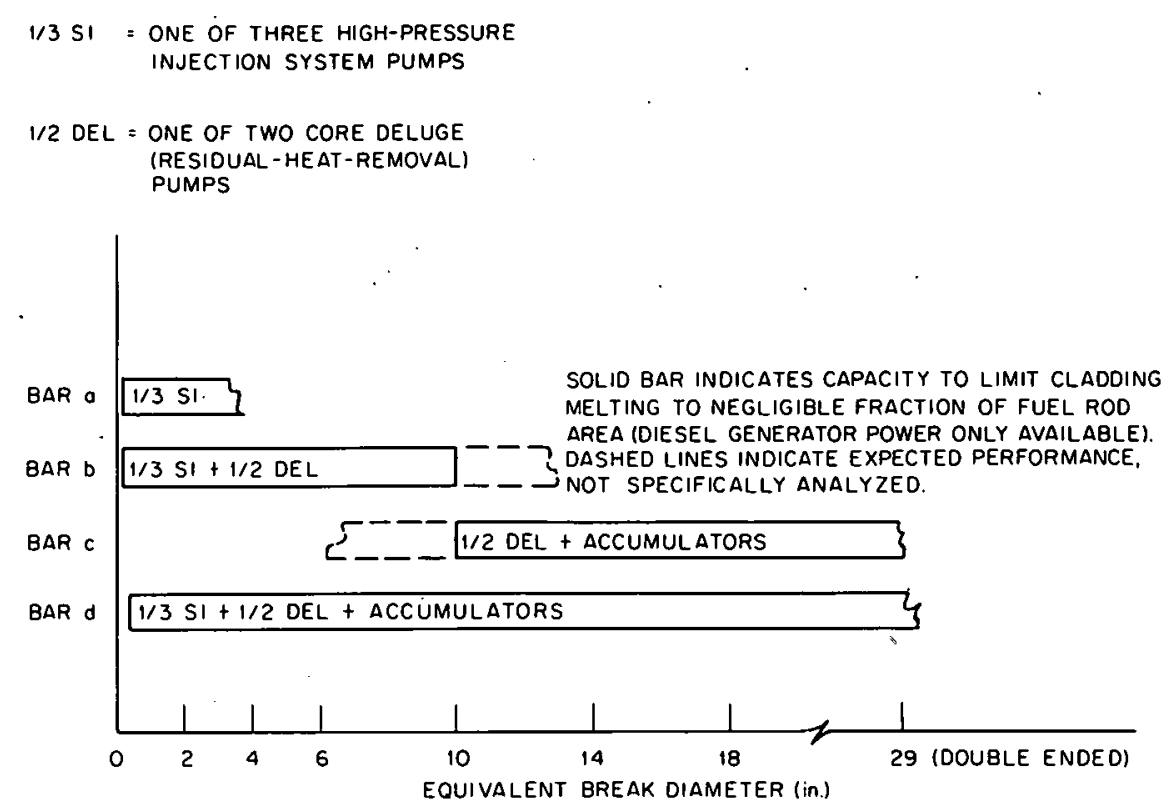

Fig. 3.17. Core Protection as a Function of Break Diameter in Lossof-Coolant Accident for Turkey Point Reactor. (From Ref. 6)

loops and two core flooding loops. These loops will each have a single pump. The pump capacity will be sufficient for a combination of one high-pressure injection purge and one flooding to satisfy all break sizes when operated with the accumulator tanks. The pump-heat exchanger layout permits each of the four loops to function as a residual-heat-removal loop.

\subsubsection{Emergency Cooling of Palisades Reactor ${ }^{12}$ ?}

3.2.3.1 Vesign Bases. The engineered safety systems of the Palisades reactor are redundant systems specifically intended to function in the event of a major loss-of-coolant accident. They are designed to provide assurance that there would be no excessive release of fission products to the environment by preventing fuel melting and minimizing the metal-water reaction and cladding melting.

The basic objectives unlerlying the performance requirements for the engineered safety systems are to restrict the release of fission products from the reactor fuel and to localize the dispersal of those fission products that are released beyond the coolant boundary. One of 
the principal means of achieving the latter objective is the limitation and reduction of internal containment pressure by removal of energy.

The emergency cooling systems and their respective functions may be summarized as follows: (I) the systems for injecting water at reactor pressure and at intermediate pressure inject boronated water into the primary cooling system, provide long-range cooling to limit core damage and fission-product release, and afford additional shutdown margin, . (2) the containment spray system removes heat and fission products by spraying cool boronated water through the containment atmosphere, and (3) the accumulators inject boronated water into the primary coolant system through the reactor vessel inlets to limit cladding melting and metalwater reaction in the case of a maximum design break.

Redundant pumps are provided for both the high-pressure and lowpressure injection systems. The basis for the maximum hypothetical accident is that only one high-pressure system pump and one low-pressure system pump are available for core cooling. The emergency cooling system is also designed for continuous long-term cooling of the core following an accident by recirculating water from the containment vessel sump. The components of these cooling systems are described in Table 3.5, and Fig. 3.13 is a flow diagram of the systems.

3.2.3.2 Operation. 'l'he accumulators are isolated from the culd ley of each reactor coolant loop through check valves. Following the rapid depressurization associated with a large leak, these accumulators would act without any electrical power to reflood the core, limit fuel cladding melting, and assure that the core was intact and in place to allow continued cooling by the other emergency cooling equipment if it withstood the blowdown.

Since power would be available from the electrical system or an emergency power supply, the five water-injection pumps would take boronated water (at refueling concentration) from the safety injection and refueling water tank and inject it into the reactor vessel inlet pipes. The rate at which the tank would be emptied would depend on the size of the break (which would determine the pressure history in the primary cooling system) and on the operation of the containment spray system. When the contents 
of the tank reached a low level, the source of injection water would be automatically switched to the containment sump and the operation of the low-pressure pumps would be discontinued. The recirculation could be continued indefinitely with the high-pressure pumps.

Each water-injection line contains a flowmeter and a remotely operated. valve to permit the operator to equalize the flow rates. Equalization of these flows insures that at least $75 \%$ of the total water injected enters the reactor vessel in the event of a break involving one of the emergency water-injection lines. The high-pressure and low-pressure injection pumps are of the motor-driven, horizontal, centrifugal type. All parts of the pumps normally in contact with boronated water are of stainless steel or other corrosion-resistant material.

If the normal and standby ac power sources were lost, one high-pressure and one low-pressure injection pump would automatically receive power - from the emergency generator. If a high-pressure or low-pressure pump did not start, an automatic transfer to the idle pump would be initiated.

The boronated-water storage tank will be maintained at its capacity of 250,000 gal of boronated water during power operation. The tank is located outside the containment vessel and is provided with heating to automatically maintain the boronated solution above its crystallization temperature. The tank level and temperature alarms in the control room alert the operator so that he can maintain the boronated water ready for emergency injections.

The injection pumps are also located outside the containment vessel to permit access for periodic testing during normal plant operation. The pumps are installed to provide adequate suction head. All pumps and remotely operated valves in the emergency injection system may be operated from the control room.

The heat-rejection system has a capacity of $175 \times 10^{6} \mathrm{Btu} / \mathrm{hr}$ for each exchanger. This is sufficient for each exchanger to remove the afterheat being generated when pumping from the sump commences.

\subsubsection{Emergency Cooling of Oconee Reactors}

The following descriptions of the emergency cooling systems of the Oconee reactors were taken trom the preliminary safety analysis report; 
and as mentioned previously the loss of flow analysis from that report is reproduced as Appendix B of this report. The components of the emergency cooling systems are described in Table 3.6, and Fig. 3.14 is a flow diagram of the systems.

3.2.4.1 Design Basis. Emergency water-injection systems are provided to prevent cladding and fuel damage that would interfere with continued core cooling and to limit metal-water reaction to less than approximately $1 \%$ for the entire spectrum of reactor cooling system failures ranging from the smallest leak to the complete severance of the largest pipe.

A high-pressure low-flow-rate water-injection system is provided that is designed to prevent uncovering of the core for small leaks and to delay uncovering of the core for intermediate-size leaks. Low-pressure water-injection and core-flooding systems are provided that are designed to recover the core and maintain core integrity for any break size up to a double-ended 36-in. reactor outlet line failure.

The water-injection systems are designed with sufficient redundancy to perform their intended function with a single active component out of service either for maintenance or due.to a failure at the time of the accident.

3.2.4.2 Piping and Instrumentation. The piping and instrumentation diagram for the emergency water-injection systems i.s shown as Fig. 3.14, with Unit 1 in the emergency water-injection operating mode. Units 2 and 3, which utilize an identical arrangement, are not shown.

In addition to the core flooding tanks, the high- and low-pressure injection systems have the following total flow capability:

\begin{tabular}{|c|c|}
\hline . & $\begin{array}{l}\text { Flow } \\
(\text { gpm })\end{array}$ \\
\hline $\begin{array}{l}\text { Low-pressure injection system } \\
\text { High-pressure injection system }\end{array}$ & $\begin{array}{l}9,000 \\
1,500\end{array}$ \\
\hline Total & 10,500 \\
\hline
\end{tabular}

3.2.4.4 High-Pressure. Injection System. During normal power operation, one high-pressure injection pump constantly supplies seal water to the reactor coolant pumps and returns letdown flow to the reactor coolant 
system. The pump, at this time, is taking suction from the letdown storage tank. A low reactor pressure signal would automatically actuate the high-pressure injection system so that (1) the two standby high-pressure injection pumps would start and come on the line, (2) the stop valve in each high-pressure injection line would open, and. (3) the two parallel stop valves in the suction line from the boronated water storage tank would open. These pumps would continue to add water to the reactor coolant system until the boronated water storage tank was empty.

\subsubsection{Low-Pressure Injection System. The low-pressure injection} and decay-heat-removal system is composed of three pumps, two heat exchangers, and the required valves and piping. Upon actuation, the three pumps will deliver $9000 \mathrm{gpm}$ of boronated water to the reactor vessel when the vessel is at 100 psig. Separate flow paths are provided through two lines from the cooler discharge through the reactor building to independent nozzles on opposite sides of the reactor vessel:

All three pumps would start if a signal indicating low reactor cooling system pressure was received. These pumps would initially take suction from the boronated water storage tank. The tank provides a reservoir of 350,000 gal of about $90^{\circ} \mathrm{F}$ water boronated to 13,000 -ppm boric acid (2270-ppm boron). The low-pressure injection pumps, in combination with pumps of other systems, would pump from this tank for about 25 to $40 \mathrm{~min}$, depending upon the number of pumps in operation. Upon an indication of low level in the tank, the valve controlling suction from the reactor building sump would be opened by the operator to permit the recirculation of spilled reactor coolant and injection water from the reactor building. The outlet valves from the boronated water storage tank would then be çlosed. At this time, the decay heat being generated in the core would be a maximum of $1.8 \%$ of full power, or $160 \times 10^{6} \mathrm{Btu} / \mathrm{hr}$ : One low-pressure injection system heat exchanger would satist'y this duty. 'I'he design basis for these heat exchangers is that each be capable of removing the decay heat being generated at the start of recirculation of spilled injection water. For each reactor, this generation rate is $160 \times 10^{6} \mathrm{Btu} / \mathrm{hr}$.

3.2.4.6 Core Flooding System. The core flooding system is composed of two flooding tanks, each connected to"'a reactor vessel injection nozzle by a line containing two isolation check valves and a normally open valve. 
The system provides for automatic flooding injection, with initiation of flow when the reactor coolant system pressure reaches approximately 600 psig. This injection provision does not require any electrical power, automatic switching, or operator action to insure the supply of emergency coolant to the reactor vessel. Operator action is required only during normal reactor cooldown, at which time the isolation valves in the flood lines are closed to isolate the contents of the flood tanks. The combined coolant content of the two flood tanks is sufficient to recover the core hot spot if no liquid remains in the reactor vessel after the blowdown. The gas overpressure, gas volume, and flooding line sizes are sufficient to accomplish this within approximately $25 \mathrm{sec}$ after a doubleended failure of a 36 -in. reactor outlet line.

\subsection{Special Considerations for Pressurized-Water Reactors}

\subsubsection{Damage from Blowdown Forces}

An instantaneous rupture of a pressurized-water reactor main coolant circulating pipe occurs in less than 0.02 sec. Such a break could, theoretically, result in a differential pressure axially across the core and radially across the core barrel of about 600 psi due to the difference in saturation pressure of the inlet and outlet coolant. Attempts to measure these pressures in exaggerated geometries have resulted in pressure differential measurements amounting to about one-half the predicted values. ${ }^{9}$ The axial loading across the core might prevent the control rods from entering the core for a short period of time, about 1 to $2 \mathrm{sec}$, according to calculation. This would cause an increase in the fission heating during an accident.

The grid structures and core barrel designs are based on a pressure difference of $1000 \mathrm{psi}$, a steady load, and ability to withstand the blowdown compression wave. The liquid leaving the primary system through the leak would have a driving. force of 2000 psi and could be damaging to the surrounding equipment if no protection was used. Accordingly, small lines; instrument channels, etc., are located. where they are sheltered from direct view of the primary piping. Redundant emergency cooling loops are located in different parts of the primary system containment 
shell to maximize the availability of a workable loop if for any reason one of the loops was inactivated by an accident. Also, LOFT and CSE programs are considering in more detail the problems associated with the blowdown phenomenon. The forces acting on the reactor system due to the blowdown forces are being calculated and measured.

\subsubsection{Distribution of Emergency Coolant Within Core}

The open-lattice construction of the PWR fuel rods permits easy distribution of water among the fuel rods once water is added; therefore, the PWR's rely on flooding systems to achieve core quenching. Since the vessel inlet and outlet lines are located above the top of the core, the core may be completely flooded if the core vessel is intact. Relying on quenching makes the emergency core-cooling problem that of delivering a large quantity of water into the reactor vessel rapidly. The use of gas-activated accumulator tanks solves the water addition problem provided the gas from the accumulator does not enter the reactor vessel and expel the coolant.

The water intended for the reactor core may bypass the core if a large break occurs in a pipeline coming from the plenum that accepts the emergency coolant. The back pressure required to accelerate the coolant as it turns to steam might prevent rapid admission of the emergency coolant to the core region and force the fluid out the break in the pipe. The Plant Application and Engineering Test Group at Phillips Petroleum Company is currently obtaining data on the rate of cooling accomplished by flooding hot fuel bundles with water entering from below. 12 Additional data will be obtained on full-length bundles through subcontracts with the General Electric Company and the Westinghouse Electric Corporation.

\subsubsection{Heat Sources Within Core Following Pipe Rupture}

In the time following a pipe rupture there exist heat sources from (1) continued fissioning due to control rod insertion delay, (2) radioactive decay of the fission products, and (3) chemical heat from reaction of Zircaloy cladding with water. Fissioning resulting from a delay in control rod insertion has been estimated to yield an equivalent of about 
2 full-power seconds of reactor energy. This estimate was made for the case of a double-ended break in the reactor outlet line. The afterheat present due to emission of radioactive energy from the fission products is well known, and methods for estimating it are available. ${ }^{13}$ However, the determination of the heat of reaction of Zircaloy and steam is complicated by the dependence of the reaction rate on the Zircaloy temperature and the quantity of reacted material on the surface as oxide. The manner in which this is done is outlined in the next section and is discussed more fully in another report in this series. 5

\subsection{Considerations Common to PWR's and BWR's}

\subsubsection{Thermal Conditions of the Fuel Elements and Pressure Vessel After Blowdown}

The thermal conditions of the fuel elements after blowdown and the specific power determine the time left to initiate the cooling system before the fuel reaches metal-water reaction temperatures. A plot of the cladding temperatures versus time from start of accident for specified volume percentages of cladding above the indicated temperature is given in Fig. 3.18 for the Browns Ferry reactor. The accident considered is a break in the recirculation line with no emergency cooling but availability of steam for the metal-water reaction. There is a plateau in temperature from 30 to $50 \mathrm{sec}$ after the break for about 10\% of the cladding due to the equalization of fuel rod heat storage. After this plateau the cladding temperature starts rising again due to the metal-water reaction. Note that the time the cladding is effectively cooled during the blowdown is from about $1 \mathrm{l} / 2$ to $5 \mathrm{sec}$. The times required for the cladding to reach $2100^{\circ} \mathrm{F}$ and the melting temperature of Zircaloy are listed in Table 3.7; the $2100^{\circ} \mathrm{F}$ temperature is the temperature at which the metal-water reaction produces energy at a rate comparable to the decay heat.

It is clear from Fig. 3.18 that if the emergency cooling system were not effective at $30 \mathrm{sec}$ or shortly thereafter, it would have to perform a function for which it has not been tested. The curves shown are calculated on the basis that water would be available for chemical reaction only and not for cooling the core. Also it was assumed that 


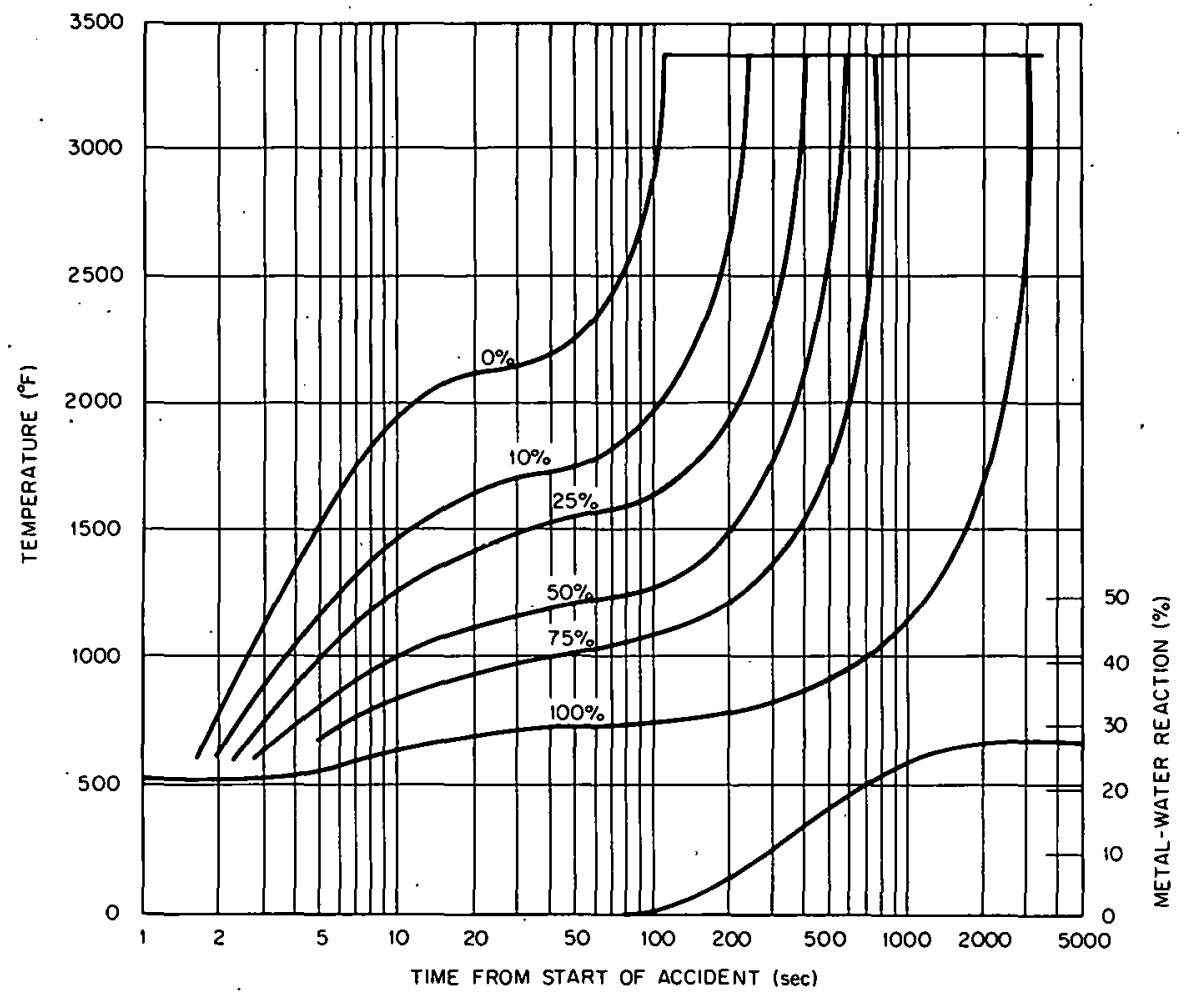

Fig. 3.18. Cladding Temperatures and Metal-Water Reaction in Browns Ferry Reactor Loss-of-Coolant Accident with No Emergency Cooling. Percentage values on curves indicate volume percent of cladding above indicated temperature. (From Ref. 3)

Table 3.7. Time Required for Cladding

to Reach $2100^{\circ} \mathrm{F}$ and the Melting Temperature of Zircaloy

\begin{tabular}{ccc}
\hline $\begin{array}{c}\text { Percentage of } \\
\text { Cladding } \\
\text { Volume }\end{array}$ & $\begin{array}{c}\text { Time to } \\
\text { Reach } \\
2100^{\circ} \mathrm{F} \\
(\mathrm{sec})\end{array}$ & $\begin{array}{c}\text { Time to Reach } \\
\text { Melting } \\
\text { Temperature } \\
(\mathrm{sec})\end{array}$ \\
\hline 0 (hot spot) & 16 & 100 \\
10 & 120 & 230 \\
25 & 240 & 410 \\
50 & 370 & 580 \\
\hline
\end{tabular}


sufficient steam would be available to sustain the chemical reaction. In reality the reaction would be severely limited by lack of steam. If the emergency cooling system did not function at all, the core would melt and the molten mass of Zircaloy and $\mathrm{UO}_{2}$ would collapse and probably melt through the pressure vessel in about $30 \mathrm{~min}$ to $1 \mathrm{hr}$. For smaller breaks or for break locations with less rapid leakage rates the core would be cooled for a longer period of time after the rupture. Therefore, the time required for the fuel and cladding to reach melting temperatures would be considerably longer. Fig. 3.7, which is also from the Browns Ferry. safety analysis report, ${ }^{3}$ shows the time to reach cladding melting temperature versus the time the core is at least half covered with water during the blowdown.

\subsubsection{Core Heat Sources}

In determining the thermal transient of the fuel and cladding during and following the pipe rupture and blowdown, it is necessary to know the fission-product heat-generation rates as a function of time and position in the core, the physical properties of the material, and the heat transfer rates between fuel and cladding, as well as between cladding and coolant. It is assumed for purposes of determining the required emergency coolant injection rate after the blowdown that there is no coolant remaining in the reactor vessel, although calculations show that a few percent of the pressure vessel volume would be filled with water. Experiments have shown that larger quantities would remain in PWR pressure vessels than is indicated by calculations. ${ }^{9}, 14$

The quantity of water left 'in the reactor vessel after blowdown would be important for three reasons: first, the greater the quantity of water left in the pressure vessel above the core bottom, the longer would the core be cooled by boiling; second, the quantity of water left in the vessel would determine the amount to be added to flood the core; and third, the water in the reactor vessel would be a source of the Zircaloy-water reaction if the cladding reached the appropriate temperatures. Thus, the water remaining in the core after the accident might be beneficial or detrimental and would be a strong factor in determining the required emergency coolant flow rate and the allowable time between pipe rupture and 
the initiation of emergency coolant injection. The manufacturers assume that steam is present for metal-water reaction after the blowdown and that water must be added to flood the core.

Fission-product decay is a major source of heat energy addition to the fuei elements throughout the loss-of-coolant accident. The time distribution of afterheat is taken into account by assuming that the reactor has been operating a long period at full power. The fission-product afterheat would start at about $6.7 \%$ of the full operating power, decrease to $3.5 \%$ in about 100 sec, and then decrease approximately as the 0.2 power of time, as shown in Fig. 3.19. For a small leak the control rods would be inserted, and the normal pump coastdown would keep the reactor fuel elements cooled until the emergency power source (if needed) and the emergency cooling system were activated. The decay of the fission power can be calculated by the ordinary neutron kinetics equations for this case. This is also shown on Fig. 3.19. About two full-power-equivalent seconds of fission power would be added.

In the case of a major break the fission power would be reduced by void generation if a negative coefficient of reactivity existed within the core without the assistance of the control rods. 'The, fission puwer is reduced in water-moderated reactors with negative temperature-reactivity coefficients when the water density* decreases, and the fissionproduct decay heat becomes the major heat source. For this case Fig. 3.19 is conservative. If the void coefficient of reactivity is positive, Fig. 3.19 greatly underestimates the fission power during depressurization. The spatial distribution of the heat source after the reactor has become subcritical is assumed to be the same as the spatial alstribution when the reactor is at power, but it is adjusted by the fission-product. decay-heat function of time after shutdown. The reactor fuel elements would be cooled somewhat during the blowdown of the coolant by the water boiling in the core. During this period of time and up to about $30 \mathrm{sec}$,

*As reactors become larger in physical size, it may be possible for a reactor to become critical in a small fraction of the core if (I) the control clusters in that area are not inserted, (2) the fuel elements are reimmersed in water, and (3) no poison is present for secondary shutdown. 


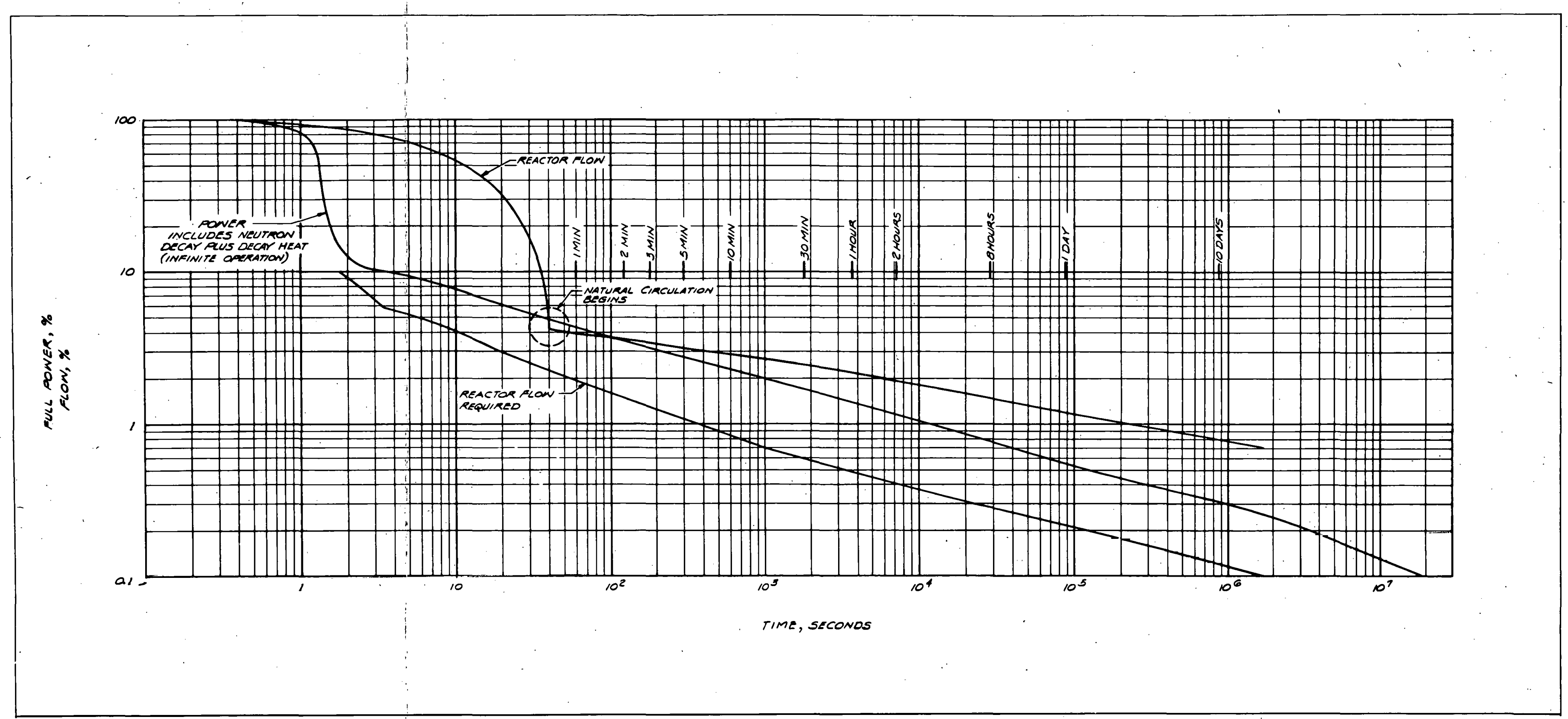

Fig. 3.19. Decay Heat Versus Time After Shutdown Following Loss of Pumping Power. (From Ref. 8) 
there would be a redistribution of the sensible heat in the fuel elements. The high heat flux and high temperature difference that existed across the core during power operation would decrease and, as the cooling diminished, the cladding would heat up, the fuel center line would.cool, and the cladding and fuel would tend toward a common temperature. Thus the sources of thermal energy in the core during a loss-of-coolant accident would be, as mentioned above,

1. The fission power generated during the blowdown before the core is shut down completely. This amounts to about 2 full-power seconds of heating, according to the manufacturers' calculations.

2. The stored energy in the fuel at the time of the accident. This is a major source of energy for cladding heating and is effective within about $30 \mathrm{sec}$ after the accident in heating the cladding.

3. The radioactive energy in the fission products in the fuel. This. energy is released at an average rate of about $2 \%$ of reactor power during. the first 2 min after the pipe break.

4. The chemical energy of the Zircaloy-water reaction, which becomes important when cladding temperatures increase above about $2100^{\circ} \mathrm{F}$.

\subsubsection{Heat Transfer Coefficients Required to Maintain' Fuel Element Integrity}

3.4.3.1. Estimates of Heat Transfer Coefficients Required After Blowdown. The heat transfer coefficients required to maintain fuel integrity depend on the maximum temperature permitted for the cladding,. the temperature of the heat sink, and the heat flux that must be dissipated from the fuel. The temperatures at which significant phenomena occur during core heatup from the viewpoint of fission-product and heat release ${ }^{2,3}$ are given in Table 3.8 .

An examination of the possible interaction of steam, Zircaloy, and steel at temperatures above about $2100^{\circ} \mathrm{F}$, coupled with the possibility of coolant channel blockage at lower temperatures, shows great need for "rapid" injection of coolant into the core to prevent the cladding temperature from increasing to above about $2100^{\circ} \mathrm{F}$. The cooling of the core during the blowdown must be capable of removing considerable heat, even though film boiling is occurring. A central question is how much energy 
Table 3.8. Temperatures at Which Significant

Phenomena Occur During Core Heatup.

\begin{tabular}{|c|c|}
\hline $\begin{array}{l}\text { Temperature } \\
\left({ }^{\circ} \mathrm{F}\right)\end{array}$ & Phenomenon \\
\hline 700 & $\begin{array}{l}\text { Approximate cladding temperature during power } \\
\text { operation }\end{array}$ \\
\hline $1500 \pm 300$ & $\begin{array}{l}\text { Cladding is perforated or swells as a result } \\
\text { of rod internal gas pressure in the postacci- } \\
\text { dent environment; some fission gases are re- } \\
\text { leased; solid reactions between stainless } \\
\text { steels and Zircaloy begin; clad swelling may } \\
\text { block some flow channels }\end{array}$ \\
\hline $2100 \pm 100$ & $\begin{array}{l}\text { Zircaloy steam reaction may produce energy in } \\
\text { excess of decay heat; gas absorption embrit- } \\
\text { tles Zircaloy }\end{array}$ \\
\hline 2700 & Steel alloys melt \\
\hline$\sim 2800$ & $\begin{array}{l}\text { Zircaloy-steam reaction may be autocatalytic } \\
\text { unless Zircaloy is quenched by immersion }\end{array}$ \\
\hline 3400 & $\begin{array}{l}\text { Zircaloy melts; fission-product release from } \\
\mathrm{UO}_{2} \text { becomes increasingly significant above } \\
3400^{\circ} \mathrm{F} .\end{array}$ \\
\hline 4800 & $\mathrm{UO}_{2}$ and $\mathrm{ZrO}_{2}$ melt. \\
\hline
\end{tabular}

must be removed during the blowdown to cool the hot spot to near. $2100^{\circ} \mathrm{F}$ ? The energy that must be removed during the blowdown includes the stored energy above $2100^{\circ} \mathrm{F}$, the decay heat energy, the chemical reaction energy, and the fission power. For the hot spot the stored energy is equivalent to about $500^{\circ} \mathrm{F} \Delta \mathrm{T}$ and the decay energy for about $10 \mathrm{sec}$ is equivalent to about $260^{\circ} \mathrm{F} \triangle \mathrm{T}$. The contribution from fission power for 2 full-power seconds is $750^{\circ} \mathrm{F} \Delta \mathrm{T}$. During much of this $2 \mathrm{sec}$, cooling would be by water flowing at nearly original velocities. There would be no metalwater reaction in the blowdown time of about $10 \mathrm{sec}$. The reduction of $1410^{\circ} \mathrm{F}$ in the $\Delta T$ during the first $10 \mathrm{sec}$ after the break would be equivalent to stored energy of $11 \mathrm{Btu} / \mathrm{lb}$ of $\mathrm{UO}_{2}$. A heat flux during the first $10 \mathrm{sec}$ of $165,000 \mathrm{Btu} / \mathrm{ft}^{2} \cdot \mathrm{hr} \cdot{ }^{\circ} \mathrm{F}$ would be required to establish this condition. The temperatures of the cladding surface and the coolant would 
determine the required heat transfer coefficient. If the cladding hot spot remained at $700^{\circ} \mathrm{F}$ and the coolant at $300^{\circ} \mathrm{F}$, the temperature drop of $400^{\circ} \mathrm{F}$ would require an $\mathrm{h}$ value of

$$
\mathrm{h}=\frac{165,000}{400}=415 \mathrm{Btu} / \mathrm{ft}^{2} \cdot \mathrm{hr} \cdot{ }^{\circ} \mathrm{F} .
$$

As the cladding temperature increased the coefficient required to remove the heat during the blowdown, when there was water-steam mixture in the core, would decrease. Typical values of film-boiling heat-transfer coefficients to high-pressure steam-water mixtures at conditions prevailing in the PWR and BWR cases during blowdown are in the range of hundreds to thousands (see Chap. 4).

After the blowdown was completed, heat transfer would be to steam by convection and, by radiation absorption, to steam-water mixtures. When the emergency coolant injection system had added water to a level corresponding to only a slight height above the bottom of the core, the splashing of coolant up to the top of the bundle would be most effective for cooling stainless steel cladding from temperatures up to $2100^{\circ} \mathrm{F}$ caused by heat fluxes corresponding to the hot spot immediately after blowdown.12,15 The concern is - how adequate would the cooling be when water was being sprayed onto the rods from above the core or when the core was being cooled by steam?

The heat flux required to remove the decay heat after completion of the blowdown is shown in Fig. 3.20, which gives the heat flux at the hot spot and at the average spot as a function of time after the blowdown. If the heat removal rates during blowdown were able to reduce the hottest cladding temperatures to $2100^{\circ} \mathrm{F}$, after the blowdown the heat removal rate for PWR's should be at least $27,000 \mathrm{Btu} / \mathrm{ft}^{2} \cdot \mathrm{hr} \cdot{ }^{\circ} \mathrm{F}$ and for $\mathrm{BWR}$ 's, at least $18,000 \mathrm{Btu} / \mathrm{ft}^{2} \cdot \mathrm{hr} \cdot{ }^{\circ} \mathrm{F}$. If the peak cladding temperature is to be kept below $2100^{\circ} \mathrm{F}$ with a coolant temperature of about $300^{\circ} \mathrm{F}$, the saturation temperature after blowdown, the minimum heat transfer coefficient with a $20 \%$ factor of safety for the FWR is

$$
h_{\min }=\frac{27,000 \times 1.2}{(2100-300)}=18 \mathrm{Btu} / \mathrm{ft}^{2} \cdot \mathrm{hr} \cdot{ }^{\circ} \mathrm{F}
$$




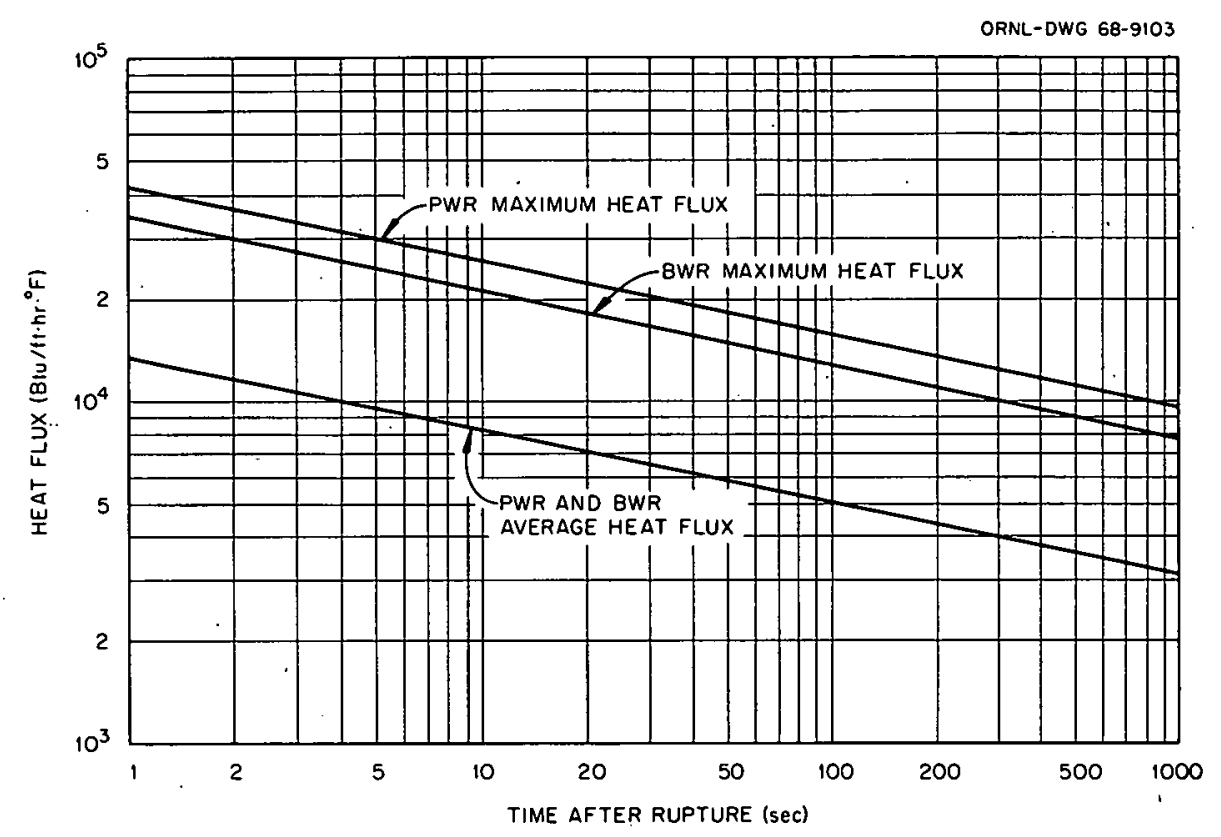

Fig. 3.20. Heat Flux Due to Decay Heat for Typical Water-CooledReactor Fuel Element After a Pipe Rupture.

and for the BWR,

$$
\mathrm{h}_{\min }=\frac{17,000 \times 1.2}{1800} \approx 11.5 \mathrm{Btu} / \mathrm{ft}^{2} \cdot \mathrm{hr} \cdot{ }^{\circ} \mathrm{F}
$$

The requirements for the above calculations are that ( 1 ) the chemical reaction contributes negligible energy, (2) the stored energy in.the fuel is at a temperature less than $2100^{\circ} \mathrm{F}$, (3) coolant is available at $300^{\circ} \mathrm{F}$ or saturation temperatures, for a heat sink, and (4) the specific power of the fuel and the rod diameters remain as they were before blowdown. If no coolant is added, no safe condition can be calculated. Thus, to recapitulate, for negligible flow interference due to cladding rupture or perforation, the cladding temperature may be kept below $2100^{\circ} \mathrm{F}$ if (1) the heat removal flux during blowdown is greater than 165,000 $\mathrm{Btu} / \mathrm{ft}^{2} \cdot \mathrm{hr} \cdot{ }^{\circ} \mathrm{F}$, and (2) immediately after blowdown, coolant is added to absorb heat. Under these conditions, heat transfer coefficients of the order of 10 to $20 \mathrm{Btu} / \mathrm{ft}^{2} \cdot \mathrm{hr} \cdot{ }^{\circ} \mathrm{F}$ should be sufficient to keep the core in a safe condition until it is flooded. 
3.4.3.2 Heat Removal During Flooding. The flooding system would add water to the core from below. Once water surrounded a rod, the rod would be cooled to temperatures approaching the temperature of the coolant by thermal, radiation and by film and nucleate boiling. Steam formation would splash water upward. This cooling method would be most effective in open-lattice systems with natural circulation, and it requires that water rise up the shrouded or semirestricted channel. There is some question about how rapidly this could occur. It might take some minutes for the high-temperatured high-powered fuel elements to be inundated because of violent film boiling, but this would affect only a small fraction of the core. This is discussed further in Chapter 4. However, all the experimental data 1,16,17 show that injection cooling imposed on an adiabatically heated rod in a closed channel requires a greater pressure head and greater time as the rod gets hotter. This makes the initiation time a major parameter in designing an effective emergency core-cooling system, since the high-power channels may become water starved.

The heat removal rates for spray cooling are limited by the steam velocity upward against the spray. This could delay the spray only momentarily, since the pump head would prevail. If the core was less than one-third covered with water, the steam boilup would keep the surface of the tube washed with water. ${ }^{3,12,15}$

3.4.3.3 Thermal Shocks and Fuel Element Bowing and Rupture. In the current generation of high-power-density cores, much of the cladding would crack or swell due to a combination of high wall temperature and high internal-to-external pressure difference before the blowdown was completed. The combined swelling and cracking of the cladding would affect gap thermal resistance. In addition the swelling might block the channel coolant flow partially or completely. This would result in higher temperatures of the cladding and fuel during and after blowdown. The manufacturers have obtained and are continuing to obtain data on these effects.11,15 The existing data show that swelling would occur, but additional information is required to determine how much and whether cooling would be prevented. A coherent research program for studying these aspects of fuel failure was recently initiated at ORNL. 


\subsubsection{Heat Sinks for Emergency Cooling Systems}

Two types of water systems are required for emergency cooling. These must supply water for primary cooling of the damaged core and water for dumping the decay heat. Pumping power is required for both systems.

3.4.4.1 Primary Cooling Water. The water for primary cooling of the damaged core would become contaminated and would have to be contained. This water would be circulated through the core and provision would have to be made to assure the presence of a neutron poison that would prevent the core from becoming critical again after the accident. This water would be recirculated through the core, collected in a sump or pool, and cooled by being pumped through a residual-heat-removal system. Emergency power would be supplied to the pumps.

3.4.4.2 Secondary Water for Heat Sinks. The water in the residualheat-removal systems would be required as a heat dump. This water would usually be pumped from the normal service water supply and isolated from the water contacting the damaged reactor core. Emergency power would be supplied to the pumps in this secondary cooling system.

\subsubsection{Reliability of Emergency Core-Cooling System}

A reliable emergency core-cooling system requires (I) design tin properly cope with anticipated situations, (2) procurement and installation of a system that will survive an accident and be able to perform its function, (3) testing on a frequency and length schedule that will assure the capability of the emergency core-cooling system to continue to perform its design function for periods of time extending well beyond the test period, and (4) inspection and maintenance of the emergency system in a manner that will assure system availability on a continuing basis.

The regulatory and licensing stat't's of the AEC, the reactor designers, and the reactor operators are directly involved in reliability assurance. Currently the Plant Applications and Engineering Test Group of Phillips Petroleum Company is making an extensive effort to obtain performance data on nonelectronic equipment for use in determining component failure rates. The reliability effort is much broader than "failure rate statistics," however. The reliability analysịs must be based on a systematized 
design approach for use by the designer that permits him to (1) select the most useful arrangement of equipment capable of performing the required functions, (2) predetermine the failure modes of the system and which failure mode is most likel.y, and (3) find the weakest link in the system. The reliability analysis is not a substitute for system effectiveness; it merely determines that if the equipment has been properly designed, the selected arrangement will function over a wider range of circumstances than. some other arrangement and identifies the component most likely to cause a malfunction so that something can be done about protecting it. (improved maintenance) or improving the layout.

The emergency core-cooling system often includes redundant systems for which the need is not clear. Unless the redundant systems are completely physically separated from each other, damage to the common components may inactivate both systems. For example, three redundant pumps leading into a common header may be ineffective if the header leaks badly. Since the emergency coolant injection system is designed to operate in situations created by accidents of unknown origin, there is good reason for having two separated loops, with each capable of accomplishing the emergency function. The reason is simply that an accident capable of destroying both emergency coolant loops if they were separated from each other physically would he of such a nature that redundant systems would not be effective; that is the accident would be in the nature of an unavoidable, unforeseeable, disastrous event, such as an act of war or sabotage.

The preliminary safety analysis reports presented to the AEC by applicants for construction permits should list each major component,. the possible modes of component failure, and the effect of each failure mode on the emergency functioning of the core. This procedure is normally followed during system design. The orderly presentation of this analysis in the preliminary safety analysis report would make the system evaluation proceed quickly and efficiently.

3.4.5.1 Testability. All emergency core-cooling systems of the current reactors are testable during reactor operation throughout the circuit from downstream of the sensor to the last valve outside the 
pressure vessel. The complete circuit is tested for operability when the reactor is shut down for refueling. The valves are exercised to show their operability and availability. All active redundant components, such as valves and pumps, are tested separately for operability. Only the high-pressure sensors in the containment shells are not tested. A method is needed to test these sensors during reactor operation without leaving the reactor unprotected.

The conditions of the tests are not the same as the conditions anticipated during the design-basis accident. The tests are conducted under the ideal conditions that exist while the reactor is operating or during refueling. The performance of valves, motors, and sensors in a wet, hot atmosphere at pressures of 2 to $3 \mathrm{~atm}$ is not determined. Hence potential short circuits, for example, are not found. The full flow capability of the emergency injection loop is tested only once while the reactor is being constructed. Testing of sensors is not performed under the forces expected during the transients associated with a lossof-coolant accident. Sensors and other appendage-type equipment are not tested under the acceleration forces associated with even the mildest earthquakes. Many of these tests should. be performed on components and emergency systems when possible to be certain that they will work when required.

3.4.5.2 System Activation and Availability Under Accident Conditions. The design accident would occur simultaneously with a loss of power. Hence, operation of the emergency cooling system requires that ( 1 ) the accident be sensed, (2) emergency instrument- and valve-operating power (batteries) be available, (3) emergency ac power for pumps be provided, (4) emergency pumps be started, (5) high-pressure blowdown be completed to the emergency coolant pressure, and (6) emergency coolant, flow enter the core. If station ac power were available from the grid, steps (2) and (3) would be omitted, and the power source should be no problem. In the highly unlikely event that ac power was lost, operation of the emergency ac power source would be required.

In a recent study by Holmes \& Narver, 18 the emergency Diesel power stations were found to have the highest unreliability in the emergency 
circuit. The emergency Diesels failed to operate $1 \%$ of the times they were tested. Failures were due to dead starting batteries, leaking fuel lines, and generally poor maintenance of the emergency power equipment. The relatively poor showing of the emergency power supply makes the effectiveness of emergency cooling systems questionable.

The pumps" for the emergency cooling systems are located outside the containment vessel for access and maintenance. The pumps are therefore not subject to damage by the design accident. They are, however, subject to accidents initiated from outside the reactor. The emergency cooling system may be available, however, for simply flooding the core or pressure vessel chamber, even in the event of a dislocation of the core, and may assure shutdown if the water source contains sufficient neutron poison to shut down the reactor without insertion of the control rods.

In general, the fewer the working parts, such as valves and instrumentation, the more reliable is the system. However, a balance must be made between increasing the accident probability with more hardware on the one hand and increasing the probability of containing a given accident on the other.

\subsection{Codes and Standards}

There are many codes, standards, and design criteria that specify the required high quality of reactor components. These standards and their status of development are given in a "Compilation of United States Nuclear Standards. "19 Reactor manufacturers often follow construction of components by assigning personal representatives to assure quality construction, ${ }^{8}$ in addition to adherence to standards. In general, all reactor manufacturers use the same standards.

The design of piping and val.ves conforms to ASA Code B3I.I for Pressure Piping and applicable nuclear code cases. Pump design conforms to the standards of the Hydraulic Institute. Motors conform to the standards of the National Electrical Manufacturers Association, the Institute of Electrical and Electronic Engineers, and the American Standards Association. Heat exchangers conform to the standards of the Tubular Exchangers Manufacturers Association (TEMA) and to the ASME Code, 
Section VIII, and applicable code cases. All portions of the emergency cooling and containment spray systems normally in contact with the primary coolant or with boronated water are fabricated from stainless steel or other corrosion-resistant material.

Design criteria issued by the $A E C$ serve as a guide to applicants for nuclear power plant construction permits. These design criteria may be considered as policy statements for designing the engineered safety features of reactors. The criteria related to the emergency core-cooling systems are listed in Appendix A.

These criteria reinforce the need for the designer to provide (1) safety features to protect the public, (2) equipment of high quality, (3) performance objectives to cope with the widest possible spectrum of design accidents, (4) an analysis of the potential hazards, such as earthquakes, floods, hur'ricanes, etc., that exist at the site and allowance of an appropriate margin in design, and (5) a procedure for testing before and during reactor life that assures reliability of engineered safeguards to perform their design function, including startup and transfer to the emergency power supply.

There are no standards based on system experience that state performance specifications in a manner which assures that the design criteria for the emergency core-cooling systems have been fulfilled. Thus the emergency core-cooling system may be considered to be a necessary engineered safety system with specifications to be negotiated among the $A E C$, the applicant, and reactor designer and which will vary with the reactor type and location. This point of view is not entirely unreasonable, since the severity of an accident could be measured in terms of the number of persons affected.

The assurance of reactor quality is ultimately the responsibility of the utility purchasing the reactor. The purchaser and the manufacturer must work together to recognize and achieve the required quality. This cooperation can best be secured by personal supervision on the part of the utility company, its appointed architect-engineer, and the manufacturer during the appropriate phases of design, construction, and installation, as well as operation and maintenance of the reactor. The manufacturers of components for reactors and reactor designers have a share 
of the responsibility that can be fulfilled by developing industry-wide standards of reliability and quality that are sufficient to satisfy the AEC safety guidelines, as well as the needs of the manufacturers.

The rapid expansion of the nuclear industry since 1964 has created a shortage of trained personnel for manufacturing and constructing nuclear components and systems having high reliability over a broad range of operating conditions. As a result of this it may be necessary for the Atomic Energy Commission to supply leadership in obtaining quality standards. 


\section{EXPERTMENTAL DATA AND ANALYSES AVAILABLE FOR DESIGN CALCULATIONS}

The loss-of-coolant accident is being evaluated both experimentally and analytically in the Loss-of-Fluid Test (LOFT) program being carried out for the Atomic Energy Commission by the Phillips Petroleum Company at the National Reactor Testing Station, Idaho Falls, Idaho.20, 21 Progress on this program is reported in quarterly progress reports (Refs. 9, 14, 22-28). The purpose of this program is to determine and predict analytically the course of a loss-of-coolant accident in a 50-Mw(th) PWR with emergency core-cooling devices and to develop and improve the capability of designers to estimate. the performance emergency of cooling systems in larger reactors.

For purposes of discussion the accident analysis has been divided into three chronological parts including:

1. analyses of blowdown-pressure and mass-flow transients within and from the reactor vessel,

2. core heatup and temperature distribution analysis,

3. analyses of emergency coolant addition and fuel element thermal control with an undamaged injection system and with partial operation of the injection system.

\subsection{Computer Programs for Calculating Consequences of Emergency In-Core Cooling Situations}

There are many computer programs available that describe the blowdownpressure transients of boiling-water and pressurized-water reactors. 29-34 Virtually every manufacturer of reactors and pressure vessels has such a program, as do some of the architect-engineers.

The LOFT program is currently making available to industry the data obtained in the semiscale blowdown facility for a point of normalization. Comparisons of computer programs are also being made, ${ }^{30}$ and LOFT has released several AEC sponsored programs for public use. An excellent summary of these programs is presented in Appendix $C$, which is taken from Ref. 1. 
Revisions have been or are being made to these computer programs to adjust the calculations to experimental data. Specifically, the mass of water ejected from the core has been overestimated, probably due to a conservative model for steam-water separation in the pressure vessel.

Discussions with reactor manufacturers suggested that the computer programs currently in use need (from an understanding point of view) more normalization to data (such as that being obtained by LOFT to account for the effect of vessel internals on the water-ejection $\mathrm{rate}^{9},{ }^{14}$ ), but enough is known to permit conservative design of water-addition loops.

The computer programs for calculating core heatup during and after a blowdown are TACT $V$ of General Electric Company and SATAN and LOCTA-R of Westinghouse Electric Corporation. The TACT V program is the only one that estimates the initial thermal condition from mocked-up blowdown experiments. 3;35,36

The forces on the pressure vessel internals are estimated from the blowdown analysis and are taken into account in designing these structures (Refs. 2, 3, 6, 7, 8, and 36). Some tests to determine the adequacy of the design procedures have been reported for PWR's ${ }^{32,37}$ and BWR's. 36

The pressure vessels are designed to withstand the reaction forces of a major line break without turning, and the pipes are constrained to prevent whipping. The LOFT program and the Containment System Experiment (CSE) program are currently reviewing these design procedures.

\subsection{Heat Sources}

Heat sources active in the loss-of-coolant accident would include fission-product decay heat, products from neutron capture in fuel and core structures, continued fissioning of ${ }^{235} \mathrm{U}$ due to delayed neutrons, continued fissioning due to incomplete shutdown, and heat produced by zirconium-steam and other chemical reactions. In addition, the redistribution of the sensible heat between cladding and fuel would be a major factor in heating the cladding during the first $30 \mathrm{sec}$ after the large break, as may be seen on Figs. 3.16 and 3.18 . 
The fission-product decay heating would be the largest single source of heat. This has been studied extensively, and a review of the subject is presented in the reactor containment handbook. ${ }^{13}$ This information is well known and reliable.

The heat associated with continued fissioning is also considered in analyzing the loss-of-coolant accident. However, the computation is made with the assumption that the control rods would not be damaged but rod insertion would be delayed by hydraulic forces. For large pipe ruptures the rapid operation of control rods would not be necessary, since the reactor would be shut down by voids in less than $2 \mathrm{sec}$ (Refs. 2, 3, 6, 7, 8, and 36). For small leaks, either the makeup pumps would operate, the reactor control rods would work, or the system could be shut down by an automatic pressure-relief system. The addition of neutron-poisoned water would be required if the control rods were inoperative after the blowdown:

The time delay before activation of the spray cooling system is possibly the single-most important variable other than the reactor specific power. Chemical energy release rates may become larger than fission-product decay energy release because of the metal-water reaction if the reactor is not cooled soon enough.

Metal-water reactions could produce large quantities of energy at high rates relative to decay heat if the cladding temperature rose above about $1100^{\circ} \mathrm{C}$ and steam was available for the reaction. Reaction rates are reasonably well known, as are the heats of reaction.4,29,38. These reactions are discussed fully in the discussion paper on metal-water reactions. 5 The calculated distribution of cladding temperatures in the Browns Ferry Reactor after a recirculating line break with no cooling but with unlimited steam available for a metal-water reaction is shown in Fig. 3.18. (The assumption of "unlimited steam". is highly conservative.) Four minutes after the break 25 to $50 \%$ of the cladding volume would be at temperatures where zircaloy and water react rapidly and possibly $10 \%$ of the cladding would be above the melting temperature. This situation would also be true for pressurized-water reactors, but more cladding would be melted because of the higher specific power. If the 
emergency power supply was delayed in operation and water was injected after some melting had occurred, the rapid generation of steam, and possibly pressure, could cause further damage. There are no known data on experiments in which water and Zircaloy in large quantities have been contacted under the above thermal conditions. Tests with a small number of rods showed embrittlement and fragmentation of the fuel after zircaloy was quenched from above $2500^{\circ} \mathrm{F}$.

The sensible heat contained in the fuel after the blowdown would influence the cladding ruptures. For a large break, the blowdown would be over before much heat could be removed from the fuel. As the cooling rate decreased toward the end of the blowdown the temperature within the fuel rod would equalize by increasing the cladding temperature while lowering the temperature near the center of the fuel. This effect is shown in Browns Ferry fuel cladding temperature distribution curves (Fig. 3.18), where the fraction of the cladding above a given temperature rises steeply and then flattens out at about 30 to $50 \mathrm{sec}$ after the rupture. The same situation would occur in a PWR, since the smaller diameter rods would be cooled more efficiently but for a shorter length of time. In addition, the PWR fuel rod would equilibrate more rapidly because of the slightly smaller fuel rod. An examination of the uncooled hot spot temperature curve of Fig. 3.16 shows the importance of a rapid cooldown of the reactor fuel. This could be accomplished only by core flooding within about $30 \mathrm{sec}$ after the break.

The pressure vessel sensible heat is known quite well after blowdown because the heat flow is limited by conduction in the wall. Cooling of the pressure vessel and the vessel internals by water remaining in the bottom would supply steam to either support the metal-water reaction or cool the fuel. ${ }^{34}$ The mass of water that would remain in the reactor vessel after blowdown is not known accurately. The computation techniques used by the manufacturers are based on steam being available for chemical reaction but not for cooling. The sensible heat contained in the vessel internals would be a function of the cooling rate during blowdown, and there is little information on this subject, as will be discussed in the next section. Information is available on the thermal conductivity and 
specific heat of Zircaloy up to the melting point, ${ }^{38}$ and stress data are currently being obtained 20,38 at temperatures up to about $2000^{\circ} \mathrm{F}$ for Zircaloy-2, Zircaloy-4, and some stainless steel alloys.

\subsection{Heat Transfer. and Cooling of Fuel Rods}

\subsubsection{Effect of Blowdown History on Cladding Temperature}

The only experiments known in which heat transfer rates were measured during blowdown of a simulated fuel element are reported in appendices of BWR preliminary safety analysis reports. ${ }^{3,36}$ In these reports the information is presented as correlations of (I) "dryout time" versus rod heat flux and (2) heat transfer coefficient after dryout versus time after dryout. The data are independent of heat flux and time- when normalized to the experimental dryout time and to the normal boiling heat transfer coefficient calculated from the Jens-Lottes correlation. ${ }^{39}$ These data apply to blowdown of saturated steam at 1000 psia with ratio of pipe to tank size applicable to the BWR for large pipe breaks, as shown in Figs. 4.1 and 4.2. These data were taken in a closed end pipe with no water circulation into the test section and hence are conservative relative to the real reactor vessel.

Lists of the heat transfer correlations used in two-phase flow are given in Tables 4.1 and 4.2. These correlations are used by some of the manufacturers in calculating blowdown heat transfer, steam boiloff, and core quenching and reflooding. These correlations apply to "steadystate" situations, and some of the empirical relationships should be checked out under highly transient conditions. The range of heat transfer coefficients calculated for the blowdown conditions is shown in column 3 of Table 4.1, which is headed design values. The estimated range of heat transfer coefficient values during blowdown is sufficient to cool the fuel hot spot of any of the current water-cooled reactors to temperatures below $2100^{\circ} \mathrm{F}$. The major remaining concern is: Does the emergency coolant water get reinjected soon enough?

LOFT and CSE could obtain blowdown heat transfer data. Westinghouse claims to have blowdown data but has not made it available because of its proprietary nature. 


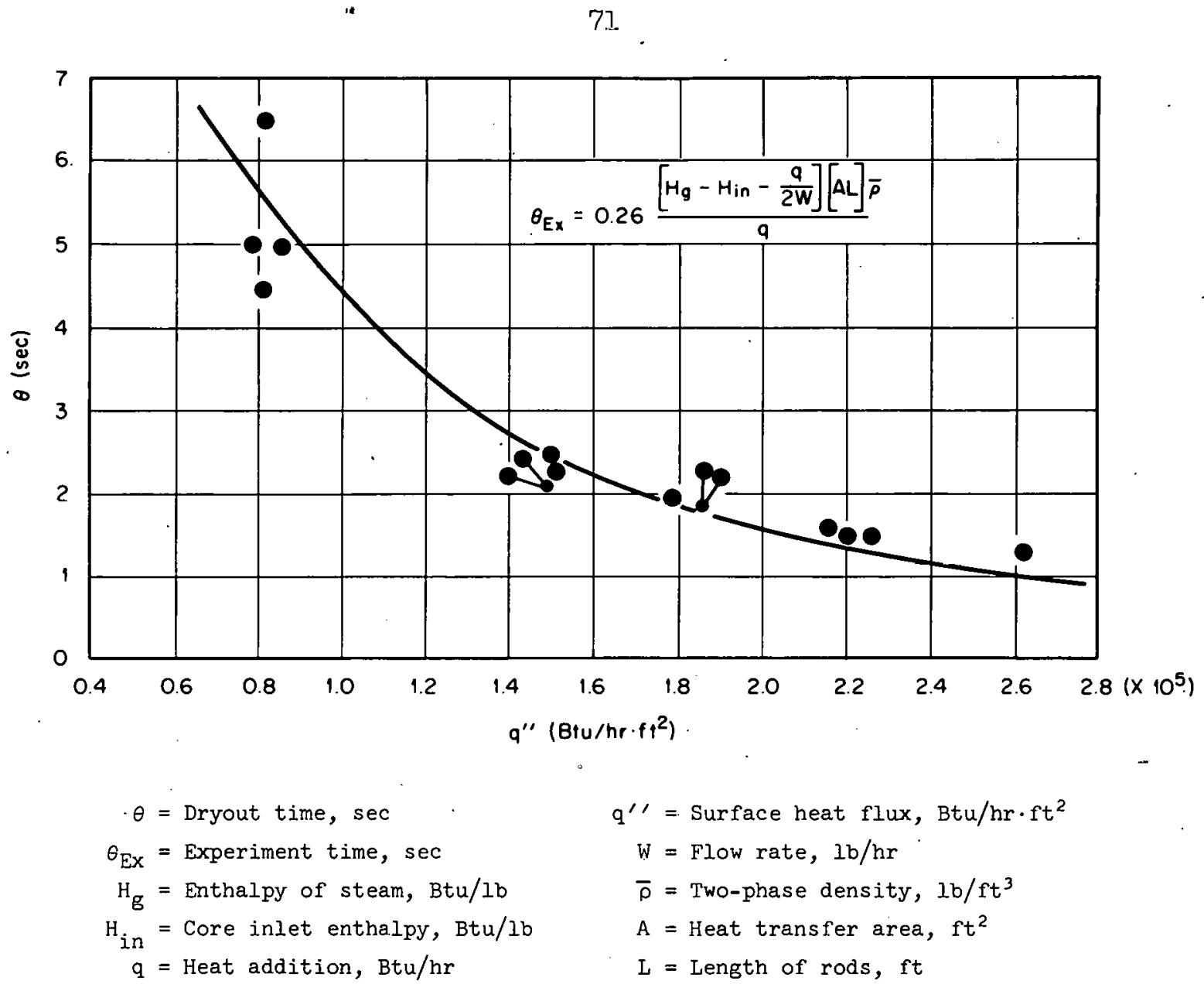

Fig. 4.1. Minimum Duration of Nucleate Boiling During Blowdown from 1000 psi. (From Ref. 3)

In the event of a more likely small break when the control rods operate, power is available, and blowdown occurs over a period of minutes, the core cladding would follow the temperature of the coolant and the decay heat would have dropped to 1 to $2 \%$ of the reactor power level.

The uncertain situation occurs in discussing the rapid blowdown situation from large breaks. The fuel hot spot temperature at the end of the pressure transient may be between the initial temperature of the coolant, approximately $280^{\circ} \mathrm{C}\left(\sim 500^{\circ} \mathrm{F}\right)$, and approximately $2500^{\circ} \mathrm{F}$. This temperature uncertainty means a difference in time to melt the cladding. Ca.coulations made by Jensen ${ }^{34}$ on the LOFT experiment show that the average fuel temperature after a 12-sec blowdown for a fuel rod initially at $700^{\circ} \mathrm{C}\left(1300^{\circ} \mathrm{F}\right)$ average temperature would vary from 316 to $730^{\circ} \mathrm{C}$ (600 to 


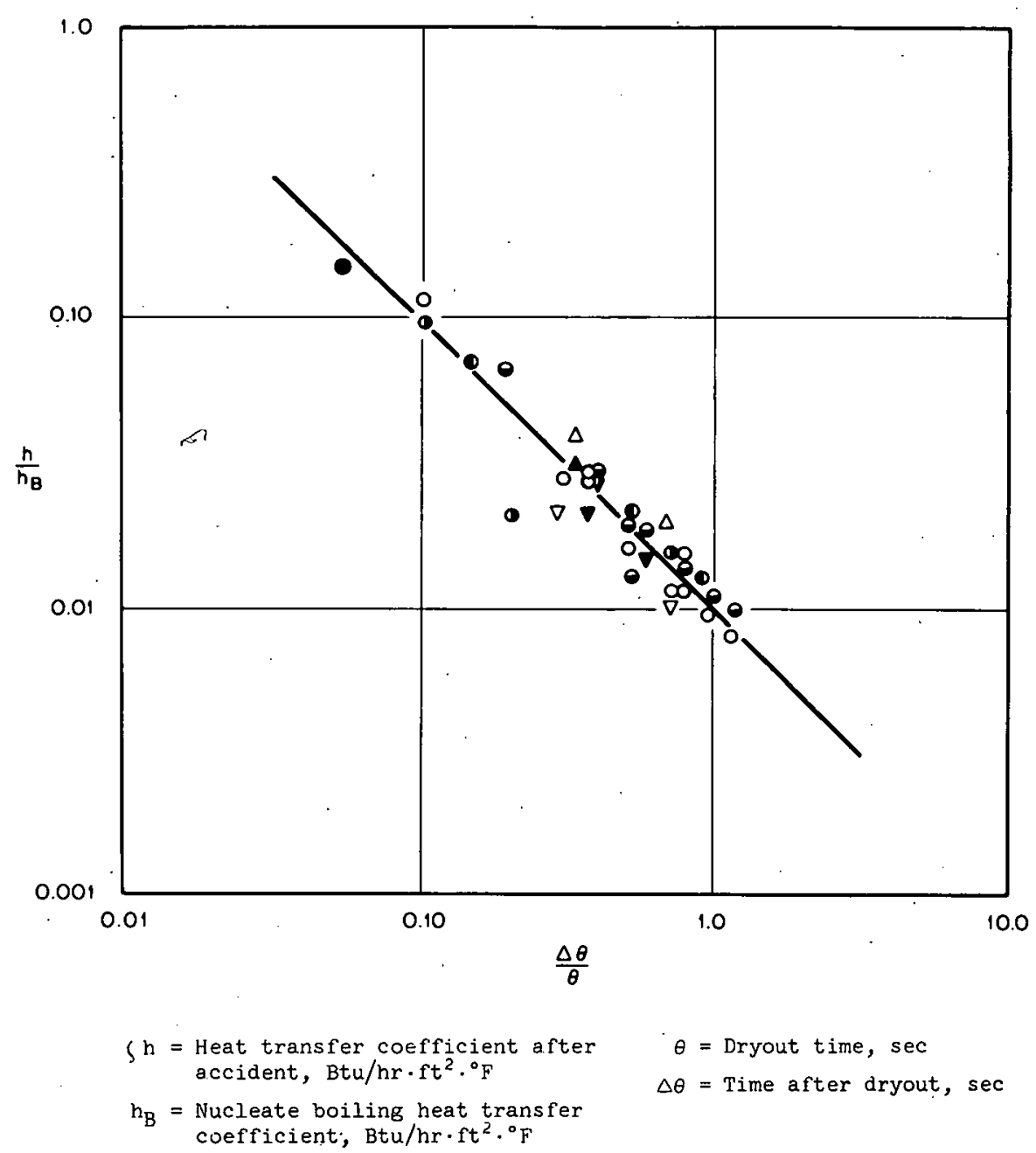

Fig. 4.2. Minimum Heat Transfer After Dryout During Blowdown from 1000 psi. (From Ref. 3)

$1350^{\circ} \mathrm{F}$ ) as the assumed surface coefficient varied as a parameter from 1038 to $1.04 \mathrm{Btu} / \mathrm{ft}^{2} \cdot \mathrm{hr} \cdot{ }^{\circ} \mathrm{F}$. This range was selected to compare the effect of water-convection cooling with gas cooling. The cladding surface varied from 148 to $730^{\circ} \mathrm{C}\left(300\right.$ to $1350^{\circ} \mathrm{F}$ ) for the same conditions.

For a coefficient of 1000 , the time required for the cladding to reach $1093^{\circ} \mathrm{C}\left(2000^{\circ} \mathrm{F}\right)$ would be about $7 \mathrm{~min}$, while for the coefficient of 1 , the time required would be about 2 min after the blowdown with no additional cooling. The realistic case would be somewhere between the two extremes. The rods at powers higher than average: would be at higher temperatures initially and have higher decay heating rates; thus they would 
Table 4.1. Heat Transfer During Blowdown and Steam Boiloff

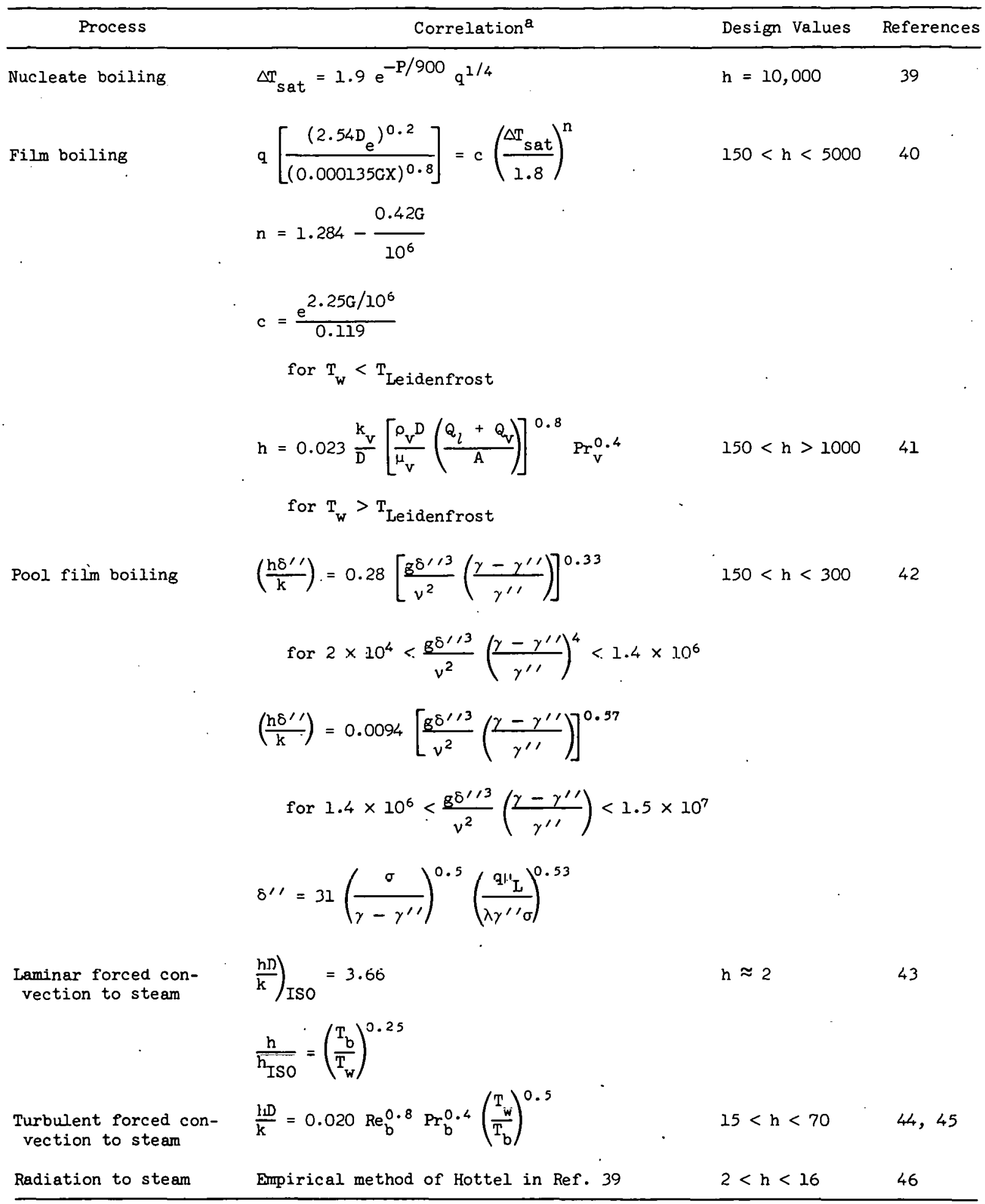

aThe terms used have the definitions given on the following page: 


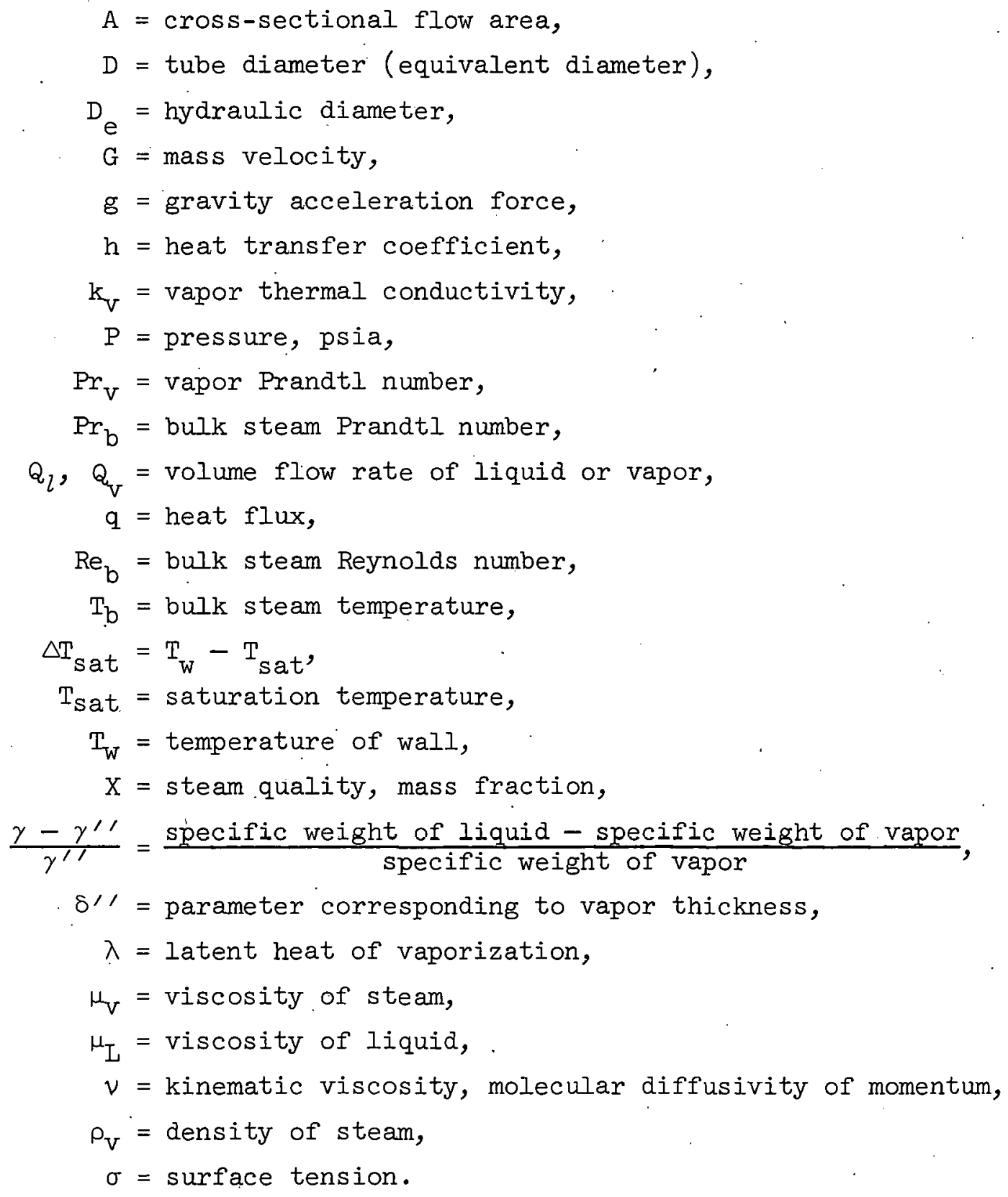


Table 4.2: Heat Transfer During Core Flooding

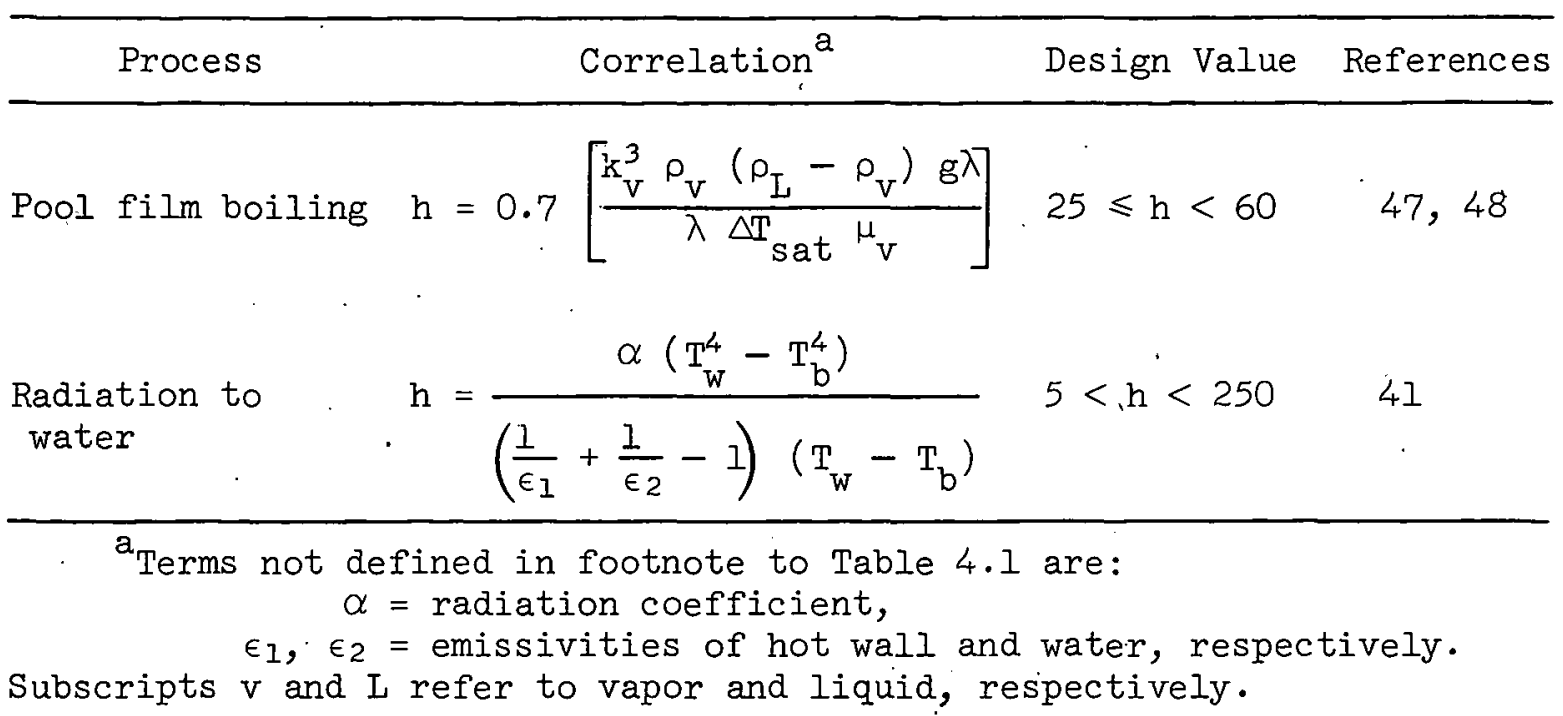

melt more rapidly. Since the specific power of the pressurized-water reactor is higher than that of the boiling-water reactor, the uncooled. heating rate is higher (see Table 3.1). In addition, the PWR blowdown is more rapid than the BWR blowdown. Unless water is left in the reactor vessel above the core bottom, the hottest cladding in the PWR will reach melting temperature sooner than the hottest cladding in the BWR. The blowdown heat transfer should be checked in large assemblies.

\subsubsection{Effect of Cladding Temperature on Heat Transfer Rates in Spray Cooling}

Heat transfer tests of spray-cooled simulated reactor fuel rods have been conducted by groups in the United States, ${ }^{49}$ Japan, ${ }^{37}, 50$ and Britain.51,52 The British work investigated the cooling of single rods and of seven rod bundles by overhead sprays with the surface held at constant temperature. It was found that the spray collected at the top of the rod and advanced down the rod at a rate which depended only on the surface temperature. A temperature of phenomenological demarcation was observed that was called the sputtering temperature. Below the sputtering temperature the film advanced rapidly down the tube at rates of 1 $\mathrm{ft} / \mathrm{sec}$ or greater. Above the sputtering temperature the time to wet a 
given length of rod increased linearly with the difference between the hot wall temperature and the sputtering temperature. At atmospheric pressure the sputtering temperature was about $138^{\circ} \mathrm{C}\left(280^{\circ} \mathrm{F}\right)$ or approximately $39^{\circ} \mathrm{C}\left(70^{\circ} \mathrm{F}\right)$ above saturation, and it may be a function of the type of surface. At a perimeter water. fiow rate near $0.1 \mathrm{lb} / \mathrm{ft} \cdot \mathrm{sec}$ and a surface temperature of $371^{\circ} \mathrm{C}\left(700^{\circ} \mathrm{F}\right)$, the falling film advanced the 12-ft rod length in $400 \mathrm{sec}$.

Experiments were also conducted in a rig containing seven rods, $0.625 \mathrm{in}$. in diameter and $12 \mathrm{ft}$ long, wire wrapped and inserted in a 2.5-in.-diam tube. A water spray was introduced at the top with water distribution by splashing onto the central rod. The results were similar to the single tube tests. It was observed in these tests that flooding* or choking of the inlet spray occurred as the subcooling of the inlet water was increased. The flooding characteristics were correlated by methods proposed by Wallis and others.16,17

The Japanese work ${ }^{37}, 50$ was performed with electrically heated, stainless steel-clad MgO rods. There were 36 rods 0.50 in. in diameter and 100 or. $60 \mathrm{in.}$ in active length. The rods were on a square array $0.7 \mathrm{in}$. apart and surrounded by a shroud $43 / 4 \mathrm{in}$. on a side. Thermocouples were located on the bottom of each tube, and some tubes had four thermocouples. Tests were run at several steady heat fluxes and water coolant flow rates. The results showed that for a given heat flux and water flow rate there is a maximum cladding temperature which appears to be limited by thermal radiation. For a heat $\mathrm{flux}$ of $11,000 \mathrm{Btu} / \mathrm{ft}^{2} \cdot \mathrm{hr}$, the maximum temperature is about $900^{\circ} \mathrm{C}\left(1650^{\circ} \mathrm{F}\right)$ with a flow rate of approximately $0.08 \mathrm{gpm}$ per rod (100 in. long). These data also showed that the flooding increased as the amount of subcooling increased. The Japanese work generally confirmed the British work on the rate of hot rod wetting.

Additional data from Japan's SAFE Program are summarized in Nuclear Safety by Uchida, 50 who presents an empirical correlation relating heat flux to the temperature difference between water and saturated steam and a correlation for determining the flooding velocities between steam and

*Flooding occurs when liquid is prevented from entering the channel from above because of the countercurrent flow of gas or vapor. 
water. The heat flux correlation is

$$
\frac{\mathrm{q}}{\mathrm{A}}=0.07 \Delta \mathrm{T}^{2},
$$

where $\mathrm{q} / \mathrm{A}$ is in $\mathrm{kcal} / \mathrm{m}^{2} \cdot \mathrm{hr}$ and $\Delta \mathrm{T}$ is the wall temperature minus the saturation temperature in ${ }^{\circ} \mathrm{C}$, with a range of 200 to $700^{\circ} \mathrm{C}$.

The Japanese data have been analyzed to separate the effects of radiation and natural convection. ${ }^{53}$ From these data the calculated heat transfer coefficient from a Zircaloy rod to steam in a $6 \times 6$ array may be estimated by the relation

$$
\mathrm{h}_{\mathrm{T}}\left(\mathrm{Btu} / \mathrm{ft} \mathrm{t}^{2} \cdot \mathrm{hr} \cdot{ }^{\circ} \mathrm{F}\right)=3.6+5.6 \times 10^{-6}\left(\mathrm{~T}_{\mathrm{W}}^{2}+\mathrm{T}_{\mathrm{S}}^{2}\right)\left(\mathrm{T}_{\mathrm{W}}+\mathrm{T}_{\mathrm{S}}\right)
$$

Here the convection coefficient is 3.6, and the product of the form factor times emissivity is 0.324 . The convection heat transfer coefficient is about twice the value expected for laminar-flow forced convection. This is believed to be caused by the promotion of a slug-flow type of velocity distribution due to the flow mixers and spray droplets. The values of heat transfer coefficients with molecular diffusivity controlling and slug flow are about twice the values for forced-convection velocity distribution. 54

The value of 0.324 for the form factor-emissivity product is reasonable because the steam is an excellent absorber of infrared energy. The above equation yields heat transfer coefficients of 14 to 15 at 2000 to $2100^{\circ} \mathrm{F}$. Uchida 50 presents a flooding correlation that is a function of mass flow of liquid and steam and heat output of the rods.

Extensive work on the flooding phenomenon is reported by Wallis ${ }^{16}$. and by Shires and Pickering. ${ }^{17}$ An excellent summary of this work is presented in Ref. 1, which shows that the large BWR's will not flood out the spray during the emergency cooling operation mode.

General Electric Company has reported work in the appendices of several preliminary safety analysis reports in which test results are presented for a full-size simulated fuel bundle containing 36 stainless steel rods $12 \mathrm{ft}$ long. The following description of the tests is based Un à GE ducument. 3 
The 36-rod electrically heated test section is shown in Fig. 4.3. The calrods were specially made to have a cosine axial power distribution. Eight of the rods were instrumented with twelve thermocouples each distributed along the length of the rod. The channel was also instrumented. with thermocouples. The positions of the instrumented rods and also the flux peaking rods are shown in Fig. 4.3. During the tests, rods B, C, $\mathrm{E}, \mathrm{F}$, and $\mathrm{H}$ generally ran the hottest, not unexpectedly. Thermocouples on rods $\mathrm{G}, \mathrm{E}$, and $\mathrm{C}$, in combination with channel thermocouples, yielded the transverse temperature profile.

The test was started by first heating the assembly with no cooling. When the highest rod temperature reached $677^{\circ} \mathrm{C}\left(1250^{\circ} \mathrm{F}\right)$ [channel temperature about $343^{\circ} \mathrm{C}\left(650^{\circ} \mathrm{F}\right)$ ] the spray was turned on, and the power was then varied as a function of time to simulate decay heat. The channel temperature traces indicated an abrupt drop in temperature about $100 \mathrm{sec}$ after the onset of spray due to wetting the top half of the channel wall. It is estimated that about this much more time was required for the remainder of the channel wail to be wetted. From that time on, the wall acted as a heat sink. The rod temperatures continued to rise, eventualiy

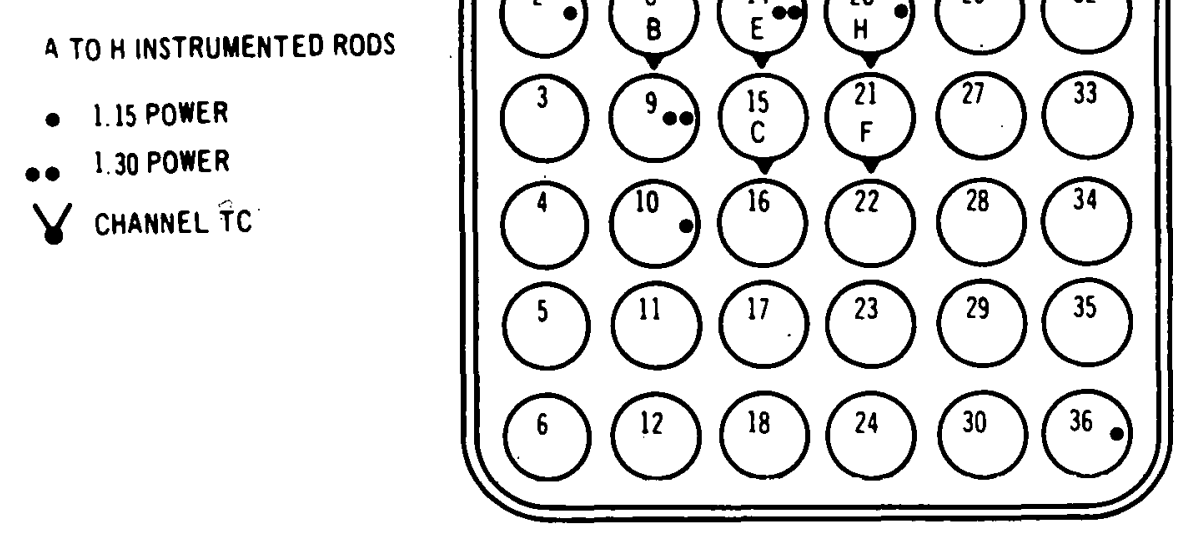

Fig. 4.3. Full-Size 36-Rod Simulated Fuel Bundle Showing Instrumentation. (From Ref. 3) 
reached a maximum and then decreased, and finally reached the saturation temperature some 20 to $40 \mathrm{~min}$ later, depending on the power.

The peak temperature occurring during the transient following onset of spraying is plotted versus full channel power in Fig. 4.4. Tests were run with provisions for venting at both top and kottom or top only at different initial rod temperatures and over a range of flows from 1.8 to $2.8 \mathrm{gpm}$. None of these parameters had a strong effect on the peak temperature. The negligible effect of flow is believed to be due to the strong radiation of heat at the temperature experienced. Radiation is a function of temperature and is unaffected by flow rate.

It must be understood that the phenomenon occurring within the fuel bundle is not one of rod wetting, nor pure convection, nor pure radiation. It is a complex combination in which radiation plays a key role. Because of the "Liedenfrost effect" (sputtering) the water is thrown off the rods near the top of the bundle and onto the channel wall. The rest falls between the rods' and sputters and splashes between them. A considerable amount of water runs down the fuel channels around the rod array and flows off onto the spacers and back into the array every $18 \mathrm{in.} \mathrm{The} \mathrm{channel}$ walls remain wet and act as a heat sink for thermal radiation. Some of the water that finds its way into the fuel rods evaporates and forms steam, which provides some convection cooling. Only a quarter or so of the water actually evaporates, depending on the point in time. Radiation takes place between rod surfaces to the water vapor, to the water droplets, and to the channel walls.

As the decay heat slowly drops the heat flux is reduced to the point where rod wetting actually occurs, since the liedenfrost effect is no longer present, and rod temperatures drop to saturation approximately $105^{\circ} \mathrm{C}\left(\sim 220^{\circ} \mathrm{F}\right)$. This occurred in the tests which simulated decay heat within $40 \mathrm{~min}$ following the design break; the temperatures throughout most of the core would reach saturation much sooner.

Of importance in considering any possible chemical reaction between cladding metal and spray water is the time at temperature, shown in Fig. 4.5. These data are for just one test run. A similar plot can be prepared for each of the other test runs. The top curve represents the 


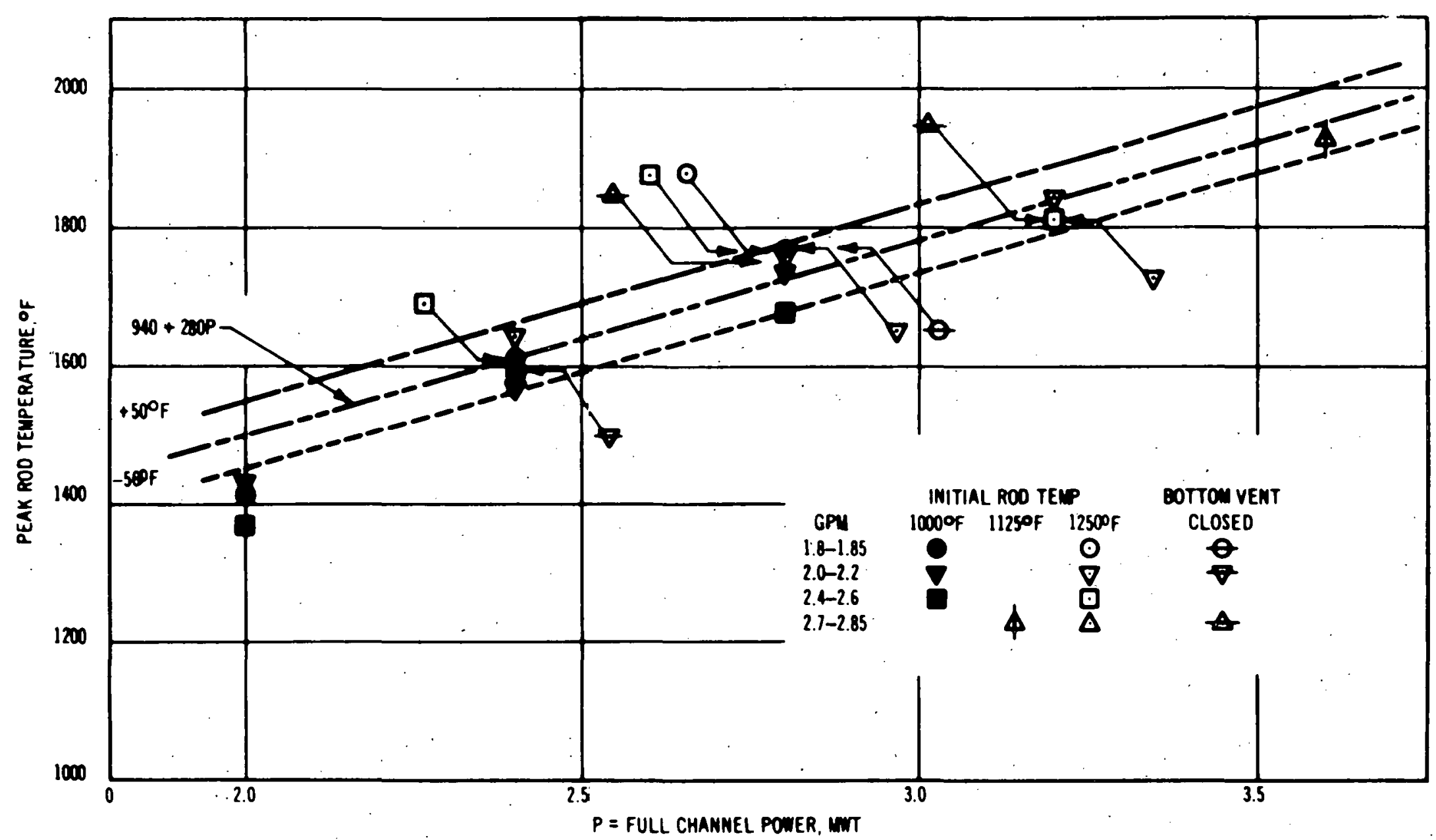

Fig. 4.4. Highest Kod Temperatures During Spray Cooling. (From Ref. 3) 


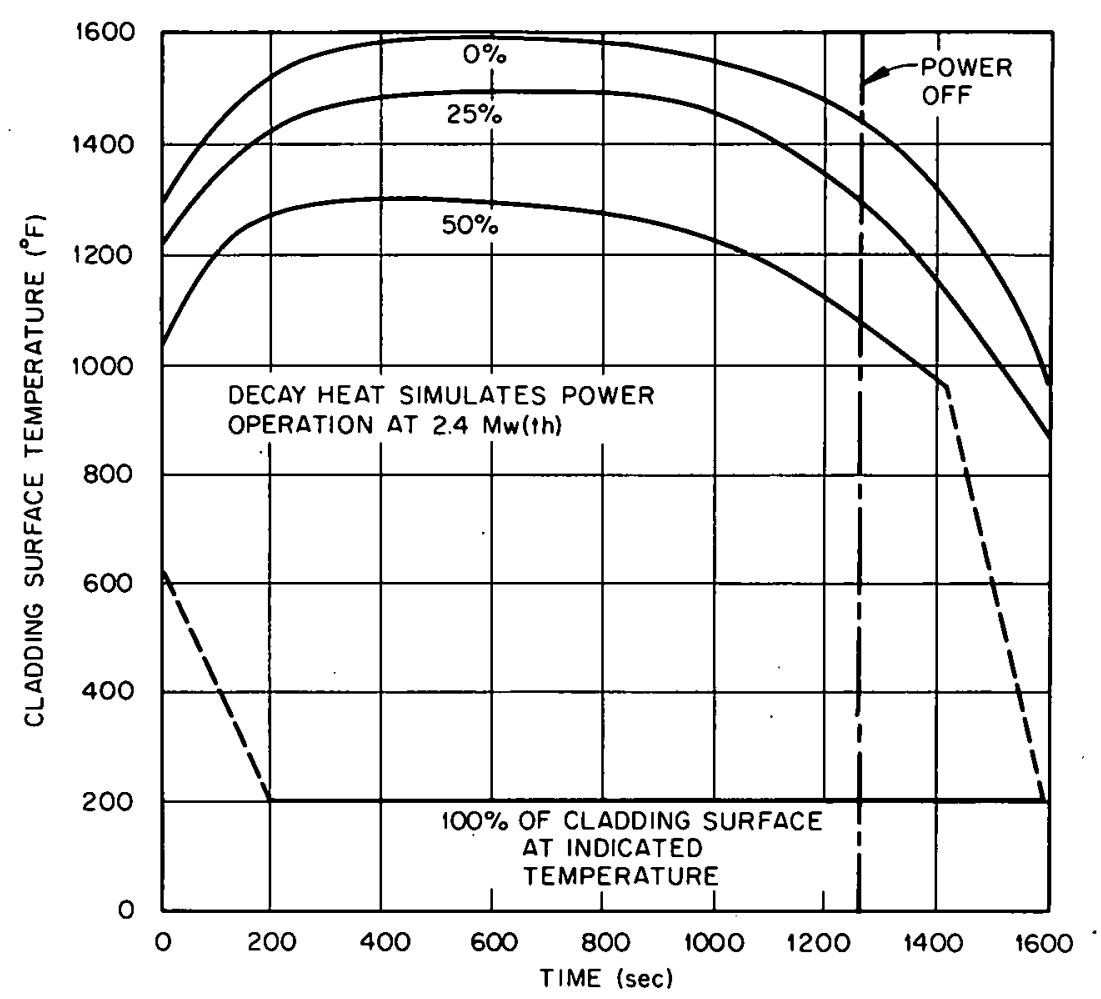

Fig. 4.5. Cladding Temperature Versus Time. (From Ref. 3)

highest temperature experienced by the hottest single point on the surface of all the rods. The label "O\%" signifies that there was no surface at a higher temperature. The second curve represents the highest temperature experienced by all but 25\% of the total surface, and so on. The extent of any metal-water reaction is a function of the temperature, time, and extent of surface.

The core heatup calculational model has built into it radiation between rods and to the channel walls, along with calculated form factors and emissivities. Hence, it accounts for a good portion of the radiation, but not that to the vapor and droplets. Good agreement with the test temperature data was obtained by empirically changing the convection coefficient in the model. Hence this is called an "effective heat transfer coefficient," since it is really the vehicle through which the test data were matched to the model. Therefore this coefficient takes into account all factors not built into the model analytically (such as radiation 
to the steam), as well as all other approximations, lack of knowledge, etc., which are inherent in any model.

A typical analysis based on this combined radiation and convection model predicted the "time at temperature" curves. A typical curve is shown in Fig. 4.6, together with data points. The model includes an effective heat transfer coefficient ( $h$ ) which was here set at a constant value of $3.6 \mathrm{Btu} / \mathrm{hr} \cdot \mathrm{ft}^{2} \cdot{ }^{\circ} \mathrm{F}$ to make the curve agree with the data. Similar good agreement has been obtained for the highest power run of the series with $\mathrm{h}$ set at $3.9 \mathrm{Btu} / \mathrm{hr} \cdot \mathrm{ft}^{2}{ }^{\circ} \mathrm{F}$.

These effective heat transfer coefficients were correlated as a weak function of initial fuel temperature at the time spray first entered the core and approximately as the power level of the fuel rods. The coefficients increase with both power and initial temperature but the latter is not a strong function.

When reduced, the data indicated that at the minimum flow substantiated by the tests, a flow of $0.05 \mathrm{gpm}$ is required per rod. To obtain the required core spray flow rate for' a given core it is necessary to multiply the total number of rods by $0.05 \mathrm{gpm}$ and divide the result by the minimum distribution factor expected for this design. The minimum distribution factor of 0.40 represents the most severe situation that is anticipated for the actual reactor configuration and was therefore used to establish core spray rates.

To determine the time at temperature following initiation of core spray, the effective heat transfer coefficient correlation determined by these experiments was used as the input to the TACT V core heatup code (see App. C). This insured that the temperature-time history would be the same as that determined experimentally.

The General Electric Company recently obtained data with sprays at initial rod temperatures up to about $1600^{\circ} \mathrm{F} .{ }^{15}$ No data with Zircaloy rods are available. The Browns. Ferry plant anticipated temperature distribution is considerably higher, as discussed in Chapter 3. Clearly the surface temperatures will be well into the metal-water reaction zone before they become quenched. The tests by GE did not show the flooding or choking phenomenon at the steam upflow rates tested. 


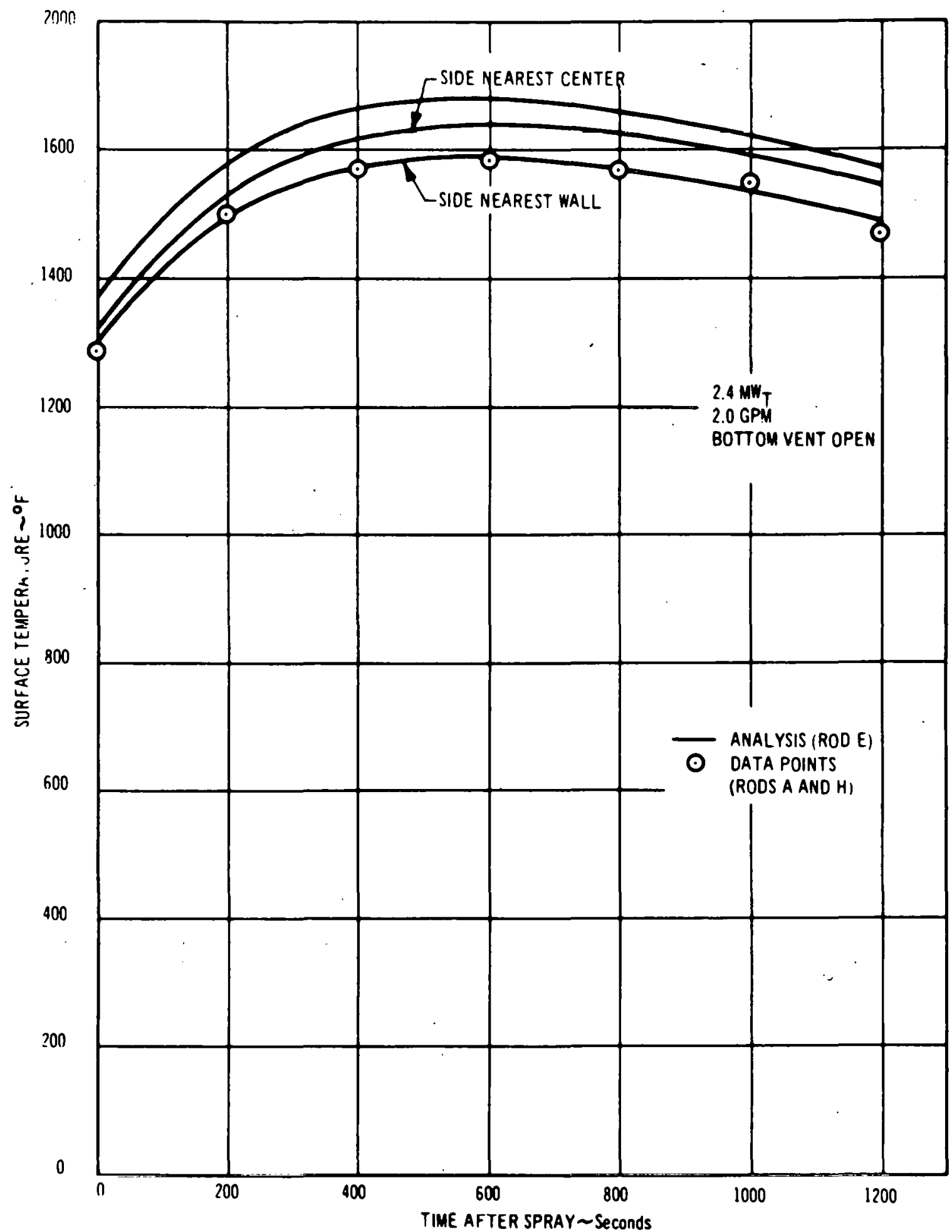

Fig. 4.6. Time-at-Temperature Curves for Fuel Cladding. (From Ref. 3) 
Tests performed. by General Nuclear Engineering Corporation in connection with the BONUS reactor ${ }^{49}$ showed that the time required to pass water through a hot stainless steel tube increased dramatically as the tube temperature increased. A tube that required about $20 \mathrm{sec}$ for flooding with a temperature below $1200^{\circ} \mathrm{F}$, required up to $70 \mathrm{sec}$ when the temperature was increased to $1400^{\circ} \mathrm{F}$; at room temperature, 2 to $4 \mathrm{sec}$ was required. In tests at $871^{\circ} \mathrm{C}\left(1600^{\circ} \mathrm{F}\right)$, water did not exit from the assembly for several minutes. 55 Recent tests performed by Southern Nuclear Engineering 56 on spray cooling of Zircaloy rods with boronated water showed that the rods could be quenched more rapidly than with unboronated water. The tests also showed that rapid quenching of hot (about $2500^{\circ} \mathrm{F}$ ) Zircaloy caused brittle rupture.

\subsection{Heat Transfer by Flooding}

\subsubsection{Effectiveness}

Deluge or core flooding systems are the major methods of core cooling utilized for pressurized-water reactors. The assumption is made that when the fuel is surrounded by water, the cladding temperature will quickly reduce to the point where nucleate rather than film boiling will occur and the release of thermal energy will be under control. Actually this is a conservative assumption, since the water added to the core would boil up and splash liquid above the water line. The correlations listed in Table 4.2 are used in calculating cladding temperatures. The pressurized-water reactor manufacturers have not published data on work of this type. The General Electric Company has reported such work in the Dresden Unit 3 supplement. ${ }^{36}$ Also, data are available from the SECHT program of Phillips Petroleum Company. ${ }^{12}$ General Electric is interested in such data because, in the event of a recirculation line break, the core can only be covered up to two-thirds the height. of the fuel rods (which are $12 \mathrm{ft}$ long). The tests show that the rods are effectively cooled even when the rods are one-third covered. A value of one-half the core height is used in the reactor designs as the minimum flooding height required for core cooling. 
Tests were conducted ${ }^{3}, 15,36$ in a BWR-type configuration to determine the cooling effectiveness as a function of the flooded height as measured by an external manometer, which essentially corresponded to the inlet lines of the jet pumps. The tests were conducted on full-scale assemblies with uniform heat generation. Steam generated in the flooded portion of the fuel caused frothing and subsequent rising of the actual level within the channel and thus cooling of the rods. Table 4.3 summarizes the test results.

To avoid getting large metal-water reaction ratẹs, even in view of the uncertainty in blowdown heat transfer rates, a deluge system in new PWR's should be capable of reflooding to the one-half core level in less than $1 / 2$ min after a major break.

Flooding tests as a means of cooling fuel rods were run recently at Phillips Petroleum Company in Idaho Falls. ${ }^{12}$ These tests showed that flooding was effective in cooling 3 -ft-high rods, as in LOFT, at initial stainless steel rod temperatures up to $2000^{\circ} \mathrm{F}$. Tests will be run on

Table 4.3. Results of Flooding Tests in BWR Type Configurationa

\begin{tabular}{|c|c|c|c|c|c|c|c|c|}
\hline \multirow{2}{*}{$\begin{array}{l}\text { Height } \\
\text { of } \\
\text { Water } b \\
\text { (ft) }\end{array}$} & \multirow{2}{*}{$\begin{array}{l}\text { Time } \\
\text { After } \\
\text { Scram } \\
(h r)\end{array}$} & \multirow{2}{*}{$\begin{array}{l}\text { Power } \\
(\mathrm{kw})\end{array}$} & \multicolumn{6}{|c|}{$\begin{array}{c}\text { Temperature }\left({ }^{\circ} \mathrm{F}\right) \text { at Indicated } \\
\text { Thermocouple Elevation }\end{array}$} \\
\hline & & & $1 \mathrm{ft}$ & $3 \mathrm{ft}$ & $5 \mathrm{ft}$ & $7 \mathrm{ft}$ & $9 \mathrm{ft}$ & $11.5 \mathrm{ft}$ \\
\hline 4 & $\begin{array}{l}40 \\
10 \\
0.4 \\
0.1\end{array}$ & $\begin{array}{l}15 \\
30 \\
60 \\
90\end{array}$ & $\begin{array}{l}215 \\
215 \\
215 \\
215\end{array}$ & $\begin{array}{l}215 \\
215 \\
215 \\
215\end{array}$ & $\begin{array}{l}540 \\
215 \\
215 \\
215\end{array}$ & $\begin{array}{l}790 \\
965 \\
750 \\
215\end{array}$ & $\begin{array}{r}920 \\
1220 \\
1090 \\
945\end{array}$ & $\begin{array}{r}910 \\
1300 \\
1290 \\
1220\end{array}$ \\
\hline 6 & $\begin{array}{l}40 \\
0.4 \\
0.1\end{array}$ & $\begin{array}{l}15 \\
60 \\
90\end{array}$ & $\begin{array}{l}215 \\
215 \\
215\end{array}$ & $\begin{array}{l}215 \\
215 \\
215\end{array}$ & $\begin{array}{l}215 \\
215 \\
215\end{array}$ & $\begin{array}{l}215 \\
215 \\
215\end{array}$ & $\begin{array}{l}945 \\
245 \\
215\end{array}$ & $\begin{array}{r}1160 \\
1025 \\
970\end{array}$ \\
\hline 8 & $\begin{array}{l}40 \\
10 \\
0.4 \\
0.1\end{array}$ & $\begin{array}{l}15 \\
30 \\
60 \\
90\end{array}$ & $\begin{array}{l}215 \\
215 \\
215 \\
215\end{array}$ & $\begin{array}{l}215 \\
215 \\
215 \\
215\end{array}$ & $\begin{array}{l}215 \\
215 \\
215 \\
215\end{array}$ & $\begin{array}{l}215 \\
215 \\
215 \\
215\end{array}$ & $\begin{array}{l}580 \\
560 \\
215 \\
215\end{array}$ & $\begin{array}{r}1150 \\
1150 \\
1075 \\
215\end{array}$ \\
\hline
\end{tabular}

arom Ref. 3.

${ }^{b}$ s indicated by external manometer. 
6-ft-long rods of stainless steel-clad and Zircaloy-4-clad rods soon with heat fluxes and temperature levels comparable to those of a loss-of-coolant accident. The heat transfer correlation is listed in Table 4.2.

\subsubsection{Limits on Steam and Heat Removal}

During core blowdown the fuel elements would heat up to a temperature at which cladding swelling would occur. This could cause the fuel rods to partially block the passage of water and steam between the swollen and heated rods. The rods would have to dissipate much of the heat by radiation or conduction. The occurrence of such phenomena should be explored, as well as methods of prevention of swelling. The extent of cooling by crossflow in PWR's should be determined.

\subsection{Heat Transfer by Radiation - Minimum Flow Determination}

The dissipation of heat by radiation is a major factor in limiting the temperature of the fuel rods. This has been pointed out in the Japanese work and the work by General Electric in which heat was radiated to a cooled wall (fuel-element shroud). The radiation phenomenon is also important in open-lattice pressurized-water reactors. Steam has an absorption band in the infrared wavelengths that affords a significant heat sink if the steam is convected through the core. ${ }^{46}$ At cladding temperatures near $1100^{\circ} \mathrm{C}\left(2000^{\circ} \mathrm{F}\right)$ the radiation to saturated steam between the fuel rods amounts to a heat flux of about $5000 \mathrm{Btu} / \mathrm{ft}^{2} \cdot \mathrm{hr}$, even with the steam at atmospheric pressure. This is comparable to the heat removal rates of laminar flow.

The fact that heat transfer coefficients from 10 to $18 \mathrm{Btu} / \mathrm{ft}^{2} \cdot \mathrm{hr} \cdot{ }^{\circ} \mathrm{F}$ are required to maintain the cladding at temperatures below $1.100^{\circ} \mathrm{C}\left(2000^{\circ} \mathrm{F}\right)$ was pointed out in Chapter 3. The asymptotic low heat transfer coefficient to steam in laminar flow is about $3.5 \mathrm{Btu} / \mathrm{ft}^{2} \cdot \mathrm{hr} \cdot{ }^{\circ} \mathrm{F}$. An analysis of the Japanese data has shown that at $2100^{\circ} \mathrm{F}$ the expected heat transfer coefficient by radiation and convection to steam is about $15 \mathrm{Btu} / \mathrm{ft}^{2} \cdot \mathrm{hr} \cdot{ }^{\circ} \mathrm{F}$. This would be more than sufficient to maintain the cladding below $2100^{\circ} \mathrm{F}$ after the blowdown. The addition of the radiation heat flux and the convective heat flux to steam should limit the cladding surface temperature 
to near $1100^{\circ} \mathrm{C}\left(2000^{\circ} \mathrm{F}\right)$ if moist steam could be kept near the fuel rods. Both the General Electric work ${ }^{36}$ and the GNEC ${ }^{49}$ work indicated that about $30 \%$ of the steam-water mixture blown out of the effectively cooled core was steam. This suggests that adding about three times the mass of water needed to remove the heat by steam generation alone would keep the core cool. On this basis and the assumption that about 3\% of the steady thermal power must be removed to maintain safety, about $1.7 \mathrm{gpm}$ per thermal megawatt is needed to cool the hot spot. This fluid must be added so that it passes through the fuel bundles and the rods "see" the wet steam. 


\section{CONCLUSION AND RECOMMENDATIONS}

The emergency core-cooling systems of several boiling- and pressurized-water reactors, were reviewed, the design basis and backup data were examined, and the need for certain additional data was established. Generally, the design approach used by the manufacturers is conservative when evaluating the energy released or the cladding temperature. Occasionally there is an absence of experimental data that is inconsistent with the apparent sophistication of the calculational procedures.

The following conclusions and recommendations are made as a result of this review.

\subsection{Removal of Eriergy Sources}

The emergency core-cooling system is an engineered safety feature designed to prevent a core thermal runaway by removing fission decay and stored energies and by preventing the release of potential energy in the Zircaloy-steam reaction. Lack of control and removal of these energy sources might lead to failure of the outer containment structure.

\subsection{Damage to Core During Blowdown}

The LOFT and the CSE programs are studying the blowdown of pressurized- and boiling-water reactors in detail. The questions relating to the mechanical integrity of the core and the piping have been defined and many can be resolved by the designers. The effect of pipe rupture propagation time and shock waves on the pressure loadings axially across the core and radially across the core barrel should be determined for short rupture times. The time to reach saturation pressure in the blowdown is about $0.05 \mathrm{sec}$ for a large pipe rupture. Therefore even a propagation time of $0.01 \mathrm{sec}$ is not considered an instantaneous break. Damage to the core internals during the depressurization may adversely affect the coolant distribution and core cooling during the blowdown and core reflooding process. 
The transient heat transfer from the fuel to the cladding to the coolant should be measured and understood for both pressurized- and boiling-water reactors during the quasi-steady-state blowdown. The fuel cooling rates during blowdown can influence by at least $1 \mathrm{~min}^{34}$ the minimum time required for water addition to prevent fuel cladding melting and/or excessive metal-water reaction. Core damage that would influence cooling rates should be prevented.

The LOFT and CSE programs are studying the amount of water remaining in the pressure vessel and high-pressure system after blowdown, since the water left in the reactor vessel affects both the time to reflood the core and the potential extent of the Zircaloy-steam reaction. Tests of the amount of water left in the vessel after blowdown have been extended to include determinations of the effect of core internals and the external piping on the amount of water left, since they may act as entrainment separators.

There are many computer programs and physical models available for calculating blowdown-pressure transients and water inventory. These computational methods are being tested by the LOFT and CSE programs. This effort should continue, since all these computer programs need normalization to data. Much time would be saved if the competence of the individuals from diverse organizations working on this effort was grouped to form a common source of information. Battelle Memorial Institute has recently initiated such a program at the suggestion of ORNL.

\subsection{Spray Cooling of Core}

Additional. work is required to assure the reliability and effectiveness of spray cooling systems for the high specific power cores currently being designed, particularly for temperatures in the range 2000 to $2500^{\circ} \mathrm{F}$. Extensive work by Phillips Petroleum Company is planned on Zircaloy rod bundles.

The data published by General Electric Company on the effectiveness of spraying $6 \times 6$ and $7 \times 7$ arrays of full-size stainless steel-clad fuel assemblies were obtained under conditions where the hottest fuel rod was assumed initially to be at $1800^{\circ} \mathrm{F}$ (representing some time after blowdown). 
However, in their Browns Ferry reactor, for example, the calculated thermal condition of the core fuel rods $30 \mathrm{sec}$ after the break when spraying was initiated would be as follows:

\begin{tabular}{lcc} 
& \multicolumn{2}{c}{ Temperature } \\
\cline { 2 - 3 } & \multicolumn{1}{c}{${ }^{\circ} \mathrm{C}$} & ${ }^{\circ} \mathrm{F}$ \\
Hot spot & - & - \\
$10 \%$ of cladding & $>948$ & $>1740$ \\
$25 \%$ of cladding & $>816$ & $>1500$ \\
$50 \%$ of cladding & $>635$ & $>1175$
\end{tabular}

Some of the core would be at temperatures in the region where the metalwater reaction rate between Zircaloy and steam becomes significant. The experimental data clearly need to be extended to the temperatures of the accident.

Temperature distributions representing the consequences of moderate delays in initiation of emergency cooling should be simulated in some spray tests. Forced- and natural-convection heat transfer between steam and high-temperature Zircaloy should be measured and analyzed.

The gas pressure inside the fuel rods should be controlled at levels representative of reactor fuel to get a proper measure of the nature of the cladding failure as the blowdown occurs. The possibility that swelling of the cladding may cause blockage of the flow channel should be eliminated if gross swelling occurs. The relationship between the amount of steam-Zircaloy reaction and gas embrittlement should be determined. The condition leading to rod fragmentation upon quenching from high temperatures should be determined so that it can be avoïded.

The possibilities of water-hammer formation by rapid addition of water to hot Zircaloy should be eliminated. The spray system relies on wetting the inside and outside of the tuel channel shroud and thereby presenting a radiation sink for the heat from the fuel rods. The Japanese and British data on the sputtering phenomenon, as well as the American work by General Nuclear Engineering Corporation on flooding of hot metal surfaces, show clearly that the time required for cooling and wetting a hot surface increases rapidly with increases in surface-to-steam temperature differences and decreases with system pressure. This influences the 
lag time for rewetting the wall and fuel rods and requires that the rods be cooled by both thermal radiation to steam and steam convection until the walls are wetted. Tests should be run with hot fuel assemblies cooled by water at the temperature and pressure of the containment and pressure vessel environments following the accident and at heat fluxes corresponding to the newer BWR fuel designs.

\subsection{Flooding or Immersion Cooling}

The pressurized- and boiling-water reactors are cooled by a rising flood of water as an emergency coolant. The flooding systems are useful because they provide a uniform distribution of coolant. Current work at Phillips Petroleum Company at Idaho Falls in the FLECHT and SECHT programs is investigating the cooling characteristics of such systems. This work should be extended to parallel channels at different temperatures to assure that hot-channel starvation of coolant does not occur in shrouded channels.

The effects of boiling in open channels should be determined at cladding temperatures above $2200^{\circ} \mathrm{F}$, since this may alter the required liquid level in the pressure. vessel for adequate cooling in the postblowdown situation.

The use of the pressurized-water tanks on pressurized-water reactors is a practical solution to adding a large quantity of water to the core rapidly. The accumulators relieve the need of emergency core-cooling systems for almost-immediate pump power. These tanks should be designed

so that the pressurized gas from the accumulator does not drive the water from the core after the initial injection.

Design efforts should continue on both PWR's and BWR's to decrease the response time of emergency core-cooling systems, since this may one day be the limiting factor on fuel specific power or on power density.

\subsection{Structural Integrity of Core During Heatup}

Some reactors still use stainless steel cladding on control plates and followers inside the hot region of the core. Since stainless steel 
and Zircaloy react at temperatures below the melting point of stainless steel, this reaction should be explored to make certain it does not interfere with core cooling.

\subsection{Structural Integrity of Vessel}

The time required ${ }^{2}, 2$ in a large-rupture loss-of-coolant accident for fuel that is unquenched to melt through the reactor vessel and possibly breach the outer containment vessel has been estimated at $1 / 2$ to $1 \mathrm{hr}$. Therefore, a design and experimental effort should be initiated to arrive at a method of containing or stopping a vessel melt-through before the containment is breached in the event of the worst case of an inoperative emergency cooling system.

\subsection{General Performance and Standards}

The current reactor emergency core-cooling systems that reflood part of the core within $30 \mathrm{sec}$ after a major break or which start adding coolant by spray distribution before the blowdown is complete appear capable of quenching the core and preventing a thermal runaway accident in which the core might melt down and penetrate the reactor vessel and containment shell. The emergency cooling system is an engineered safety feature of prime importance under some accident conditions in protecting the containment shell and controlling the radioactivity release from the fuel. Sufficient data should be obtained with heated Zircaloy-clad uranium dioxide fuel rods and water-steam mixtures to establish the physical phenomena that occur at temperature levels between $2000^{\circ} \mathrm{F}$ and the melting point of Zircaloy. Significant cladding swelling and cracking occur at temperatures from 1200 and $1800^{\circ} \mathrm{F}$ in all water-cooled reactors. The effect of these failures, if any, on flow channel blockage or flow distribution is not known.

Rapid activation, of the emergency cooling system and Iong-term operation are the most urgent requirements in the event of a large-scale primary cooling system break. Therefore a continuing effort should be made to develop more rapidly acting systems with even better reliability than 
systems currently being designed. To this end, systems tests that determine the effectiveness of the hardware acting in concert should be performed in environments designed to simulate an accident situation. There is no other certain demonstration of adequacy. These tests should be performed on a prototype of large scale. The revised LOFT programs 21 may satisfy this need. The ability to predict system performance analytically could demonstrate an adequate level of understanding. Consideration of the improbable accidents (sabotage, earthquakes, falling airplanes, etc.) and the potential plant damage requires complete redundancy and protection of cooling systems in order to assure a working coolant-injection system in all circumstances.

Finally, the emergency provisions for a loss-of-coolant accident should be examined to determine that the provisions themselves do not create hazards. Specifically, the BWR automatic-relief system and the gas in the PWR water storage tanks could both worsen the situation by ejecting coolant from the core needlessly under certain circumstances.

\subsection{System Tests}

The accidents discussed in this report all lead to temperature, pressure, and humidity environments far different than those normally prevailing. Tests on the emergency cooling equipment for each reactor should be performed to supply assurance that hardware meets appropriate specifications and can survive and perform in accident situations and the resulting environments. Separate tests to (1) demonstrate hardware reliability and (2) system effectiveness may be sufficient. These are different from the prototype tests.

Maintenance and retesting of the emergency cooling system hardware, including power supplies, should be routine and sufficiently frequent to assure availability on demand. ${ }^{57}$ Results of tests of emergency cooling systems for operating reactors show that emergency power supply availability can be improved by more thorough preventive maintenance. ${ }^{18}$

Frequent and routine tests of the availability of emergency equipment, such as are proposed in the preliminary design reports, should be carried out. The results of these tests should supply data that can 
demonstrate the availability of equipment and the reliability to perform as designed by comparison with data obtained from the prototype tests proposed in Section 5.7 .

\subsection{Design Improvements}

Efforts to improve the emergency cooling systems. should be continued by design studies for reactors with higher specific power and flatter power distribution. Emergency cooling systems are designed to control the thermal and radioactive energy release from the fuel, limit the damage to the reactor complex, including the containment shells, and thereby help protect the public from gross exposure to radioactivity in the event of a primary coolant rupture and loss of power. The reactor operating variables of fuel specific power, plant thermal output, and to a lesser extent fuel burnup strongly influence economics as well as the emergency cooling system design requirements. The factors that improve economics also increase the demand on the cooling system pumps and power supply through increased demands on the time-to-startup margin and flow rates. The design studies would clarify specific future needs for the nuclear industry and the AEC.

The trend toward power flattening within the core of the next generation of water-cooled reactors requires more detailed knowledge of the water-steam-Zircaloy interaction to assess the details of the loss-ofcoolant accident. An effort should be started soon to estimate the relationship between the power distribution within a large core, the maximum design cladding temperature in the postaccident situation, and the emergency cooling system design requirements in order to assess accurately the adequacy of the no-cladding-melting criteria or other criteria that may be suggested.

0

\subsection{Priorities}

All the items dicussed above are of prime importance in assessing the safety of a reactor plant. In establishing priorities among the items for effort it is clear that those items that relate to future-generation 
plants or to plant maintenance may be given a lower priority than other items. However, all the questions should be answered before the newer plants have operated any appreciable time. No actual priorities may therefore be stated. 
REFERENCES

1. W. K. Ergen (Ed.), Emergency Core Cooling, Report of Task Force Established by the U. S. Atomic Energy Commission to Study Fuel Cooling Systems of Nuclear Power Plants, USAEC Report, 1967 (undocumented).

2. Consolidated Edison Company of New York, Inc., Indian Point Nuclear Generating Unit No. 2, Preliminary Safety Analysis Report, Supplement No. 2, Docket No. 50-247, 1966.

3. Tennessee Valley Authority, Browns Ferry Nuclear Power "Station, Design and Analysis Report; Docket Nos. 50-259 and 50-260, 1966.

4. L. Baker, Jr., and L. C. Just, Studies of Metal Water Reaction at High Temperatures: III Experimental and Theoretical Studies of the Zirconium-Water Reactions, USAEC Report ANL-6548, Argonne National Laboratory, May 1962.

5. H. A. McLain, Potential Metal-Water Reactions in Light-Water-Cooled Power Reactors, USAEC Report ORNL-NSIC-23, Oak Ridge National Iaboratory, August 1968.

6. Florida Power and Light Company, Turkey Point Nuclear Generating Units, No. 3 and No. 4, Preliminary Safety Analysis Report, Docket Nos. 50-250 and 50-251, 1966.

7. Consumers Power Company, Palisades Plant, Preliminary Description and Safety Analysis Report, Docket No. 50-255, 1966.

8. Duke Power Company, Oconee Nuclear Station, Units 1 and 2, Preliminary Safety Analysis Report, Docket Nos. 50-269 and 50-270, 1966.

9. K. A. Dietz, Quarterly Technical Report, January 1, 1967-March 31, 1967, Step Project, USAEC Report IDO-17239, Phillips Petroleum Company, August 1967.

10. R. C. Gwaltney, Missile Generation and Protection in Light-WaterCooled Power Reactor Plants, USAEC Report ORNL-NSIC-22, Oak Ridge National Laboratory (to be published).

11. Pacific Gas and Electric, Nuclear Plant, Diablo Canyon Site, Preliminary Safety Analysis Report, Supplement No. 3; Docket No. 50-275, July 31, 1967.

12. W. S. Little et al., Monthly Letter Program Report for September 1967, Plant Applications and Engineering Test Group, Phillips Petroleum Company, Idaho Falls, Idaho, October 1967. 
13. Wm. B. Cottrell and A. W. Savolainen (Eds.), U. S. Reactor Containment Technology, Vols. I and II, USAEC Report ORNL-NSIC-5, Oak Ridge National Laboratory, August 1965.

14. K. A. Dietz (Ed.), Quarterly Technical Report, April 1966-June 1966, Step Project, USAEC Report IDO-17187, Phillips Petroleum Company, Atomic Energy Division, January 1967.

15. Jersey Central Power and Light Company, Oyster Creek Nuclear Power Plant Unit No. 1, Améndment 10, Emergency Core Cooling Effectiveness, Docket No. 50-219, August 1967.

16. G. B. Wallis, Flooding Velocities for Air-Water in Vertical Tubes, British Report AEEW-R-123, December 1961.

17. G. L. Shires and A. P. Pickering, The Flooding Phenomenon in CounterCurrent Two-Phase Flow, paper presented at Symposium on Two-Phase Flow, Exeter, England, June 20-23, 1965.

18. B. J. Garrick, W. C. Gekler, and H. P. Pomrehn, An Analysis of Nuclear Power Plant Operating and Safety Experience, HN-185, Holmes \& Narver, April 1966.

19. W. B. Cottrell, Compilation of United States. Nuclear Standards, 4th ed., USAEC Report ORNL-NSIC-43, Oak Ridge National Laboratory, May 1968.

20. Water Reactor Safety Program Summary Description (Draft), prepared by Water Reactor Safety Program Office, Phillips Petroleum Company, Idaho Falls, Idaho, January 1967.

21. K. A. Dietz (Ed.), Engineered Safety System Investigations, USAEC Report IDO-17258 (Draft), Phillips Petroleum Company, November 1967.

22. K. A. Dietz (Ed.), Quarterly Technical Report, January 1964-March 1964; April 1964-June 1964, Step Project, USAEC Report IDO-17070, Phillips Petroleum Company, Atomic Energy Division, June 1965.

2.3. K. A. Dietz, E. W. Mellow, and N. E. Pace, Quarterly Technical Report, July 1964-September 1964, October 1964-December 1964, Step Project, USAEC Report IDO-17077, Phillips Petroleum Company, Atomic Energy Division, March 1966.

24. H. D. Curet (Ed.); Quarterly Technical Report, January 1965-March 1965, Step Project, USAEC Report IDO-17126, Phillips Petroleum Company, Atomic Energy Division, March 1966.

25. K. A. Dietz, Quarterly Technical Report, April 1965-June 1965, Step Project, USAEC Report IDO-17145, Phillips Petroleum Company, Atomic Energy Division, May 1966. 
26. K. A. Dietz (Ed.), Quarterly Technical Report, July 1965-September 1965, Step Project, USAEC Report IDO-17165, Phillips Petroleum Company, Atomic Energy Division, July 1966.

27. K. A. Dietz (Ed.), Quarterly Technical Report, October 1965-December 1965, Step Project, USAEC Report IDO-17167, Phillips Petroleum Company, Atomic Energy Division, September 1966.

28. K. A. Dietz (Ed.), Quarterly Technical Report, January-March 1966, Step Project, USAEC Report IDO-17186, Phillips Petroleum Company, Atomic Energy Division, November 1966.

29. D. L. Morrison et al., An Evaluation of the Applicability of Existing Data to the Analytical Description of a Nuclear Reactor Accident, USAEC Report BMI-1779, Battelle Memorial Institute, August 1966.

30. C. E. Parks, Blowdown Models Applicable to the Loss-of-Fluid Test Facility, USAEC Report BAW-1195-4, Babcock \& Wilcox, June 1965.

31. H. S. Isbin et al., Critical Flow Phenomena in Two-Phase Flow Mixtures and Their Relationship to Nuclear Safety, Proceedings of the Third United Nations International Conference on the Peaceful. Uses of Atomic Energy, Geneva, 1964, Vol. 8, pp. 286-293, United Nations, New York, 1965.

32. S. G. Margolis and J. A. Redfield, Heat Transfer Aspects of the Lossof-Coolant Accident, USAEC Report WAPD-T-1811, Westinghouse Atomic Power Division, April 1965.

33. F. J. Moody, An Analytical Model for Pressure Suppression, USAEC Report APED-4734, General Filectric Company, Atomic Power Equipment Division, 1964.

34. S. E. Jenson, The Effects of Metal-Water Reaction on the Loss-ofCoolant Accident, USAEC Report IDO-17168, Phillips Petroleum Company, August 1966.

35. D. M. Gluntz, R. H. Moen, and J. L. Wray, Jet Pumps Advance BWR Recirculation Flow Design, Nucleonics, 23(12): 58-61. (December 1965).

36. Commonwealth Edison Company, Dresden Nuclear Power Station, Unit No. 3 Plant Design and Analysis Report, Amendment No. 5, Docket No. 50-249, 1966.

37. Takashi Tagami, Interim Report of Safety Assessments and Facilities Establishment Project in Japan for Period to June 1965 (No. 1), Available from LOFT, Test Area North, Phillips Petroleum Company, NRTS, Idaho Falls, Idaho, February 1966. 
38. J. F. White et al., Recommended Property and Reaction Kinetics Data for Use in Evaluating a Light-Water-Cooled Reactor Loss-of-Coolant Incident Involving Zircaloy-4 or 304SS-Clad-UO 2 , USAEC Report GEMP482 (Preliminary Draft), General Electric Company, January 1967.

39. W. H. Jens and P. A. Lottes, Burnout Heat Transfer and Pressure Drop for High Pressure Water, USAEC Report ANL-4627, Argonne National Laboratory, 1951.

40. S. Bertolette et al., Critical Heat Flux Data for Steam-Water Mixtures in Round Tubes - Nonuniform Heat Flux, Centro Informasia Studi Esperiment, Report CISE R-74, 1963.

41. L. S. Tong, Boiling Heat Transfer and Two Phase Flow, p. 132, Wiley, New York, 1965.

42. V. M. Borishancki and B. Fokin, Correlation of Heat Transfer Data in Stable Film Boiling - Vertical Plates - Free Convection, Intern. Chem. Eng., 5(4): 666 (1965).

43. W. M. Kays, Laminar Flow Heat Transfer in Tubes, Trans. ASME, 77: 1265 (1955).

44. D. M. McEligat, P. M. Magee, and G. Leppert, Effect of Large Temperature Gradients on Convective Heat Transfer, J. Heat Transfer, Trans. ASME, $87(\dot{C}): 67$ (1965).

45. D. M. McEligat, L. W. Ormond, and H. C. Perking, Jr., Internal Low Reynolds Number Turbulent and Transitional Gas Flow with Heat Transfer, J. Heat Transfer, Trans. ASME, 88(C): 239 (1966).

46. W. McAdams (Ed.), Heat Transmission, 3rd ed., pp. 82-96, McGraw-Hill, New York, 1954.

47. L. A. Bromley, Heat Transfer in Stable Film Boiling, Chem. Eng. Prog., 46(b): 24 (1930).

48. Y. Y. Hsu and J. W. Westwater, Film Boiling from Vertical Tubes, ATChE J., $4(1): 5$ (1958).

49. G. Brown, Superheater Flooding Tests for Bonus Reactor, USAEC Report GNEC-156, General Nuclear Engineering Company.

50. Hideo Uchida, Experimental Investigation of Core Spray, Nucl. Safety, $7(3)$ : 338 (Spring 1966).

51. A. W. Bennett et al., The Wetting of Hot Surfaces in a Steam Environment at High Pressure, British Report AERE-R-5146, May 1966.

52. G. L. Shires, A. R. Pickering, and P. T. Blocker, Film Cooling of Vertical Fuel Rods, British Report AEEW-R-343, 1964. 
53. C. G. Lawson, On Analysis of Spray Cooling Heat Transfer Data to Rods, Nucl. Safety, 9 (I) : 43-45 (January-February 1968).

54. R. N. Lyon, Liquid Metal Heat Transfer Coefficients, Chem. Eng. Prog., $47(2): 75$ (1951).

55. G. Brown, Southern Nuclear Engineering Company, personal communication to C. G. Lawson, Oak Ridge National Laboratory.

56. C. R. McCullough, G. M. Brown, R. R. Hancock, Investigation of the Use of Aqueous Solution as Emergency Coolants, SNE-38, Southern Nuclear Engineering; Apr. 1, 1968.

57. B. J. Garrick et al., Reliability Analysis of Nuclear Power Plant Protective Systems, HN-190, Holmes \& Narver, May 1967. 


\section{PAGES 101 to 102 WERE INTENTIONALLY LEFT BLANK}


Appendix A

PERTINENT AEC GENERAL DESIGN CRITERIA*

INTRODUCTION

Every applicant for a construction permit is required by the provisions of $\$ 50.34$ [Code of Federal Regulations] to include the principal design criteria for the proposed facility in the application. These General Design Criteria are intended to be used as guidance in establishing the principal design criteria for a nuclear power plant. The General Design Criteria reflect the predominating experience with water power reactors as designed and located to date, but their applicability is not limited to these reactors. They are considered generally applicable to all power reactors.

Under the Commission's regulations, an applicant must provide assurance that its principal design criteria encompass all those facility design features required in the interest of public health and safety. There may be some power reactor cases for which fulfillment of some of the General Design Criteria may not be necessary or appropriate. There will be other cases in which these criteria are insufficient, and additional criteria must be identified and satisfied by the design in the interest of public safety. It is expected that additional criteria will be needed particularly for unusual sites and environmental conditions, and for new and advanced types of reactors. Within this context, the General Design Criteria should be used as a reference allowing additions or deletions as an individual case may warrant. Departures from the General Design Criteria should be justified.

The criteria are designated as "General Design Criteria for Nuclear Power Plant Construction Permits". to emphasize the key role they assume at this stage of the licensing process. The criteria have been categorized as Category A or Category B. Experience has shown that more definitive information is needed at the construction permit stage for the items listed in Category A than for those in Category $B$.

*Introdurtion and excerpts from AEC News Release K-172, July 10, 1967. 


\section{OVERALL PLANT REQUIREMENTS}

\section{CRITERION 1 - QUALITY STANDARDS (Category A)}

Those systems and components of reactor facilities which are essential to the prevention of accidents which could affect the public health and safety or to mitigation of their consequences shall be identified and then designed, fabricated, and erected to quality standards that reflect the importance of the safety function to be performed. Where generally recognized codes or standards on design, materials, fabrication, and inspection are used, they shall be identified. Where adherence to such codes or standards does not suffice to assure a quality product in keeping with the safety function, they shall be supplemented or modified as necessary. Quality assurance programs, test procedures, and inspection acceptance levels to be used shall be identified. A showing of sufficiency and applicability of codes, standards, quality assurance programs, test procedures, and inspection acceptance levels used is required.

\section{CRITERION 2 - PERFORMANCE STANDARDS (Category A)}

Those systems and components of reactor facilities which are essential to the prevention of accidents which could affect the public health and safety or to mitigation of their consequences shall be designed, fabricated, and erected to performance standards that will enable the facility to withstand, without loss of the capability to protect the public; the additional forces that might be imposed by natural phenomena such as earthquakes, tornadoes, flooding conditions, winds, ice, and other local site effects. The design bases so established shall reflect: (a) appropriate consideration of the most severe of these natural phenomena that have been recorded for the site and the surrounding area and (b) an appropriate margin for withstanding forces greater than those recorded to reflect uncer-. tainties about the historical data and their suitability as a basis for design. 
CRITERION 3 - FIRE PROTECTION (Category A)

The reactor facility shall be designed (I) to minimize the probability of events such as fires and explosions and (2) to minimize the potential effects of such events to safety. Noncombustible and fire resistant materials shall be used whenever practical throughout the facility, particularly in areas containing critical portions of the facility such as containment, control room, and components of engineered safety features.

CRITERION 4 - SHARING OF SYSTEMS (Category A)

Reactor facilities shall not share systems or components unless it is shown safety is not impaired by the sharing.

CRITERION 5 - RECORDS REQUIREMENTS (Category A)

Records of the design, fabrication, and construction of essential components of the plant shall be maintained by the reactor operator or under its control throughout the life of the reactor.

\section{ENGINEERED SAFETY FEATURES}

CRITERION 37 - ENGINEERED SAFETY FEATURES BASIS FOR DESIGN (Category A)

Engineered safety features shall be provided in the facility to back up the safety provided by the core design, the reactor coolant pressure boundary, and their protection systems. As a minimum, such engineered safety features shall be designed to cope with any size reactor coolant pressure boundary break up to and including the circumferential rupture of any pipe in that boundary assuming unobstructed discharge from both ends.

CRITERION 38 - RET.TABILITY AND TESTABILITY OF ENGINEERED SAFETY FEATURES (Category A)

All engineered safety features shall be designed to provide high functional reliability and ready testabllity. In determining the 
suitability of a facility for a proposed site, the degree of reliance upon and acceptance of the inherent and engineered safety afforded by the systems, including engineered safety features, will be influenced by the known and the demonstrated performance capability and reliability of the systems, and by the extent to which the operability of such systems can be tested and inspected where appropriate during the life of the plant.

CRITERION 39 - EMERGENCY POWER FOR ENGINEERED SAFETY FEATURES (Category A)

Alternate power systems shall be provided and designed with adequate independency, redundancy, capacity, and testability to permit the functioning required of the engineered safety features. As a minimum, the onsite power system and the offsite power system shall each, independently, provide this capacity assuming a failure of a single active component in each power system.

CRITERION 40 - MISSIIE PROTECTION (Category A)

Protection for engineered safety features shall be provided against dynamic effects and missiles that might result from plant equipment failures.

CRITERION 41 - ENGINEERED SAFETY FEATURF.S PERFORMANCE CAPABILITY (Category A)

Engineered safety features such as emergency core cooling and containment heat removal systems shall provide sufficient performance capability to accommodate partial loss of installed capacity and still fulfill the required safety function. As a minimum, each engineered safety feature shall provide this required safety function assuming a failure of a single active component.

CRITERION 42 - ENGINEERED SAFETY FEATURES COMPONENTS CAPABILITY (Category A)

Engineered safety features shall be designed so that the capability of each component and system to perform its required function is not impaired by the effects of a loss-of-coolant accident. 
CRITERION 43 - ACCIDENT AGGRAVATION PREVENTION (Category A)

Engineered safety features shall be designed so that any action of the engineered safety features which might accentuate the adverse aftereffects of the loss of normal cooling is avoided.

CRITERION 44 - EMERGENCY CORE COOLING SYSTEMS CAPABILITY (Category A)

At least two emergency core cooling systems, preferably of different design principles, each with a capability for accomplishing abundant emergency core cooling, shall be provided. Each emergency core cooling system and the core shall be designed to prevent fuel and clad damage that would interfere with the emergency core cooling function and to limit the clad metal-water reaction to negligible amounts for all sizes of breaks in the reactor coolant pressure boundary, including the double-ended rupture of the largest pipe. The performance of each emergency core cooling system shall be evaluated conservatively in each area of uncertainty. The systems shall not share active components and shall not share other features or components unless it can be demonstrated that (a) the capability of the shared feature or component to perform its required function can be readily ascertained during reactor operation, (b) failure of the shared feature or component does not initiate a loss-of-coolant accident, and (c) capability of the shared feature or component to perform its required function is not impaired by the effects of a Ioss-of-coolant accident and is not lost during the entire period this function is required following the accident.

CRITERION 45 - INSPECTION OF EMERGENCY CORE COOLING SYSTEMS (Category A)

Design provisions shall be made to facilitate physical inspection of all critical parts of the emergency core cooling systems; including reactor vessel interrixis and water injection nozzles.

CRITERION 46 - TESTING OF EMERGENCY CORE COOLING SYSTEMS COMPONENTS (Category A)

Design provisions shall be made so that active components of the emergency core cooling systems, such as pumps and valves, can be tested periodically for operability and required functional performance. 
CRII'ERION 47 - TESTING OF EMERGENCY CORE COOLING SYSTEMS (Category A)

A capability shall be provided to test periodically the delivery capability of the emergency core cooling systems at a location as close to the core as is practical.

CRITERION 48 - TESTING OF OPERATIONAL SEQUENCE OF EMERGENCY CORE COOLING SYSTEMS (Category A)

A capability shall be provided to test under conditions as close to design as practical the full operational sequence that would bring the emergency core cooling systems into action, including the transfer to alternate power sources. 
Appendix B

THE LOSS-OF-COOLANT ACCIDENT ANALYSIS FOR OCONEE NUCLEAR STATION (Reproduced from Ref. 10) 
THIS PAGE

\section{WAS INTENTIONALLY LEFT BLANK}


14.2.2.3 Loss-of-Coolant Accident

14.2.2.3.1 Identification of Accident

Failure of the reactor coolant system would allow partial or complete release of reactor coolant into the Reactor Building, thereby interrupting the normal mechanism for removing heat from the reactor core. If all the coolant were not released immediately, the remaining amount would be boiled of $f$ owing to residual heat, fission product decay heat and possible heat from chemical reactions unless an alternate means of cooling were available. In order to prevent significant chemical reactions and destructive core heatup, emergency core cooling equipment rapidly recovers the core and provides makeup for decay heat removal.

\subsection{Accident Bases}

Al1 components of the reactor coolant system have been designed and fabricated to insure high integrity and thereby minimize the possibility of their rupture. The reactor coolant system, the safety factors used in its design and the special provisions taken in its fabrication to insure quality are described in Section 4.

In addition to the high-integrity system to minimize the possibility of a loss of coolant, emergency core cooling is provided to insure that the core does not melt even if the reactor coolant system should fail and release the coolant. This emergency core cooling is provided by the core flooding system, the high pressure injection system and the low pressure injection system. These systems are described in detail in Section 6, and their characteristics are summarized in the following paragraphs.

The core flooding system has two independent core flooding tanks, each of which is connected to a different reactor vessel injection nozzle by a line containing two check valves and a normally open, remotely operated stop valve. Since these tanks and associated piping are missile-protected and are connected directly to the reactor vessel, a rupture of reactor coolant system piping will not affect their performance. These tanks provide for automatic flooding when the reactor coolant system pressure decreases below 600 psi. The flooding water is injected into the reactor vessel and directed to the bottom of the reactor vessel by the thermal. shield. The core is flooded from the bottom upward. The combined contents of the two tanks $\left(1,880 \mathrm{ft}^{3}\right)$ rapidly reflood the core immediately after the blowdown to provide cooling untii coolant flow can be established by low pressure injection.

High pressure injection, actuated by low reactor coolant system pressure, supplies coolant at pressures up to the design pressure of the reactor coolant system and at a rate up to $1,500 \mathrm{gpm}$. Low pressure injection actuated by $10 \mathrm{w}$ reactor coolant system pressure supplies coolant at pressures below 100 psig and at a rate up to $9,000 \mathrm{gpm}$. Both of these systems can operate at full capacity from the on-site emergency electrical power supply and will be in operation within $25 \mathrm{sec}$ after the accident. In the reactor vessel, decay heat is transferred to the injection water. 
Injection water is supplied from the borated water storage tank. When this tank empties, water is recirculated from the Reactor Building sump through heat exchangers and returned to the reactor vessel.

Engineered safeguards are also provided to cool the Reactor Building environment following a loss-of-coolant accident and thereby limit and reduce pressure in the building. Reactor Building sprays, actuated on a high building pressure signal of $10 \mathrm{psig}$, deliver 3,000 gpm to the Reactor Building atmosphere. This spray water reaches thermal equilibrium within the building atmosphere during its passage from the nozzles to-the sump. Spray water is supplied from the borated water storage tank. until it is emptied. Thereafter, water collected in the sump is recirculated to the sprays. Cooling is also provided by the Reactor Building emergency cooling system in which recirculating fans direct the steam-and-air mixture through emergency coolers, where steam is condensed. Heat absorbed in the emergency coolers is rejected to the service water cooling system. The heat removal capacity of either of these two Reactor Building cooling systems is adequate to prevent overpressurization of the building during a loss-of-coolant accident.

This analysis demonstrates that in the unlikely event of a failure of the reactor coolant system, both of the other two boundaries that prevent fission product release to the atmosphere, ie, the reactor core and the Reactor Building, are protected from failure. Accordingly, the public would be protected against potential radiation hazards.

In order to evaluate this accident, a range of rupture sizes from sma11-leaks up to the complete severance of a 36 in. ID reactor coolant system line has been evaluated. A core cooling analysis is presented for the complete severance of the 36 in. ID reactor coolant piping.

Since the large rupture removes the least amount of stored energy from the core, this represents the minimum temperature margin to core damage and, therefore, places the most stringent requirements on the rore flonding systom.

The Reactor Building pressures have been evaluated for a complete spectrum of rupture sizes without the action of core flooding tanks and, therefore, are conservative. The peak pressure occurs for a $3 \mathrm{ft}^{2}$ rupture rather than.

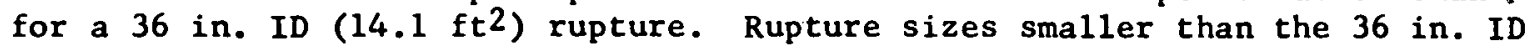
leak result in longer blowdown times, and the amount of energy transferred to the Reactor Building atmosphere is increased.

\subsection{Accident Simulation}

a. Hydraulic Model

Blowdown of the reactor coolant system following an assumed rupture has been simulated by using a modified version of the FLASH ${ }^{(9)}$ code. This code calculates transient flows, coolant mass and energy inventories, pressures, and temperatures during a loss-of-coolant accident. The code calculates inflow from the emergency cooling and calculates heat transferred from the core to the coolant. 
Modifications were made to FLASH to make the model more applicable to this system. The changes are as follows:

(1) The calculation of reactor coolant pump cavitation was based on the vapor pressure of the cold leg instead of the hot leg water.

(2) Core flooding tanks have been added. Water flow from the core flooding tanks is calculated on the basis of the pressure difference between the core flooding tanks and the point of discharge into the reactor coolant system. The line resistance and the inertial effects of the water in the pipe are included. The pressures in the tanks are calculated by assuming an adiabatic expansion of the gas above the water level in the tank. Pressure, flow rate and mass inventories are calculated and printed out in the computer output.

(3) Additions to the water physical property tables (mainly in the subcooled region) have also been made to improve the accuracy of the calculations.

(4) A change in the steam bubble rise velocity has been made from the constant value in FLASH to a variable velocity as a function of pressure. The bubble velocity term determines the amount of water remaining in the system after depressurization is complete. For large ruptures, this change in velocity shows no appreciable change in water remaining from that predicted by the constant value in the FLASH code. For smaller ruptures, an appreciable difference exists. The variable bubble velocity is based on data in Reference 10 and adjusted to correspond to data from the LOFT semiscale blowdown tests.

Test No. 546 from the LOFT semiscale blowdown tests is a typical case for the blowdown through a small rupture area. A comparison of the predicted and experimentally observed pressures is shown in Figure 14-31. Figure 14-32 shows the per cent mass remaining in the tank versus time as predicted by the code. At the end of blowdown, the predicted mass remaining is 13 per cent. The measured mass remaining is approximately 22 per cent.

The FLASH code describes the reactor coolant system by the use of two volumes plus the pressurizer. The system was grouped into two volumes on the basis of the temperature distribution in the system as follows:

Volume 1 includes half of the core water volume, the reactor outlet plenum, the reactor outlet piping and approximately 55 per cent of the steam generaturs.

Volume 2 includes half of the core water volume, the reactor inlet plenum and downcomer section, the reactor inlet piping, pumps and 45 per cent of the steam generators. 
Volume 3 represents the pressurizer.

The resistances to flow were calculated by breaking the reactor coolant system into 24 regions and calculating the volume-weighted resistance to flow for a given rupture location based on normal flow resistances. For the double-ended ruptures, all of the leak was assumed to occur in the volume in which that pipe appeared.

-The reactor core power was input as a function of time as determined by the CHIC-KIN code in conjunction with the FLASH output. Steam generator heat removal was assumed to cease when the rupture occurred.

While the modified FLASH code now has the capability of simulating injection flow from the core flooding tanks, the calculations shown in this report were made prior to the time that the core flooding simulation was added to FLASH. Core flooding was calculated by taking the reactor vessel pressure as predicted by FLASH without core flooding and using this pressure as input to a separate program to get the flow from the core flooding tanks. Reactor vessel filling was calculated by adding the mass remaining in the vessel as predicted by FLASH to the mass injected from the core flooding tanks. This method of calculation is conservative in that condensation of steam by the cold injection water is not taken into account. A more recent analysis using the FLASH code confirms that conservatism was used in this analysis.

Pressure, temperature, mass and energy inventories and hydraulic characteristics as determined by FLASH are input into the core thermal code (SLUMP) and the Reactor Building pressure buildup code (CONTEMPT).

b. Core Thermal Model

The core heat generation and heat transfer to the fluid are dependent upon the blowdown process. The FLASH program includes a core thermal model and the feedbacks of heat transfer and flow on each other. While the FLASH thermal model is acceptable for determining the effect of core heat transfer on the blowdown process, a more extensive simulation is necessary for evaluation of the core temperature transient.

Additional analytical models and a digital computer program were developed to simulate the core thermal transient for the period beginning with the initiation of the leak and ending after the core temperature excursion had terminated.

The model includes the effects of heat generation from neutrons before reactor trip, neutron decay' heat, and fission and 
activation product decay heat; the exothermic zirconium-water reaction based on the parabolic rate law; heat transfer within the fuel rods, limited heat convection from the fuel clad surface to any fluid within the core region, heat transfer from reactor vessel walls and internals to the coolant, and heat transfer from fuel rods to the steam necessary to sustain a metal-water reaction; and emergency injection flow and boiloff.

The basic model structure provides 50 equal-volume core regions with input provisions to allow any choice of power distribution. The model may be used to simulate the entire core or any subdivision of the core. Therefore, the core geometry may be detailed to the degree consistent with the results desired.

The following parabolic law for the zirconium-water reaction equation(11) with the following constants is simulated for each of the regions:

$$
-\frac{d r}{d t}=\frac{K}{\left(r_{0}-r\right)}\left(\exp -\frac{\Delta E}{R T}\right)
$$

where:

$$
\begin{aligned}
& r=\text { radius of unreacted metal in fuel rod } \\
& r_{0}=\text { original radius of fuel rod } \\
& t=\text { time } \\
& K=\text { rate law constant }\left(0.3937 \mathrm{~cm}^{2} / \mathrm{sec}\right) \\
& \Delta E=\text { activation energy }(45,500 \mathrm{cal} / \mathrm{mole}) \\
& R=\text { gas constant }(1.987 \mathrm{cal} / \mathrm{mole} \mathrm{K}) \\
& T=\text { temperature, } K
\end{aligned}
$$

The zirconium-water reaction heat is assumed to be generated completely within the clad node. The heat necessary to increase the steam temperature from the bulk temperature to the reaction temperature is transferred from the clad at the point of reaction. The above equation implies no steam limiting. However, the program does have provision for steam rate limiting to any degree desired, but no steam limiting of the reactions has been assumed. All heat from neutron, beta, and gamma sources is assumed to be generated within the fuel according to the preaccident power distribution and infinite irradiation.

Within each of the regions there is a single fuel node and a single clad node with simulation of thermal resistance according to the normal fuel rod geometry. Provision is made to simulate four different modes of heat transfer from the clad node to the fluid sink node by specifying the time-dependent surface coefficient. 
The surface heat transfer coefficient input data are determined from calculations which are based on flow and water inventory as furnished from the blowdown and the core flooding tank performance analysis.

In the event that insufficient cooling is provided, the program will allow clad heating to progress to the melting point. At this point the latent heat of zirconium must be added before the clad melts. Provisions are also incorporated to allow the clad to be heated to temperatures above the melting point before slump occurs.

As each region slumps it may be assumed to surrender heat to a water pool or to some available metal heat sink. If water is available an additional 10 per cent reaction is assumed to occur.

The program output includes the following (as a function of time unless otherwise specified):

Average fuel temperature of each region.

Average clad temperature of each region.

Per cent metal-water reaction in each region.

Time for the clad of each region to reach the metal-water threshold, the beginning and end of melting, and the slump temperature.

Heat transferred to the Reactor Building from the core:

Heat generation by hydrogen and oxygen recombination.

Total zirconium-water reaction.

Total heat stored in metal sinks.

\section{c. Reactor Building Pressure Model}

The Reactor Building pressure-temperature analysis is performed using the digital computer code "CONTEMPT" developed by Phillips Petroleum Company in conjunction with the LOFT project. This program and its capabilities are described in Reference 12. With minor modifications this program was adapted for use on The Babcock \& Wilcox Company's computer.

In this model, the Reactor Building is divided into two regions: the atmosphere (water vapor and air mixture) and the sump region (liquid water). Each region is considered to be well mixed and in thermal equilibri:um, but the temperature of each region may be different. The Reactor Building and its internal structures are subdivided into five segments, as shown in Table 14-4, and treated as slabs with 1-dimensional heat transfer. Each segment, divided into several heat conducting subregions, may act as a 
heat source or sink. The program includes the capability of cooling the Reactor Building atmosphere by air coolers (Reactor Building emergency cooling units) and spray cooling (Reactor Building spray system), and cooling the liquid region by sump coolers (low pressure injection coolers).

During blowdown, mass and energy are added directly to the atmosphere where the liquid water present is assumed to fall to the liquid region. After blowdown is over and emergency injection has been initiated, mass and energy are also added directly to the vapor region as steam. When the water level in the reactor vessel reaches the nozzle height, all mass and energy are added directly to the liquid region since no boiling of the injection water occurs after the core has been covered. When the supply of injection water is depleted, recirculation and cooling of sump water is simulated.

The Reactor Building calculations are begun by computing steadystate results using initial atmospheric conditions as the input. Following the rupture, the mass and energy addition is determined from the energy input rates for each time step. Heat losses or gains due to the heat-conducting slabs are calculated. Then the pressure and temperature of the 1 iquid and vapor regions are calculated from the mass, volume, and energy balance equations.

Table 14-4

Reactor Building Structural Heat Capacitance Segments

\begin{tabular}{c} 
Segmen \\
\hline 1 \\
2 \\
3 \\
4 \\
5
\end{tabular}

Description

Reactor Building Walls and Dome Refueling Cavity (Type 304 SS Liner - One Side) Reactor Building Floor Internal Concrete Internal Steel

The model has been developed so that the effectiveness of the natural heat sinks and the engineered safeguards can be clearly demonstrated. The model can readily produce the Reactor Building pressure history for any assumed combination of nperable safeguards. Therefore, the effectiveness of any given arrangement can be analyzed. 
14.2.2.3.4 Core Flooding Tank Design Base Accident Analysis

The 36 in. ID, double-ended pipe rupture produces the fastest blowdown and lowest heat removal from the fuel. This case therefore represents the most stringent emergency core cooling requirements. Result.s from the modified version of FLASH indicate that the core flooding tank simulation provides for the retention of all injection plus a portion of the original reactor coolant that would otherwise have been released. Thus, the cool injection water provides a cooling and condensing effect which reduces overall leakage. For the present analysis, no credit has been taken for the extra accumulation of water due to the condensing effect.

The blowdown was analyzed using the version of FLASH without core flooding tank simulation. This resulted in higher transient reactor vessel pressure than would have occurred if core flooding tank flow feedback effects were included. The core flooding tank transient analysis was then performed using reactor vessel back pressure which was provided by the FLASH analysis. To determine the fluid remaining in the reactor vessel at any point in time during the blowdown transient, the integrated flnw from the core flooding tank is added to the fluid remaining which is predicted by FLASH. The inventory obtained by this method is conservative because it neglects the condensing effect which leads to an additional accumulation of water.

The SLUMP digital computer program, as described in 14.2.2.3.3.b above, is used to evaluate core flooding tank performance in terms of core cooling capability. In the analysis, the hottest 5 per cent of the core was simulated in segments of $1 / 4$ of one per cent each. The hottest segment was assigned a peaking factor of 3.1 times the average of the total core power density.

The reactor is assumed to be initially at the ultimate power level $(2,568$ MWt). The core analysis simulates reactivity effects which correlate with the results which were obtained from a detailed analysis of vnid shutdnun without controi rod insertion. The detailed analysis was made with the digital computer program CHIC-KIN which included positive moderator and initially positive void coefficients. The results from the void shutdown calculation yield a total integrated neutron energy generation of approximately 2.1 full-power seconds.

The transient core flow from the FLASH analysis of the 36 in. ID, doubleended rupture was used to determine the core cooling mechanism used in SLUMP. The very high flow rates during the initial blowdown period provide nucleate boiling conditions. However, the time for Departure from Nucleate Boiling (DNB), especially for the hot regions, is extremely difficult to determine. Therefore, a conservative approach was adopted by 
When water from the borated water storarie tanks is depleted, the water collected in the reactor buildin sur is recirculated through coolers to supply the low pressure injection water and reactor buildinis sprays. The result is an increased injection and spray water temperature. Some boilinz of the injection vater may occur due to the decrease in subcooling. The reactor building spray effectiveness will also decrease. The net result is a decrease in the enercy removal rate from the reactor building atmosphere.

The model has been developed so that the effectiveness of the natural heat sinks and the enjineered safezuards systems can be clearly demonstrated. The model can readily produce the reactor buildin; pressure history for any assumed combination of operable safecuards systems. Therefore, the effectiveness of any given system can be analyzed.

Cooling of the reactor building followin; a loss-of-coolant accident is provided by three reactor buildin. emergency coolin. $\Im$ units and a spray system. The heat removal capability of the spray system is at least equal to the heat removal capability of the three reactor building ercersency coolins units. Each system is designed so that it alone can protect the reactor building ajainst overpressure.

Minfmum reactor building cooling is considered to be three reactor building emergency cooling units. However, two cooling units plus 1,500 spm sprays, or 3,000 $\mathrm{epm}$ sprays, provide cooling that is at least equivalent to the threereactor building emergency cooling units.

The reactor bullding pressure transient for the rupture of a 10 in. ID pipe using minimum reactor bullding cooling is shown in Figure 14-34: The peak reactor building pressure during this accident is 41.5 psig. Smaller leaks result in lower peak pressures due to the lower rate of eneray input to the reactor building.

Figure 14-35 shows the reactor building pressure for complete severance of a 36 in. ID reactor coolant system pipe with $14,000 \mathrm{spm}$ of borated water injection into the reactor coolant system bezinning at 16 seconds after the rupture. Reactor building cooling is provided by three emergency cooling units and the 3,000 cpm sprays. The peak pressure attained is $40.2 \mathrm{psi}$.

Flgure 14-36 shows the reactor building pressure for the case of 8,000 zpm of borated water injection beginning at 16 seconds after the rupture. This is the minimum injection flow from the injection system fallure analysis presented in Section 6. Pressure traces are shown for the maximum and minimum reactor building cooling. The peak pressure attained for minimum injection and minimum cooling is 48.2 psig.

Figure 14-37 shows the effect of minimum (8,000 cpm) and full (14,000 spm) injection flow on the reactor building pressure. For both injection conditions, the peak pressure attained is $48.2 \mathrm{psig}$. The pressure starts decreasing sooner for the full injection flow condition due to the reduction in steam release to the reactor building atmosphere when the vessel is filled. 
Figure 14-38 shows the effect of injection delay on the reactor building pressure for the case of minimum injection and minimum cooling. For all reference cases, a 16-second delay from the time of the rupture to the time injection begins has been used. Under emergency power conditions there may be as much as a 38 -second delay before injection of borated water begins. Th1s 11gure shows that this longer delay actually results in a secondary reactor building pressure peak which is slightly lower than that for the 16-second delay. However, the peak reactor building pressure is st1ll 48.2 psis corresponding to the initial reactor coolant system mass and enerey release.

Criterion 17 of the $A B C$ General Design Crlterla states that the containment (reactor bullding) be deslgned to accomodate the largest credible energy release including tine effects of credible metal-water reactions uninhibited by active quenching systems. Although the evaluation of the emergency injection systems demonstrates that only a small amount of metal-vater reaction can occur, the case of no injection flow has been evaluated in response to the above criterion. This case assumed that after blowdown, the reactor vessel would have water up to the bottom of the core. The core was allowed to heat up by decay heat and metal-water reaction heat.

Steam flow rate-limiting of the reaction was not considered so long as any water was assumed to be in the vessel. If and when the clad reached the welting temperature, it was assumed that the whole region slumped into the bottom of the vessel with the attendant reaction of 10 per cent more of the remaining zirconium and the release to the reactor bullding of all sensible and latent heat above $281 \mathrm{~F}$.

Upon completion of boiloff, heat input to the reactor building was assumed to cease. Figure 14-39 shows a peak reactor building pressure of $49.8 \mathrm{psig}$ at $360 \mathrm{sec}$, the time at which the reactor vessel bolls dry.

The following tabulation summarizes the above cases for the 36 in. In doubleended rupture:

\begin{tabular}{|c|c|c|c|c|c|}
\hline $\begin{array}{l}\text { Injection } \\
\text { Flow Rate, } \\
\text { gpm } \\
\end{array}$ & $\begin{array}{l}\text { Spray } \\
\text { Flow } \\
\text { Rate, } \\
\text { gpm }\end{array}$ & $\begin{array}{c}\text { Alr } \\
\text { Coolers } \\
\text { Oper- } \\
\text { ating } \\
\end{array}$ & $\begin{array}{l}\text { Delay } \\
\text { Time, } \\
\text { sec } \\
\end{array}$ & $\begin{array}{c}\text { Peak } \\
\text { Building } \\
\text { Pressure, } \\
\text { psig } \\
\end{array}$ & $\begin{array}{l}\text { Reference } \\
\text { Flgure } \\
\text { No. } \\
\end{array}$ \\
\hline $\begin{array}{r}14,000 \\
8,000 \\
8,000 \\
14,000 \\
8,000 \\
8,000 \\
\text { None }\end{array}$ & $\begin{array}{r}3,000 \\
3,000 \\
1,500 \\
0 \\
0 \\
0 \\
0\end{array}$ & $\begin{array}{l}3 \\
3 \\
2 \\
3 \\
3 \\
3 \\
3\end{array}$ & $\begin{array}{l}16 \\
16 \\
16 \\
16 \\
16 \\
38 \\
16\end{array}$ & $\begin{array}{l}48.2 \\
48.2 \\
48.2 \\
48.2 \\
48.2 \\
48.2 \\
49.8\end{array}$ & $\begin{array}{l}14-35 \\
14-36 \\
14-36 \\
14-37 \\
14-36,37 \\
14-38 \\
14-39\end{array}$ \\
\hline
\end{tabular}


assuming DNB at $0.25 \mathrm{sec}$. Nucleate boiling surface coefficients at high flow rates may exceed $50,000 \mathrm{Btu} / \mathrm{hr}-\mathrm{ft}^{2}-\mathrm{F}$. A nucleate boiling surface coefficient of $25,000 \mathrm{Btu} / \mathrm{hr}-\mathrm{ft}^{2}-\mathrm{F}$ was used in the analysis. However, the series heat transfer from the clad node to the fluid sink is limited to $6,500 \mathrm{Btu} / \mathrm{hr}$ $\mathrm{ft}^{2}-\mathrm{F}$ by the relatively low conductance of the $\mathrm{clad}$.

After DNB the surface heat transfer was calculated using the flow provided by FLASH results and Quinn's modified version of the Sieder-Tate(13) correlation:

$h_{T P F}=0.023 \frac{k}{D_{h}}\left(N_{R e}\right)^{0.8}\left(N_{P r}\right)^{1 / 3}\left[1+\frac{1-X}{X}\left(\frac{P_{B}}{P_{F}}\right)\right]^{0.8}\left(\frac{\mu_{B}}{\mu_{W}}\right)^{0.14}$

where $h_{T P F}=$ two-phase film heat transfer coefficient, Btu/hr-ft ${ }^{2}-F$

$$
\mathrm{k}=\mathrm{fluid} \text { conductivity, } \mathrm{Btu} / \mathrm{hr}^{-\mathrm{ft}^{2}-\mathrm{F}}
$$$$
D_{h}=\text { hydraulic diameter, } \mathrm{ft}
$$$$
\mathrm{N}_{\mathrm{Re}}=\text { Reynolds number }
$$$$
\mathrm{N}_{\mathrm{Pr}}=\text { Prandt } 1 \text { number }
$$$$
x=\text { quality }
$$$$
p=\text { density }
$$$$
\mu=\text { viscosity }
$$

subscript $B=$ "Bulk"

subscript $F=$ "Film"

subscript $\mathrm{W}=$ "Wall"

With this correlation, bulk steam properties are used in the basic form, and the last two bracketed terms are modifiers which correct for quality and different conditions at the wall.

Figure 14-33 shows the core flow vs time for the $14.1 \mathrm{ft}^{2}$ leak as calculated by FLASH.

Figure 14-34 shows the clad ourface heat transfer coefficient versus time based on the flow of Figure 14-33 and the modified Sieder-Tate equation. The straight line in Figure 14-34 indicates the surface heat transfer values which were used in SLUMP, and which are conservative as compared to the results obtained from the Sieder-Tate equation. 
In applying the Sieder-Tate equation constant values of bulk steam quality and temperature corresponding to the most conservative assumptions were used.

A sensitivity analysis was made for maximum coefficients in SLUMP ranging from 400 to $2,000 \mathrm{Btu} / \mathrm{hr}-\mathrm{ft}^{2}-\mathrm{F}$ initially and decreasing to zero at the end of blowdown. Results are discussed below.

After blowdown no core cooling is assumed until after core recovering starts. When the water level reaches the core bottom and starts to rise up on the core, the submerged portion will be cooled by pool boiling, and any steam thus produced will provide some cooling for that portion of the core above the water line. However, in determining peak clad temperatures no cooling is assumed for that portion of the core which is above the water line.

At the point of initial contact of cool water against hot cladding the heat flux and temperature differences will be such that film boiling is the probable mode of heat transfer. This mode provides the lowest surface coefficients which would be in the range of 100 to $300 \mathrm{Btu} / \mathrm{hr}-\mathrm{ft}^{2}-\mathrm{F}$. However, in evaluating the core flooding tank design a conservative approach was used by assuming a value of $20 \mathrm{Btu} / \mathrm{hr}-\mathrm{ft}^{2}-\mathrm{F}$. This value is adequate for terminating the temperature excursion in the clad.

The core flooding tank analysis incorporated the study of performance sensitivity to three significant core flooding tank parameters: (a) gas pressure (400 to 1,000 psig), (b) ratio of nitrogen gas volume to total volume ( $1 / 3$ and $1 / 2)$, and (c) size of piping between the core flooding tanks and the reactor vessel (12 in. and 14 in. ID). Figure 14-35 shows the reactor vessel water volume versus time for core flooding tanks operating at 600 psig with different combinations of volume ratio and line size. This figure includes an allowance for boiloff and also shows the effect of the flow provided by high pressure and low pressure injection beginning at $2.5 \mathrm{sec}$ when emergency power is available. Similar curves for $400 \mathrm{psig}$ and 1,000 psig core flooding tanks are shown in Figure 14-36. Figure 14-37 shows the maximum clad temperature reached by the hot spot and by the 1 , $2,3,4$ and 5 percentiles of the core as a function of quench time.

The quench time for a given percentile is taken as that time when the water level reaches the highest point in the core at which the peaking factor corresponding to that percentile exists. The fact that the same peaking factor may exist at some lower point in the core provides an inherent conservatism in the data as plotted. The axial peaking factor profile for the beginning of core life was used as it imposes the most stringent requirements on the core flooding tank design. 
A reactor buildin; ccoling capability evaluation was rade to deternine the amount of metal-water reaction that could occur without exceeding the butlding desion pressure. The following assumptions were made:

a. All reactor coolant inass and enerjy were released during blowdown.

b. All core stored heat was transferred to the coolant during blowdown.

c. lieat jeneration from 2 seconds at full power was transferred to the coolant during blowdow.

d. Decey l:eat was added to the reactor buildin's as generated in the Sor: of steam.

e. lietal-water reaction heat was added to the reactor building at a linear rate in the forn of steam. Hydrojen recombination enerisy was added as superheat.

Although this set of assumptions is obviously incompatible, Figure 14-40 shows the amount of metal-water reaction that could be allowed and not exceed the reactor bullding desion pressure. Fjoure 14-41 shows the neat removal by the natural heat sinks as a function of time for the above case.

This analysis demonstrates that, for the ranire of safety injection flows from $3,000 \mathrm{spm}$ to $14,000 \mathrm{~cm}$, the reactor buildinj desicn pressure is never exceeded when only the minimum reactor building cooling is available and when only emer:ency power is available. 
Peak temperatures for the core flooding systems described above are alsi shown on Figure 14-37. These curves demonstrate that all of the systems presented are capable of keeping the peak temperature at the hot spot more than $1000 \mathrm{~F}$ below the melting temperature of the clad. The amount of zirconium-water reaction which occurs for each of these core flooding systems is shown in Table 14-5.

The core flooding tank design selected is for a 600 psi charge pressure, $940 \mathrm{ft}^{3}$ water, $470 \mathrm{ft}^{3}$ of nitrogen, and a $14 \mathrm{in}$. supply line. The per-. formance of this system in limiting core temperatures is approximately in the center of the range for the systems described. For this 600 psi charge pressure, Figure 14-37 indicates that the hot spot clad temperature would reach $1950 \mathrm{~F}$ at $17.5 \mathrm{sec}$ and that less than 5 per cent of the core would exceed $1690 \mathrm{~F}$. For this same case calculations indicate less than 0.005 per cent total zirconium-water reaction for the whole core.

Table 14-5

Core Flooding Tank Performance Data

\begin{tabular}{|c|c|c|c|}
\hline Pressure & $\begin{array}{l}\text { Line } \\
\text { Size, } \\
\text { In. } \\
\end{array}$ & $\begin{array}{c}\text { Nitrogen } \\
\text { Volume, } \\
\% \text { of Total } \\
\end{array}$ & $\begin{array}{c}\text { Total Metal } \\
\text { Water Reaction } \\
\% \\
\end{array}$ \\
\hline 400 & 14 & 33 & .022 \\
\hline 400 & 14 & 50 & .009 \\
\hline 600 & 14 & 33 & .005 \\
\hline 600 & 14 & 50 & .002 \\
\hline 600 & 12 & 33 & .022 \\
\hline 600 & 12 & 50 & .010 \\
\hline 1000 & 12 & 33 & .003 \\
\hline 1000 & 12 & 50 & $\approx 0$ \\
\hline
\end{tabular}

Additional analysis was performed to evaluate the sensitivity of the maximum clad temperature to three important thermal parameters. All cases discussed below have in common the following parameters:

$\begin{array}{ll}\text { Leak size: } & 14.1 \mathrm{ft}^{2} \\ \text { Time of DNB: } & 0.25 \mathrm{sec} \\ \text { Time at full power: } & 2 \mathrm{sec} \\ \text { Time that blowdown cooling ends: } & 9.5 \mathrm{sec} \\ \text { Core region: } & \text { Hot spot } \\ \text { Time to initiate quenching: } & 18 \mathrm{sec} \\ \text { Dependent variable examined: } & \text { Clad temperature } \\ & \text { for hottest } 5 \text { per } \\ & \text { cent of core. }\end{array}$

Figure 14-38 shows the clad maximum temperature sensitivity to the initial surface heat transfer coefficiert after the 0.25 sec nucleate boiling period. The coefficient is linearly decreased to zero at $9.5 \mathrm{sec}$. Zero cooling is maintained until quenching is initiated with a clad surface coefficient of $20 \mathrm{Btu} / \mathrm{hr}-\mathrm{ft}^{2}-\mathrm{F}$. Figure 14-38 shows that the assumed value of $1000 \mathrm{Btu} / \mathrm{hr}-$ $\mathrm{ft}^{2}-\mathrm{F}$ is not on the most sensitive part of the curve and a 20 per cent decrease 
in $h$ would only result in increasing the peak clad temperature $120 \mathrm{~F}$ :

Figure 14-39 shows hot spot clad temperature transients for a range of injection cooling coefficients. All cases have a clad surface coefficient of 1000 $\mathrm{Btu} / \mathrm{hr}-\mathrm{ft}^{2}-\mathrm{F}$ at $0.25 \mathrm{sec}$, decreasing to zero at $9.5 \mathrm{sec}$. Heat removal is then zero until the effect of injection cooling is simulated. Figure 14-39 shows that without any cooling the temperature reaches the melting point in approximate1y $50 \mathrm{sec}$.

An $h$ value of 15 stops the fast temperature excursion and allows only a low rate of increase thereafter. Since the continuously increasing depth of coverage provided by the flooding tanks and the pumped flow injection systems provide additional cooling capability with time, an initial cooling value as low as 15 is probably adequate.

An $h$ value of 20 provides immediate quenching action and a slow cooling rate thereafter.

An $h$ value of 100 provides very fast cooling. Even though the 100 is a realistic value for film boiling in a pool - the probable mode for the submerged portion of the core - a more conservative value of 20 has been used as the reference for evaluating core flooding tank performance.

Figure 14-40 shows hot spot clad temperature transients for a range of pool fluid sink temperatures. Parameters for heat transfer prior to $18 \mathrm{sec}$ are the same as discussed in the preceding paragraph. At 18 sec a surface coefficient of $20 \mathrm{Btu} / \mathrm{hr}-\mathrm{ft}^{2}-\mathrm{F}$ was applied with sink temperatures as indicated. All results reported herein previously have had a sink temperature of $280 \mathrm{~F}$ during the quenching period. Prior to quenching, the sink temperature in all cases is based on the transient fluid pressure which results from the FLASH analysis. Figure 14-40 shows that any sink temperature below approximately $500 \mathrm{~F}$ is adequate for holding or reducing the clad temperature which existed at $18 \mathrm{sec}$. The core flooding tanks will provide a high flow of water at $90 \mathrm{~F}$. Although some heating will occur from contact with hot metal before the injection water reaches the core, the temperature rise could not be over $50 \mathrm{~F}$ assuming that the water came in contact with all reactor coolant system metal below the nozzle level before it contacted the core. Using a reference value of $280 \mathrm{~F}$ provides an added conservatism to the analysis.

In conclusion, the analysis has shown that the design of the core flooding system will provide for covering approximately 80 per cent of the core at $25 \mathrm{sec}$ after the double-ended rupture of the $36 \mathrm{ln}$. ID pipe. The high pressure and low pressure injection will then provide for continued increase in the water level.

The clad hot spot temperature excursion is terminated at $1950 \mathrm{~F}$ and less than 5 per cent of the total cladding exceeds $1690 \mathrm{~F}$. Only a minute amount ( 0.005 per cent) of zirconium-water reaction occurs, and the maximum temperature is at least $1400 \mathrm{~F}$ below the clad melting point. 


\section{$14.3 \quad$ REFERENCES}

(1) Watson, L. C., Bancroft, A. R., and Hoelke, C. W., Iodine Containment by Dousing in NPD-11, AECL-1130.

(2) Styrikovich, M. A., et al., "Transfer of Iodine from Aqueous Solutions to Saturated Vapor," Soviet Journal of Atomic Energy 17, July 1964.

(3) Dispersion of Soluble Radioactive Material in Water, CF-58-3-109.

(4) International Symposium on Fission Product Release and Transport Under Accident Conditions, Oak Ridge, Tennessee, April 1965.

(5) Liimatainen, R. C., et al., Studies of Metal-Water Reactions at High Temperature, ANL-6250.

(6) Ackerman, R., et al., "High Temperature Vapor Pressure of $\mathrm{UO}_{2}$, " Journal of Chemical Physics, December 1956.

(7) Reactor Development Program Progress Report, ANL-6912, June 1964.

(8) AEC Research and Development Reports, WIGL2 - A Program for the Solution of the One-Dimensional Two-Group, Space-Time Diffusion Equations Accounting for Temperature, Xenon and Control Feedback, WAPD-TM-532, October 1965.

(9) Margolis, S. G. and Redfield, J. A., FLASH: A Program for Digital Simulation of the Loss-of-Coolant Accident, WAPD-TM-534, May 1966.

(10) Grenda, R. J. and Patterson, J. F., "The Velocity of Rising Steam in a Bubbling Two-Phase Mixture," Transactions of The ANS 5, No. 1, p 151, June 1962 .

(11) Possible Z1rconium Water Reactions in Water Reactors, AEC Regulatory Staff Symposium, Apri1 27, 1965.

(12) Wagner, R. J. and Finnegan, L. J., "An Analytical Model for Predicting the. Pressure-Temperature History Within a Containment Vessel in Response to a Loss-of-Coolant Accident," Phillips Petroleum Company, Atomic Energy Division, Idaho Falls, Idaho, Presented at ANS Meeting, Washington, D. C., November 1965.

(13) Quinn, E. P., Forced-Flow Heat Transfer to High-Pressure Water Beyond the Critical Heat Flux, ASME 66WA/HT-36, November 27, 1966.

(14) Hilsmeier, W. F. and Gifford, F. A., Jr., Graphs for Estimating Almospheric Dispersion, ORO-545.

(15) Culkowski, W. M., Deposition and Washout Calculations Based on the Generalized Gaussian Plume Model, ORO-599. 


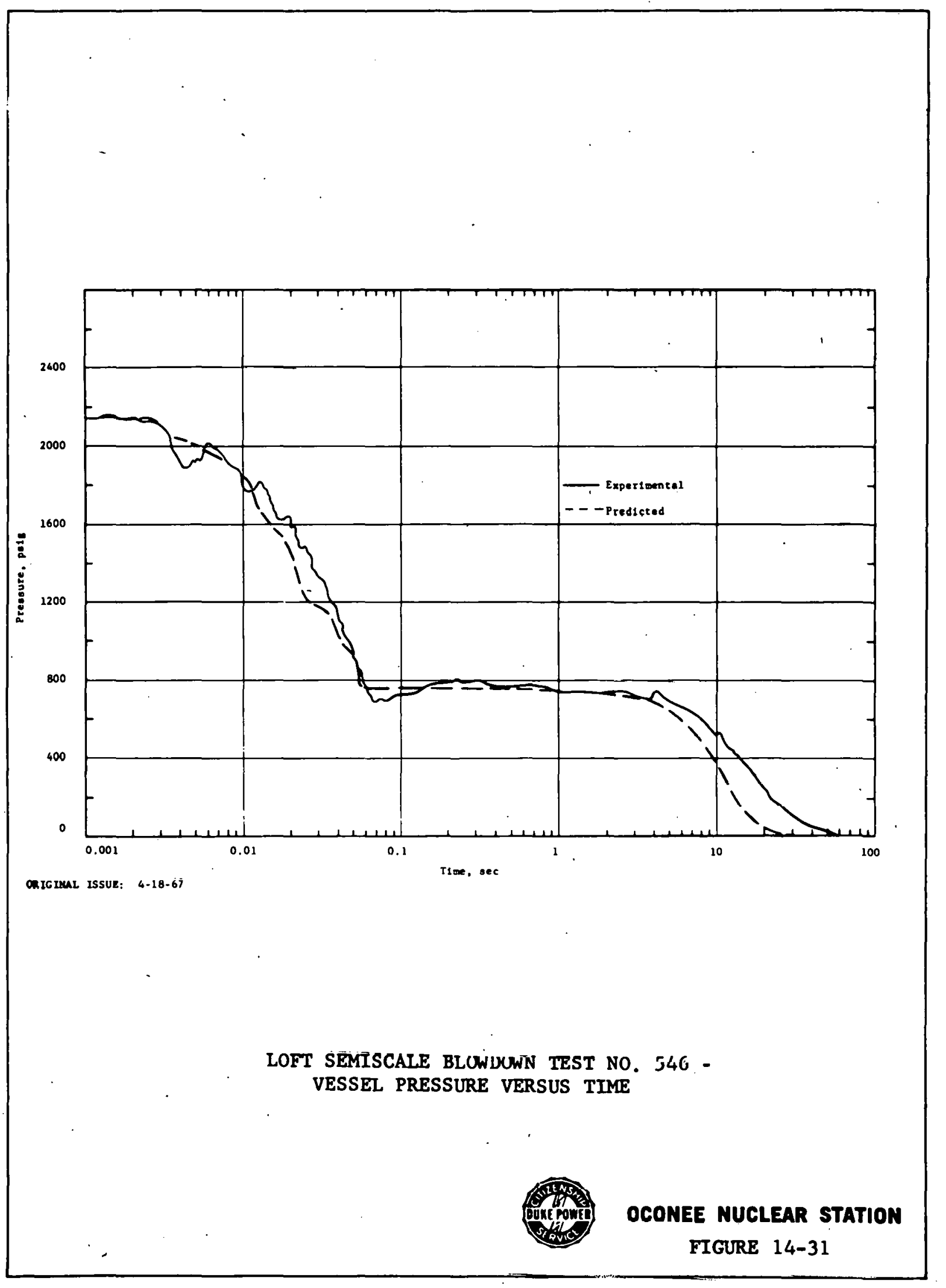




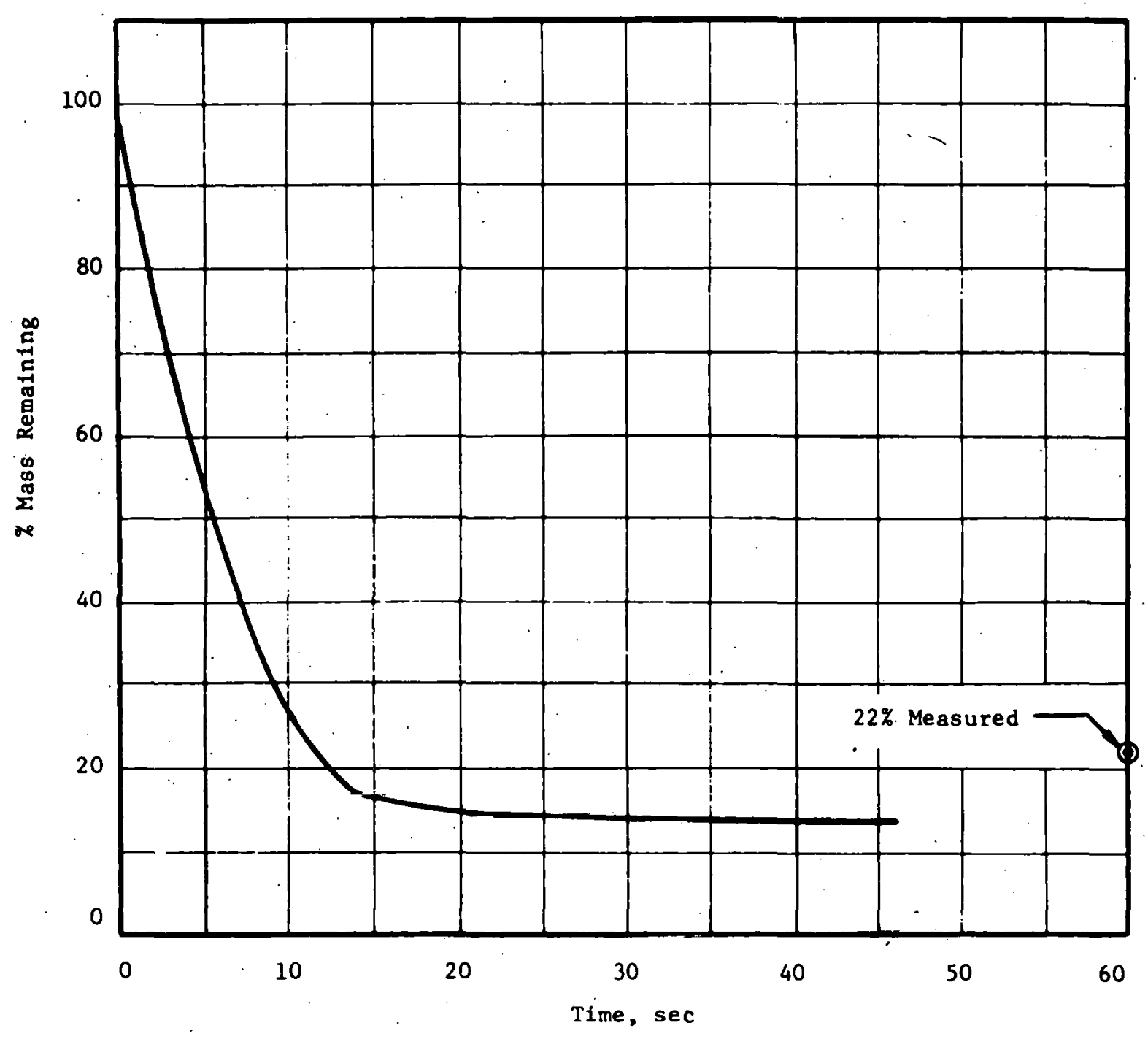

PREDICTED PER CENT MASS REMAINING VERSUS TIME LOFT TEST NO. 546

ORIGINAL ISSUE: $4-18-67$ 


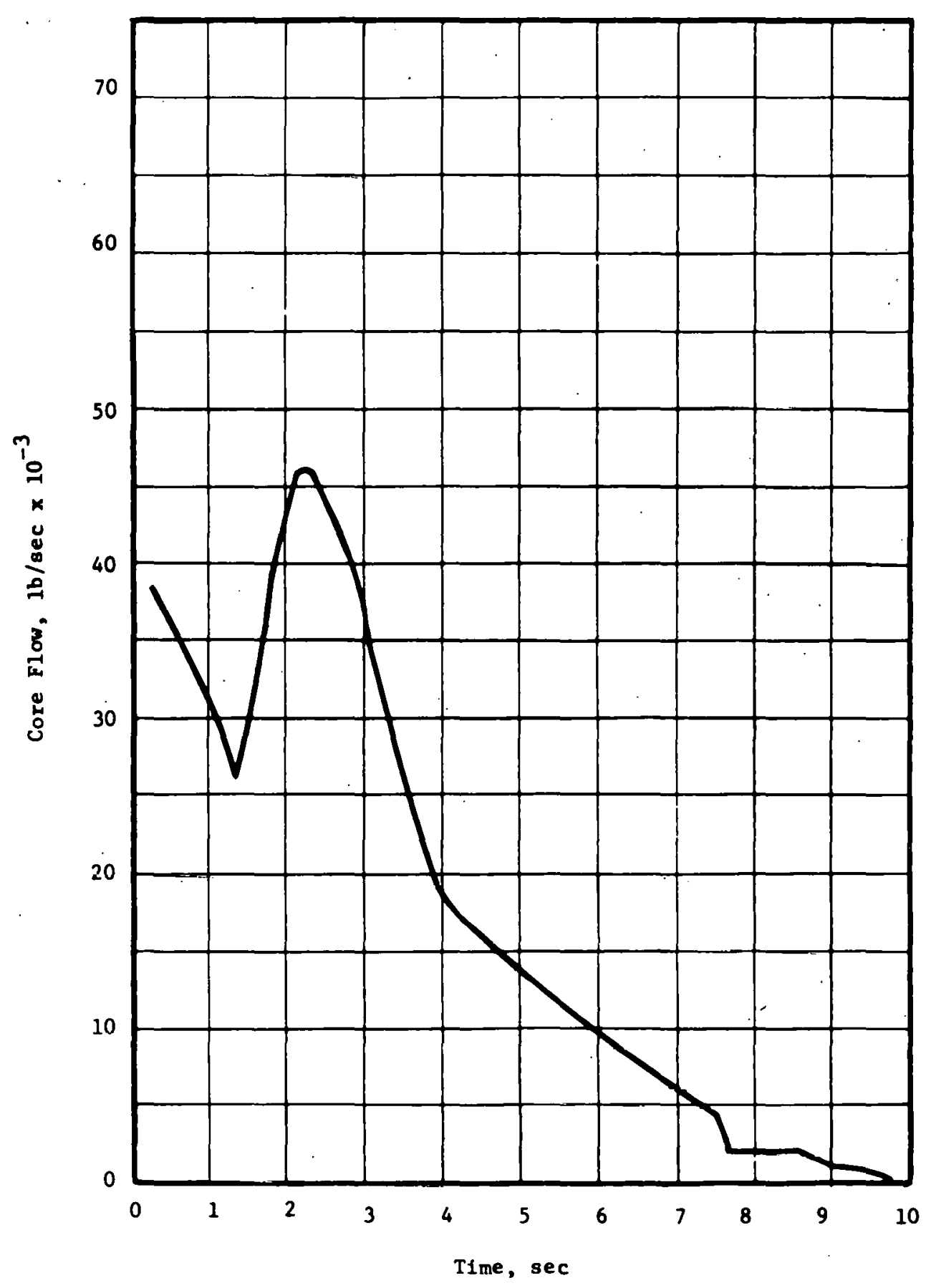

CORE FLOW VERSUS TTME FOR A 36 IN. ID DOUBLE-ENDED PIPE RUPTURE

ORIG INAL ISSUE: $\quad 4-18-67$

oconeE nUClear station FIGURE 14-33 


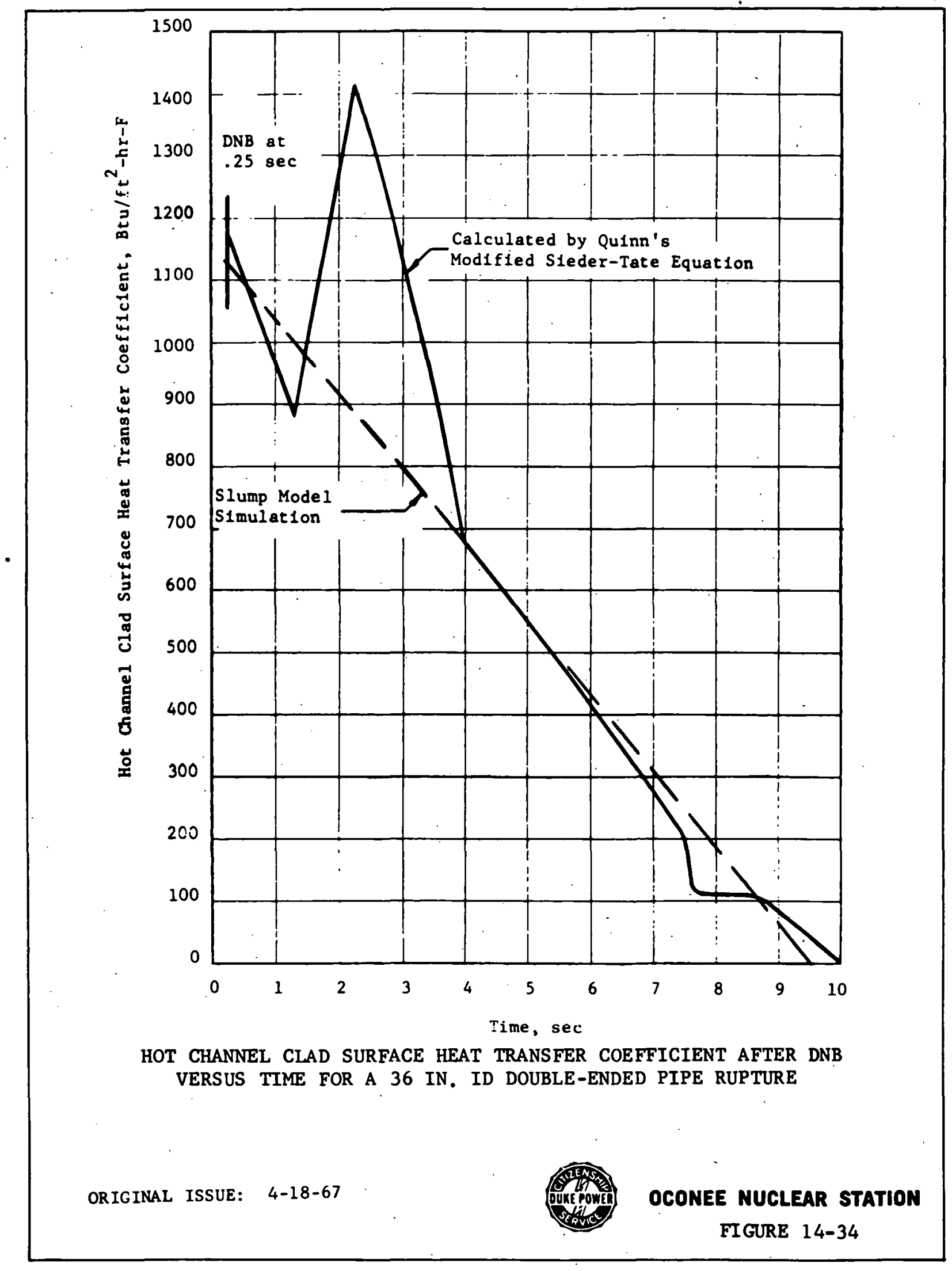




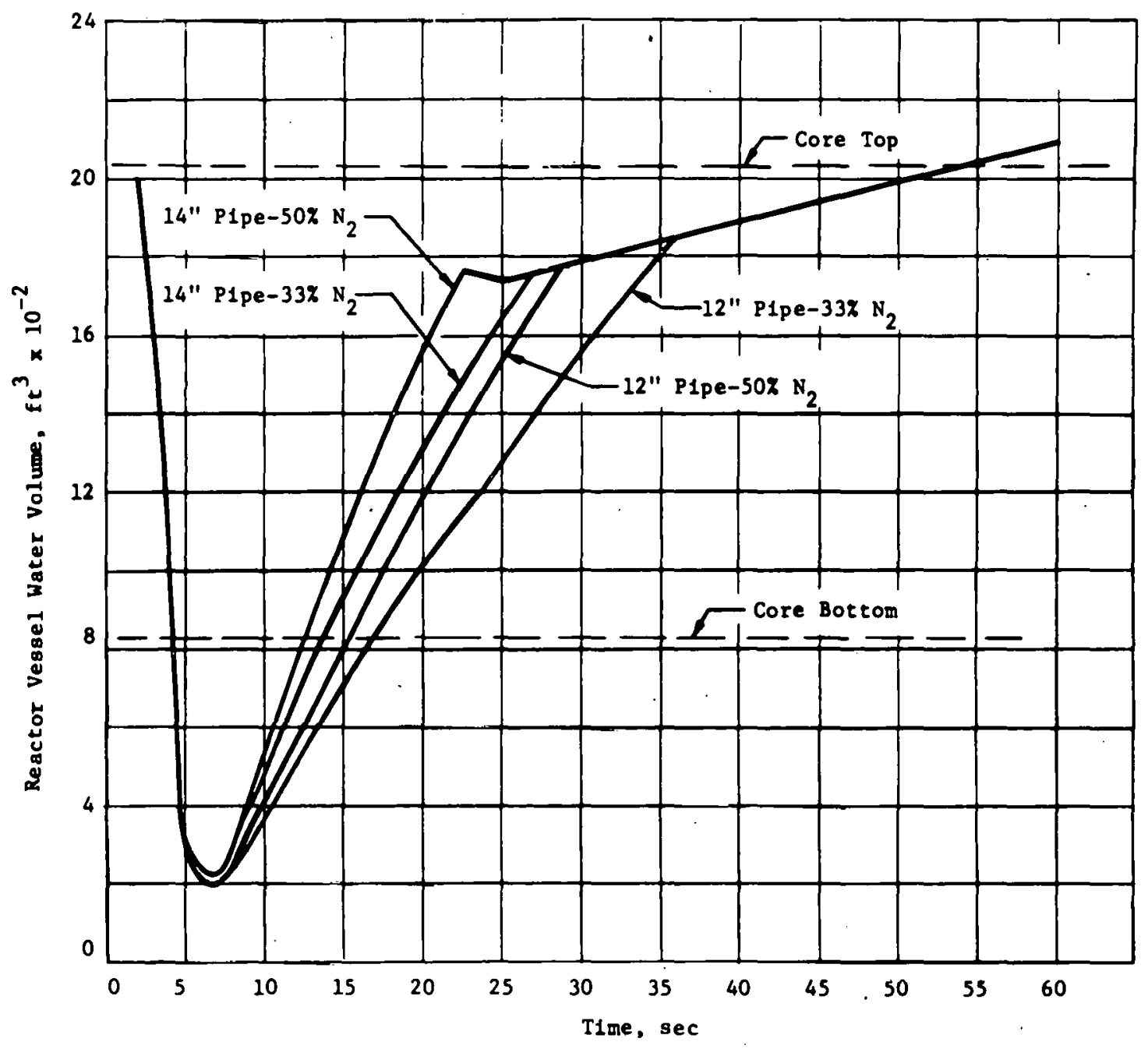

REACTOR VESSEL WATER VOLUME VERSUS TIME FOR 36 IN. DOUBLE-ENDED PIPE RUPTURE - FOR 600 PSIG CORE FLOODING TANK

REV: $\quad 4-18-67$

FIG 14-32 (12-1-66) REDRAWN

TO REFLECT SYSTEM CHANGES 


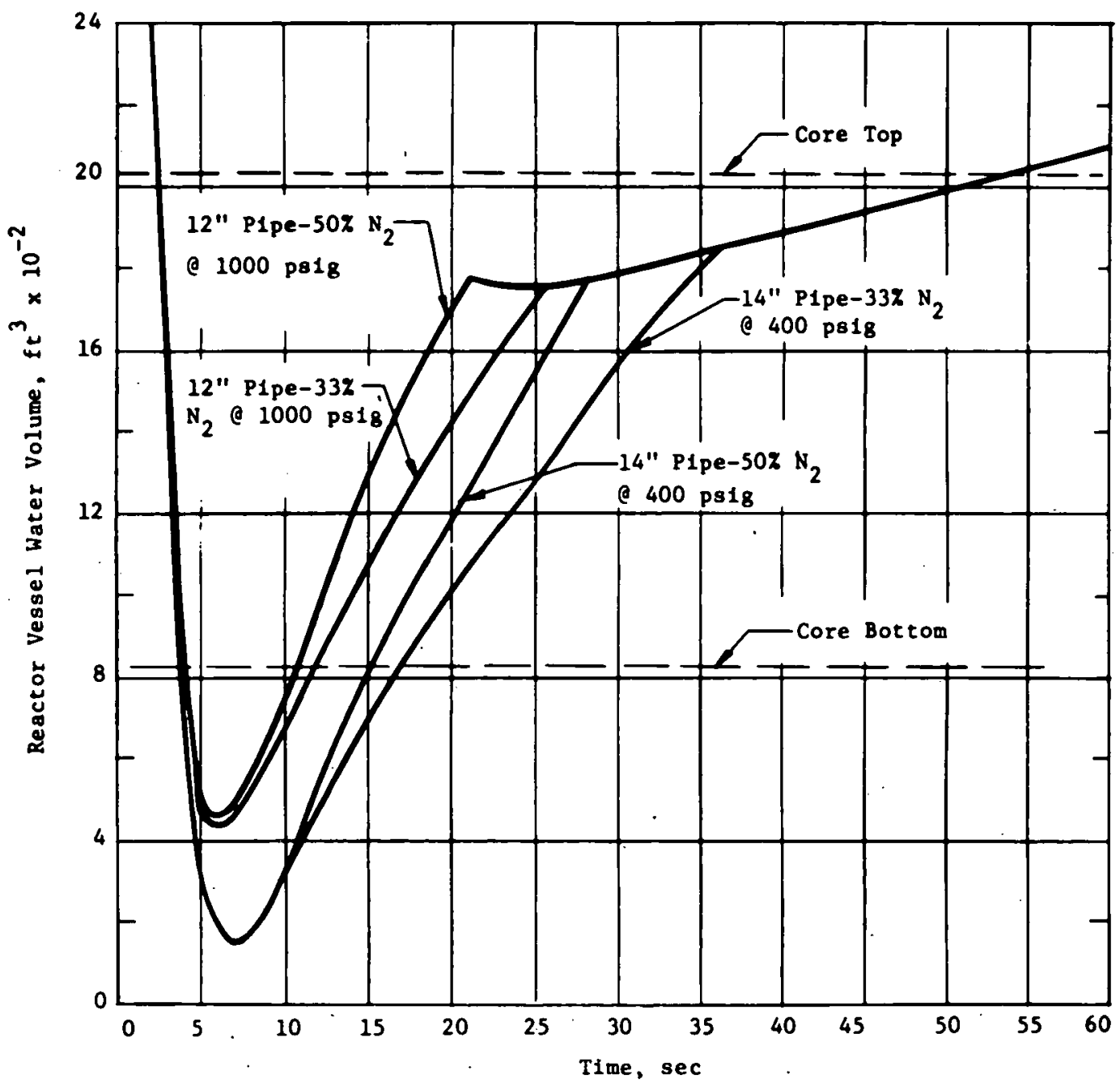

REACTOR VESSEL WATER VOLUME VERSUS TTME FOR 36 IN, DOUBLE-ENDED PIPE RUPTURE - FOR 400 PSIG AND 1,000 PSIG CORE FLOODING TANK

REV : $\quad 4-18-67$

FIG 14-32 (12-1-66) REDRAWN TO REFLECT SYSTEM CHANGES 


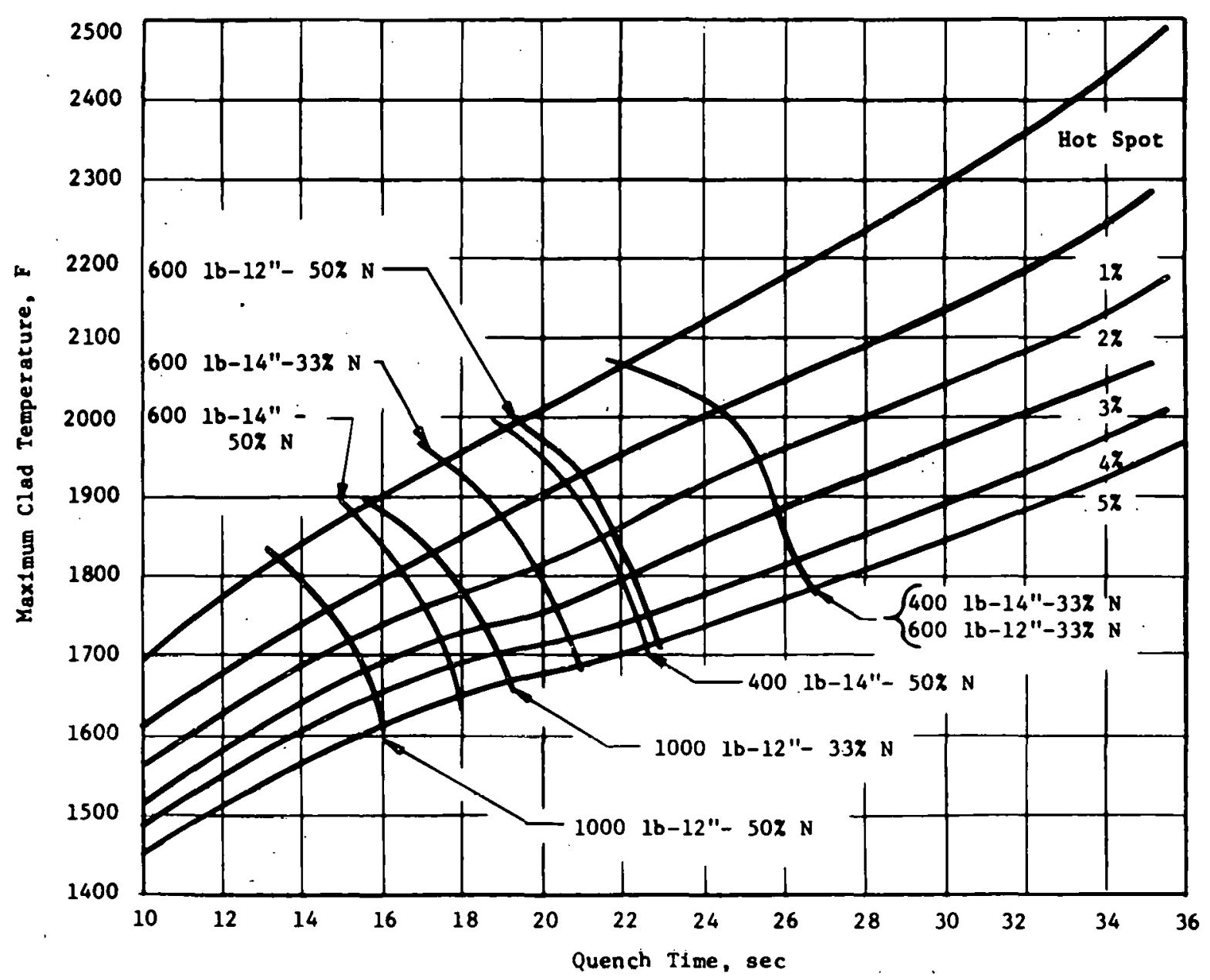

MAXIMUM CLAD TEMPERATURE VERSUS TIME TO QUENCH FOR A 36 IN. ID DOUBLE-ENDED PIPE RUPTURE

ORIG INAL ISSUE: $4-18-67$ 


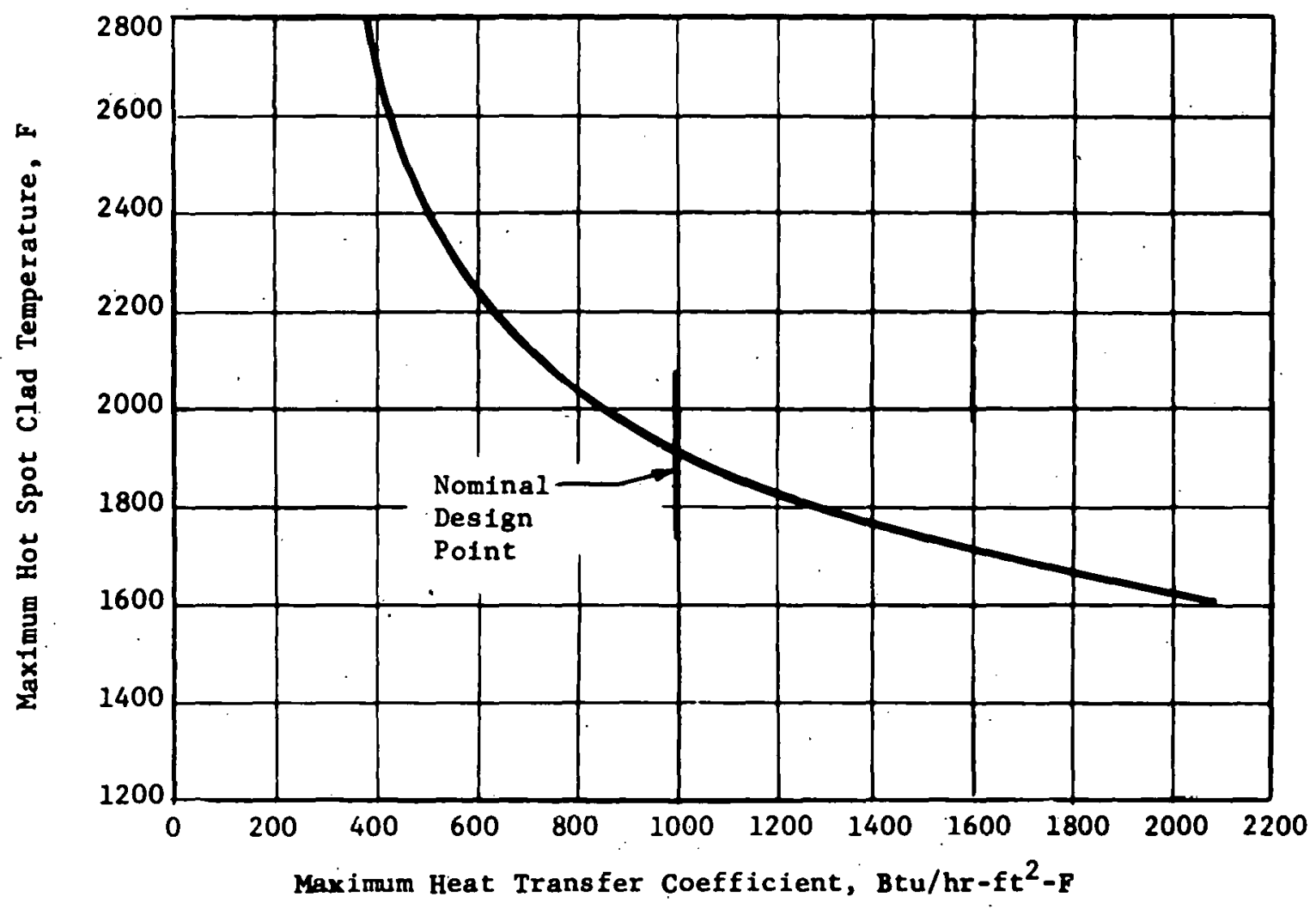

MAXIMUM HOT SPOT CLAD TEMPERATURE VERSUS MAXIMUM HEAT TRANSFER COEFFICIENT AFTER DNB FOR A 36 IN. ID DOUBLE-ENDED PIPE RUPTURE

ORIG INAL ISSUE: $\quad 4-18-67$ 


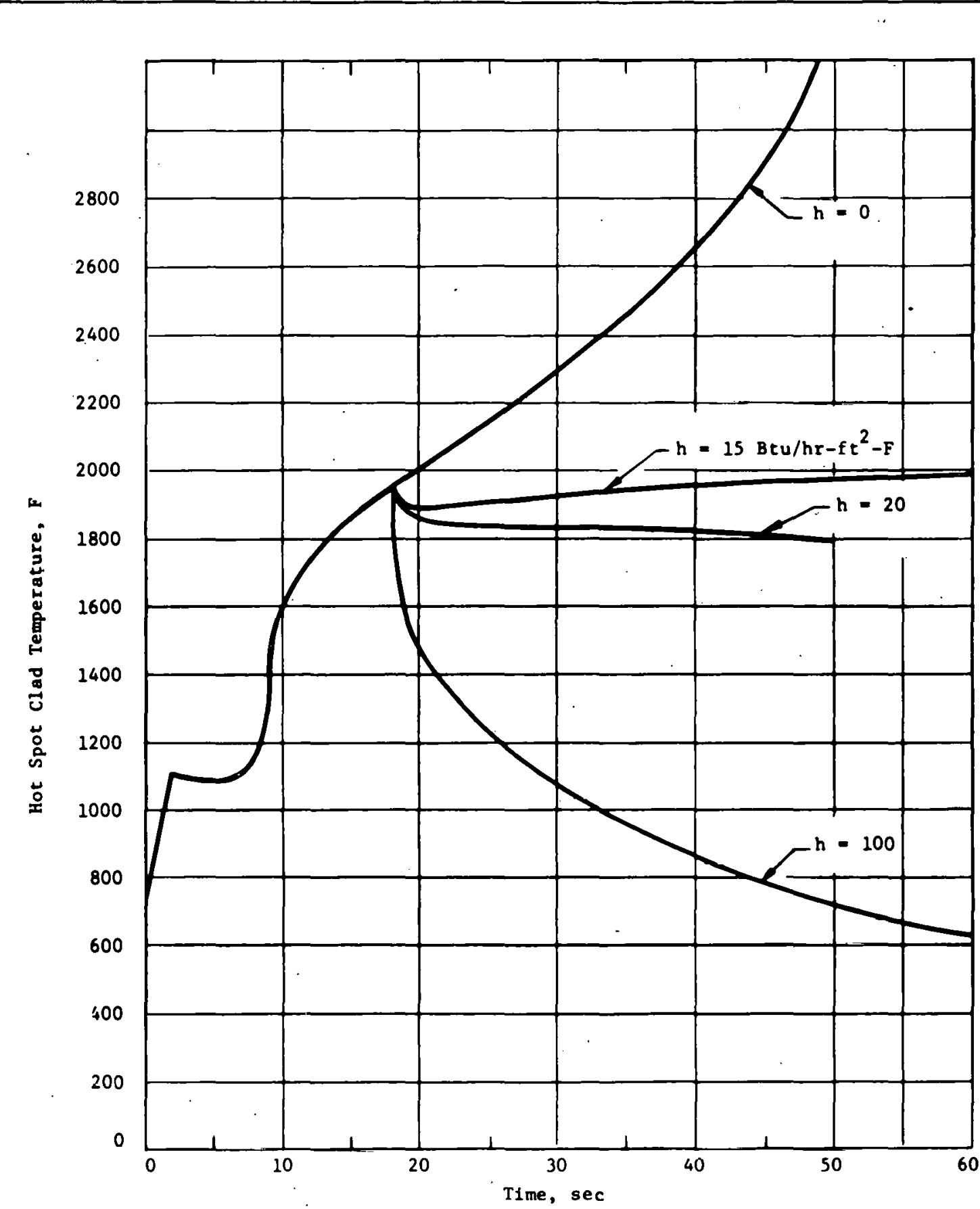

HOT SPOT CLAD TEMPERATURE VERSUS TIME FOR 36 IN. ID DOUBLE-ENDED PIPE RUPTURE AND VARIABLE QUENCH COEFFICIENT

ORIGINAL ISSUE: $\quad 4-18-67$ 


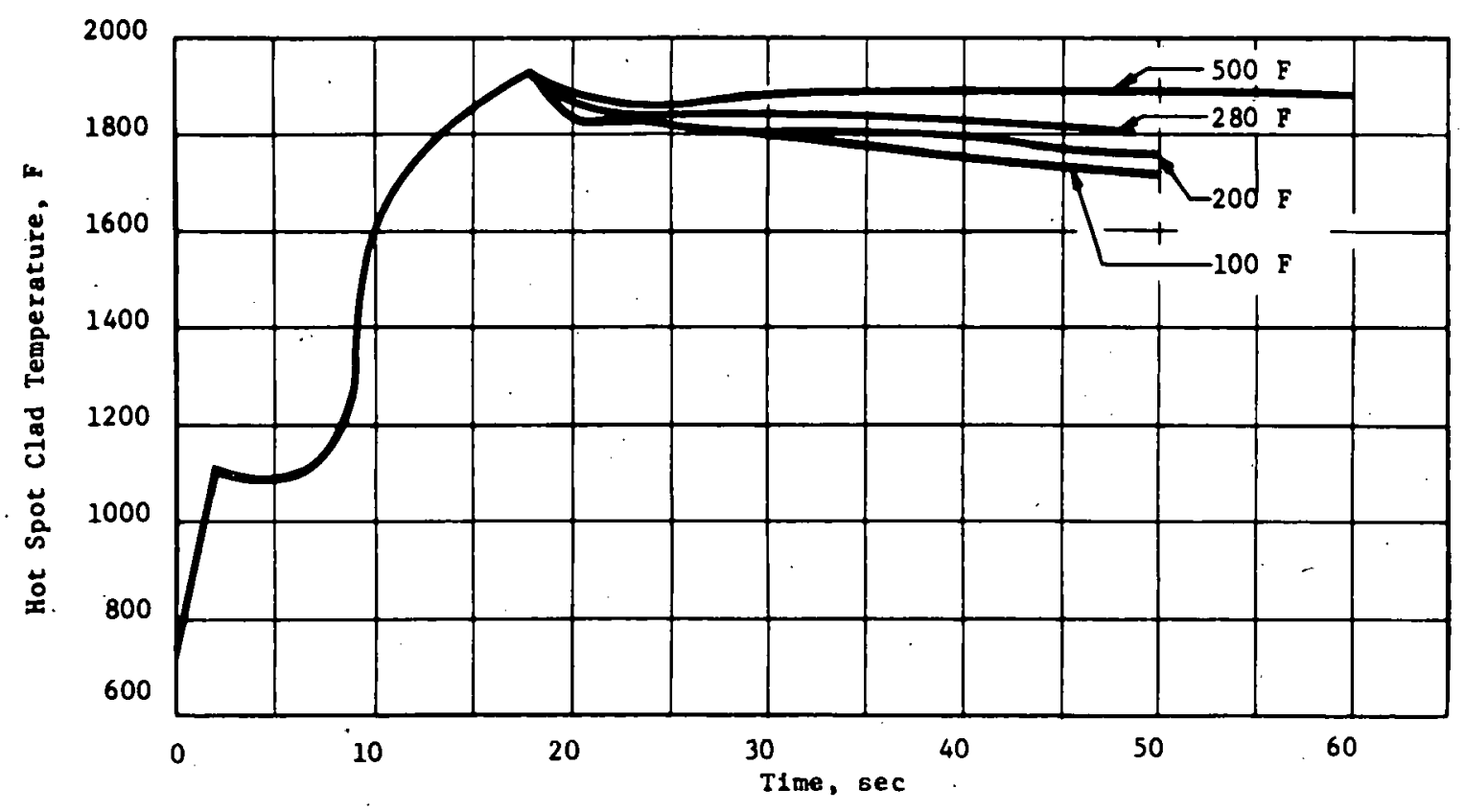

HOT SPOT CLAD TEMPERATURE VERSUS TIME FOR 36. IN. ID DOUBLE-ENDED PIPE RUPTURE AND VARIABLE SINK TEMPERATURE

OR IG INAL ISSUE: $\quad 4-18-67$ OCONEE NUCLEAR STATION FIGURE $14-40$ 
DESCRIPTION OF CALCULATIONAL METHODS AND DIGITAL COMPUTER CODES FOR ANALYZING COOLANT BLOWDOWN AND CORE HEATUP PHENOMENA

(This appendix is a copy of Appendix 1 from USAEC Report TID-24226 on "Emergency Core Cooling, Report of Advisory Task Force on Power Reactor Emergency Cooling," 1967.) 
THIS PAGE

\section{WAS INTENTIONALLY \\ LEFT BLANK}




\section{APPENDIX 1}

DESCRIPTION OF CALCUIATIONAL METHODS AND DIGITAL COMPUTER CODES FOR ANALYZING COOIANT BLOWDOWN AND CORE HEATUP PHENOMENA

This Appendix consists of a brief discussion of the analytical techniques available for analyzing the coolant-blowdown and core-heatup phenomena associated with a postulated loss-of-coolant accident.

This discussion is presented in the framework of safety philosophy discussed on p. 3 of this report: First, the nuclear plant is designed so that it is safe by a considerable margin in normal operation. Specifically, as discussed in Conclusions 7 and 8, and in Appendices 3 and 4, the occurrence of a large and rapid primary-system break is guarded against by great and increasing care in design, fabrication, quality control, inspection, and operation, and such occurrence is contrary to experience. Secondly, analyses such as those presented in this Appendix are made to find those component malfunctions which could affect safety, for instance to identify the size and speed of development of a break that would be serious. The analyses tell where the care in design, fabrication, quality control, inspection, and operation is most appropriately applied. Thirdly, failures and malfunctions are assumed to occur nonetheless, and engineered safeguards, such as the emergency core-cooling systems discussed in Appendix 2, are provided to keep the plant safe despite such failures. The coolant-blowdown and coreheatup analyses serve to firm up the requirements on the above engineered safeguards.

This Appendix includes summary descriptions of digital-computer programs frequently employed to obtain numerical solutions to specific postulated situations. The computer program descriptions were compiled from information obtained from the various investigators noted and are included for the purposes of indicating the available analytical tools and their intended functions.

The Task Force has not attempted, in the time available, to evaluate the validity or assess the accuracy of each of these analytical methods and computer programs, since such an evaluation is a massive effort. It is the Task Force's opinion that analytical methods for conservatively predicting the effects of coolant blowdown of importance to safety and describing the core heatup and cooling up to the time when core disassembly begins is within the capability of present technology. 
Currently available techniques for analysis of reactor system coolant blowdown and subsequent core heatup usually involve subdividing the overall problem into parts. Such a subdivision can be based on a chronological approach to blowdown, for example, in which the rapid subcooled decompression is treated separately from the slower two-phase portion of the blowdown transient. In other instances, the problem subdivision is constructed along the lines of various portions of the reactor primary system. For example, an approximate treatment of the over-all system would be used to provide approximate conditions for a separate and more detailed analysis of a component such as the reactor core. Even where the prediction of blowdown behavior is subdivided along lines such as these, the complexity of the problem invariably results in the use of digital computer programs to obtain numerical results. Descriptions of blowdown and core heatup analysis models and associated digital computer programs in current use are included in this appendix.

\section{Comparative Features of Analytical Models}

Current: blowdown and core heatup analyses invariably require approximations and simplifying assumptions to permit a tractable solution to the problem. These analyses vary greatly in detail accoraing to the purpose for which they were formulated. For example, an approximate treatment of the various components in the primary system of a PWR is incorporated in the FLASH $^{1}$ and RELAPSE ${ }^{2}$ programs so that the PWR primary system may be described and solutions obtained which are not economically prohibitive. On the other hand, the treatment contrined in the BURST ${ }^{3,4}$ computer program has considerable detail in treating a spatial distribtuion of flow quantities in one dimension so that the propagation and reflection of acoustic disturbances can be adequately predicted. BURST calculations become very.expensive, however, if the analysis is continued beyond the first few hundred milliseconds of the blowdown transient. Accordingly, more detailed analyses of blowdown and core heatup phenomena are generaily less suitable for extensive parametric studies.

Approximations in formliating blowdown analyses can generally be classified under the following topics:

1. Degree of spatial detail,

2. Components of the system included, and

3. Physical phenomena represented. 
Jdeally one would like to formulate a blowdown analysis based on a threedimensional representation of the hydraulics in the reactor coolant system. In practice a three-dimensional representation would probably exceed the capabilities of even the latest-generation digital computers. Current digital computer. solutions consist of, at most, one or two dimensions and, in several cases, a lumped parameter approach is utilized. Even in one- or twodimensional analyses there are limits on how fine the subdivisions can be made, i.e. how many mesh or node points can be used in representing the spatial distribution of quantities such as pressure, enthalpy and mass velocity. Components represented in blow-down analysis included such items as the main coolant pumps, check valves, steam generators and pressurizer in a typical pressurized water reactor system. In practice some of these components are neglected in certain analyses. For example, the system pressurizer is occasionally neglected in treating the early or subcooled portion of the blowdown transient, since its response time is relatively long compared to the phenomena of interest. Approximations or simplifying assumptions with regard to physical phenomena included in blowdown analyses frequently involve fluid properties (for example, neglect of the superheated steam region), heat transfer modes in the reactor core, reactor kinetics calculations and terms to represent the acoustic effects in the blowdown process. These acoustic effects, for example, can typically be neglected in a PWR blowdown analysis if the break initiation time is long compared to the roundtrip acoustic transport time in the primary system coolant.

a. Comparison of Computer Codes in Current Use for Blowdown. A comparative tabulation of various features and approximations contained in currently used computer codes is presented in Tables $I$ and 11 . Further details on each of these computer programs are described in the latter portion of. this appendix. The purpose of the comparison in Tables I and II is to provide a means for readily tabulating some of the more significant features contained in these blowdown computer programs. A similar tabulation of core heatup programs is also included in this appendix. Table I contains features in the representation of the reactor coolant system. The first three programs listed, BURST, SATAN, ${ }^{5}$ and WATER-HAMMER ${ }^{6}$ are intended primarily to include provision for rapid decompression in the subcooled portion of blowdown for a PWR reactor system. Consequently, these are distributed models in which one 
Table I Blowdown Computer Programs, Coolant System Features

\begin{tabular}{|c|c|c|c|c|c|c|c|}
\hline Computer Program & BURST & SATAN & $\begin{array}{l}\text { WATER } \\
\text { HAMMER }\end{array}$ & RELAPSE & LOCO & RIP & $\begin{array}{l}\text { K.E. } \\
\text { SAT. }\end{array}$ \\
\hline Originating org. & PPCO. & WAPD & K.E. & $\begin{array}{l}\text { PPCO. } \\
(\text { W-BAPL })\end{array}$ & WAPD & GE -APED & $\mathrm{K} . \mathrm{E}$. \\
\hline $\begin{array}{l}\text { Distributed or } \\
\text { Lumped Model }\end{array}$ & $D$ & $\mathrm{D}$ & $\mathrm{D}$ & L & $\mathrm{L}$ & $\mathrm{L}$ & $D$ \\
\hline $\begin{array}{l}\text { Subcooled and/or } \\
\text { 2-Phase Properties }\end{array}$ & Both & Both & $\mathrm{S}$ & Both & Both & Both & $2-P$ \\
\hline Sonic Effects & Yes & Yes & Yes & No & No & No & No \\
\hline $\begin{array}{l}\text { Slif or } \\
\text { Homogeneous Flow }\end{array}$ & $\mathrm{H}$ & $\mathrm{S}$ & $\mathrm{H}$ & $\mathrm{H}$ & - & $\mathrm{H}$ & $\mathrm{H}$ \\
\hline Free Liquid Surface & No & No & INo & Yes & Yes & Yes & No \\
\hline $\begin{array}{l}\text { Portion of } \\
\text { Blowdown Treated }\end{array}$ & $\because 1 \mathrm{sec}$ & All & $\sim 1$ sec. & All & All & $\begin{array}{c}\text { All } \\
\text { (BWR) }\end{array}$ & Sat. only \\
\hline $\begin{array}{l}\text { Pipe and Vessel } \\
\text { Heat Capacity }\end{array}$ & No & No & No & No & Yes & No & Yes \\
\hline Separate Pressurizer & No: & Yes & Yes & Yes & Yes & No (BWR) & Yes \\
\hline No. of Nodes & $\leq 4000$ & $\leq 70$ & 100 & 3 & $1-2$ & 5 & 53 \\
\hline
\end{tabular}


Table II Blowdown Computer Programs, Core and Leakage Features

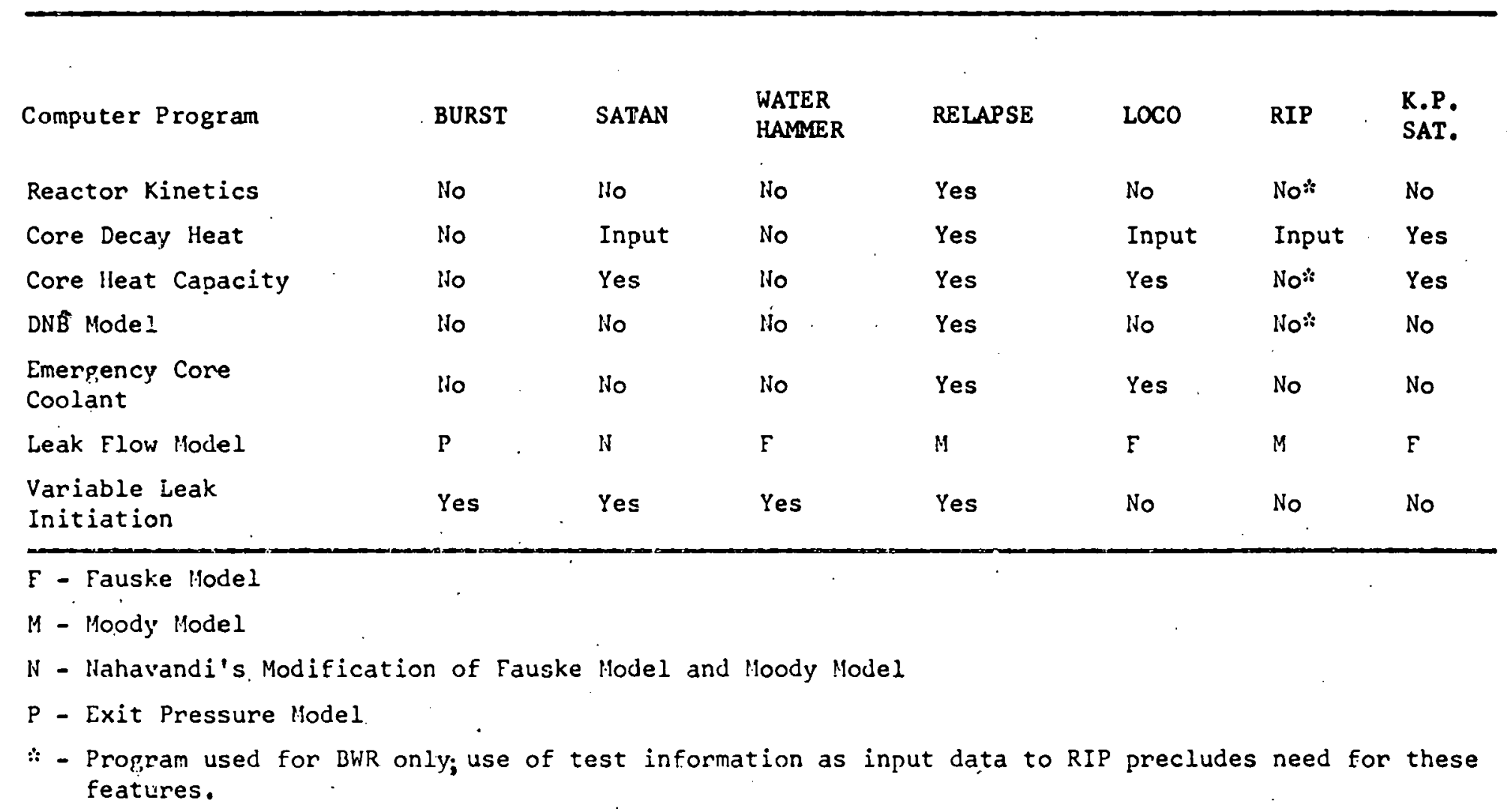


dimension (or, in a portion of the SATAN system, two dimensions) can be used in representing the primary system coolant. The appropriate terms in the conservation of energy are retained in BURST and SATAN to represent sonic effects and in the case of WATER-HAMMER, a wave superposition technique is employed for the acoustic propagation phenomenon. Certain items not of prime significance in the subcooled portion of the blowdown are neglected such as the provision for a free liquid surface, incorporation of pipe and vessel heat capacity and, in the case of BURST, provision for a separate pressurizer. The core and leakage features contained in Table II also show that reactor kinetics, DNB and emergency core coolant provisions are not incorporated in the first three programs. On the other hand variable leak initiation is provided so that the effects of differing rupture time on loads induced in the primary system can be studied. The remaining four computer codes listed in Tables I and II are primarily oriented toward the saturated portion of the blowdown transient ${ }^{7}$ and in the case of RIP, ${ }^{8}$ oriented toward a BWR system. Most of these codes contain lumped descriptions with acoustic effects neglected, provisions for a free liquid surface, and for PWR applications, a separate pressurizer. The information presented in Table II shows that RELAPSE is the more detailed of these computer codes describing the saturated portion of blowdown with regard to provisions for core heat transfer. RELAPSE contains a heat source description in terms of internally computed reactor kinetịcs and core decay heat and has a relatively complete description of heat transfer regimes including subcooled heating, nucleate boiling atd film boiling. Variable leak initiation is also a significant feature in RELAPSE, since the lack of acoustic terms in the analysis gives erroneous results for instantaneous leak initiation.

b. Comparison of Computer Codes in Current Use for Core Heatup. A comparative tabulation of various features and approximations contained in currently used core heatup computer codes is presented in Tables III and IV. Table III contains features in the representation of the reactor geometry and heat transfer mechanisms. The geometry applied most frequentily in these computer codes is radial and axial or annular ring. The number of nodes that can be utilized in describing the system varies from. 60 to 3500 , although this quantity is usually quite dependent upon the type of digital computer on which the computer program is run. The LOCTA-R ${ }^{5}$ and TACT-V ${ }^{8}$ programs are most frequently utilized for relatively large reactors where emergency core cooling 
Table III Core Heatup Computer Programs, Geometry and Heat Transfer Features

\begin{tabular}{|c|c|c|c|c|c|c|}
\hline Computer Program & LOCTA-R & TACT -V & NURLOC & $A R C-I I$ & MOXY - II & CHEMLOC-II \\
\hline $\begin{array}{l}\text { Originating } \\
\text { Organization }\end{array}$ & WAPD & GE - APED & BMI & PPCO. & PPCO. & ANL \\
\hline Type Geometry & $\begin{array}{l}\text { Radial \& } \\
\text { Axial }\end{array}$ & $\begin{array}{l}\text { Radial \& } \\
\text { Axial }\end{array}$ & $\begin{array}{l}\text { Annulạr } \\
\text { Ring }\end{array}$ & $\begin{array}{l}\text { Annular } \\
\text { Ring }\end{array}$ & $\begin{array}{l}\text { Quarter } \\
\text { Core:X-Y }\end{array}$ & $\begin{array}{l}\text { Radial \& } \\
\text { Axial }\end{array}$ \\
\hline Max. No. of Nodes & 60 & 1250 & 3500 & 350 & 460 & 2500 \\
\hline $\begin{array}{l}\text { Part of System } \\
\text { Represented }\end{array}$ & $\begin{array}{l}\text { Core } \\
\text { Fuel }\end{array}$ & Core & $\begin{array}{l}\text { Vesse1 } \& \\
\text { Core }\end{array}$ & $\begin{array}{l}\text { Vesse } 1 . \& \\
\text { Core }\end{array}$ & $\begin{array}{l}\text { Vessel } \alpha \\
\text { Core }\end{array}$ & Core \\
\hline $\begin{array}{l}\text { Conductive Heat } \\
\text { Transfer }\end{array}$ & $\begin{array}{l}\text { Radial } \\
\text { Oaly }\end{array}$ & $\begin{array}{l}\text { Radial } \\
\text { On:y }\end{array}$ & $\begin{array}{l}\text { Radial \& } \\
\text { Axial }\end{array}$ & $\begin{array}{l}\text { Radial } \& \\
\text { Axial }\end{array}$ & $\begin{array}{l}\text { Radial in } \\
\text { Fuel Pins }\end{array}$ & $\begin{array}{l}\text { Radial } \& \\
\text { Axial }\end{array}$ \\
\hline $\begin{array}{l}\text { Convective Heat } \\
\text { Transfer }\end{array}$ & Yes & Yes & Yes & No & Nò & Yes \\
\hline $\begin{array}{l}\text { Radiative Heat } \\
\text { Transfer }\end{array}$ & Yes & Yes & Yes & Yes & Yes & Yes \\
\hline Reflectivity & Yes & Yes & No & Yes & Yes & Yes \\
\hline View Factors & $\begin{array}{l}\text { Supplied } \\
\text { as Input }\end{array}$ & $\begin{array}{l}\text { Supplied } \\
\text { as Input }\end{array}$ & $\begin{array}{l}\text { Internally } \\
\text { Calculated }\end{array}$ & $\begin{array}{l}\text { Supplied } \\
\text { as Input }\end{array}$ & $\begin{array}{l}\text { Supplied } \\
\text { as Input }\end{array}$ & $\begin{array}{l}\text { Supplied } \\
\text { as Input }\end{array}$ \\
\hline $\begin{array}{l}\text { Type Solution of } \\
\text { Conduction Equation }\end{array}$ & Explicit & Explicit & Explicit & Explicit & $\begin{array}{l}\text { Lumped } \\
\text { Explicit }\end{array}$ & Explicit \\
\hline
\end{tabular}


Table IV Core Heatup Computer Proprams, Zr-Steam Reaction and Disassembly Features

\begin{tabular}{|c|c|c|c|c|c|c|c|}
\hline Somputer Program & & LOCTA-R & TACT $-V$ & INURLOC & ARC-II & MOXY - II & CHEMLOC-II \\
\hline $\begin{array}{l}\text { Zirconium-Steam } \\
\text { Reaction }\end{array}$ & $\cdot$ & Parabolic & Parabolic & $\begin{array}{l}\text { Parabolic } \\
\text { iNConc. Gra }\end{array}$ & Parabolic & Parabolic & $\begin{array}{l}\text { Parabolic } \\
\text { is Conc. Grad }\end{array}$ \\
\hline Steam Limiting, & & Yes & No & Yes & Yes & Yes & Yes \\
\hline $\begin{array}{l}\text { Clad Melting } \\
\text { (Heat of Fusion) }\end{array}$ & & Yes & Yes & No & Yes & No & Yes \\
\hline $\begin{array}{l}\text { Fuel Melting } \\
\text { (Heat of Fusion) }\end{array}$ & & No & Ho & No & Yes & No & Yes \\
\hline Core Migration & & $\begin{array}{l}\text { Cladding } \\
\text { Only }\end{array}$ & $\begin{array}{l}\text { Cladding, } \\
\text { Only }\end{array}$ & Yes & No & No & Yes \\
\hline $\begin{array}{l}\text { Emergency Coolant } \\
\text { Injection }\end{array}$ & & Yes & $\begin{array}{l}\text { Yes } \\
\text { Specify } h\end{array}$ & $\begin{array}{l}\text { Yes } \\
\text { Specify } h\end{array}$ & No & No & No \\
\hline $\begin{array}{l}\text { Steam Flow } \\
\text { Calculation }\end{array}$ & & $\begin{array}{l}\text { Supplied } \\
\text { As Input }\end{array}$ & Ho & $\begin{array}{l}\text { Internally } \\
\text { Computed }\end{array}$ & $\begin{array}{l}\text { Internally } \\
\text { Computed }\end{array}$ & $\begin{array}{l}\text { Supplied } \\
\text { As Input }\end{array}$ & $\begin{array}{l}\text { Supplied } \\
\text { As Input }\end{array}$ \\
\hline
\end{tabular}


system effects are of prime importance. Hence, the system description is restricted to the reactor core. Programs such as NURLOC, ${ }^{9} \mathrm{ARC}^{10}$ and MOXY, ${ }^{11}$ on the other hand, are frequently utilized to examine core heatup transients without coolant injection. Hence, points further away from the core such as the core barrel, thermal shields, and reactor vessel are represented. In general, core heatup analysis without emergency core injection results in higher temperatures over longer periods of time so that axial conductance as well as heat sinks further distant from the fuel element must be considered. Radiative heat transfer is incorporated in all heatup computer programs and convective heat transfer in most programs. Radiative heat transfer is usually calculated based on geometric view factors supplied as input to the computer programs and utilizing the reflectivity concept so that part of the radiation heat flux incident upon a given surface is absorbed and the remainder is reflected. Some form of the explicit difference equations is used in all of these computer programs as opposed to other techniques such as alternating direction of predictor-corrector techniques. ${ }^{12}$

The zirconium-steam reaction and disassembly features of the core heatup computer programs are presented in Table IV. In all instances, the reaction kinetics of the zirconium-steam reaction are treated using the parabolic rate law of Baker and Just. ${ }^{13}$. In NURLOC and CHEMLOC-II, ${ }^{14}$ an additional limitation on the reaction rate is imposed by the steam-hydrogen concentration gradients in the fluid adjacent to the cladding surface. In addition, most of these programs incorporate provision for determining the rate of steam supply to each cladding region in the core to determine whether the reaction is limited by steam availability to the local cladding region. Temperature dependent properties are provided in most instances, including the cladding heat-of-fusion and, in some cases, the fuel heat-of-fusion. Migration or changes in geometry of the core following the melting of cladding or fuel is treated in some instances. Emergency coolant injection is treated in the LOCTA-R program based on a core flood model. In the TACT-V and NURLOC programs, emergency coolant injection is treated by specifying a bulk fluid temperature and a film coefficient, $h$, as input parameters to the program. The steam flow to the core to determine the steam availability for zirconiumsteam reactions is internally computed by determining the boiloff rates of fluid in the lower reactor vessel in NURLOC and ARC-II. These data are supplied as input quantities to the other core heatup programs except for TACT-V 
in which the limitations on zirconium-steam reaction rates due to steam availability have not been included. More detailed descriptions of the core heatup computer programs included in these tables are presented in the next section of Appendix 1 .

\section{Description of Digital Computer Programs}

\section{BURST-I}

The BURST-I computer code was developed by Phillips Petroleum Company for the analysis of the early portion of blowdown transients, including considerations of leakage flow and decompression through the subcooled region, with provisions for vapor formation. A complete reactor primary system can be treated.

The time-dependent fluid conditions throughout the primary system are determined by direct numerical integration of the laws of conservation of mass, momentum, and energy including those terms necessary to represent acoustic propagation effects. Analysis of non-adiabatic systems are possible, with provisions for conditions of non-zero initial flow and with further provisions for use of both subcooled and two-phase fluid properties.

The analysis is one-dimensional, with that dimension being in the usual flow direction, i.e., parallel to the pipe or vessel axis; flashing occurs under conditions of thermodynamic equilibrium; slip flow is not included; computation time is long, but it is not excessive for the calculation of the first $100 \mathrm{msec}$ of blowdown time which is approximately the duration of that portion of the transient which BURST is intended to treat. BURST includes acoustic propagation effects in the fluid and therefore has no limitation on break opening time, provided the mesh spacing chosen to describe the system is sufficient to accommodate the desired break opening time.

Input required for BURST includes physical geometry, such as flow areas and pipe lengths; hydraulic flow characteristics such as pressure loss coefficients and friction factors; initial components of pressure, enthalpy and mass velocity throughout the system; time dependent distribution of heat input to (or removal from) the fluid; pressure-time history at the break.

Complete spatial distrituions of pressure, enthalpy and mass velocity throughout the system are established as functions of time. For convenience in anaiyzing these computational results, a detailed printout is provided of fluid qualities such as steam quality, sonic velocity, fluid density, the 
partial derivative of density with respect to pressure at constant enthalpy, and the partial derivative of density with respect to enthalpy at constant pressure. BURST has the capability of preparing graphs of pressure and mass-velocity distributions throughout the system at specific times during the transient and time histories of these quantities at specific locations within the system.

The time histories of the transient hydraulic loads on primary system components during blowdown are generated for use in structural analyses. Ultimately, BURST will. provide the initial conditions for a twophase forced-convection analysis of the remainder of the blowdown transient.

A preliminary comparison with data from subcooled tests in the LOFT Semiscale Blowdown Program shows that the predicted pressure-time history in the blowdown pipe represents the cyclic behavior observed in the experimental data quite well.

The reflection and transmission ratios at an area change based on BURST calculations agree with the ratios predicted by Transmission Line Theory as applied to acoustic distrubances. Studies of truncation-error characteristics have provided guidelines for obtaining accurate numerical solutions.

Rules of thumb are currently used to establish the mesh spacing and length-of-time step which will give satisfactory numerical solutions. Experience has shown that satisfactorily accurate numerical solutions can be obtained when the shape of the perturbing wave is represented by at least ten mesh points, when at least ten mesh points describe a change of area, and when a time step is used which is 98 to $99 \%$ of the stabilitylimiting time step. Since a time-step ratio of 0.98 to 0.99 gives optimum truncation-error characteristics, a choice of uniform mesh spacing is preferred for calculations where the acoustic velocity is nearly constant, a situation which characterizes the subcooled portion of a blowdown.

The LOFT studies to date have employed constant average fluid properties and have used about 900 mesh points to describe the LOFT primary system. Approximately 3600 time steps are needed to represent the first $100 \mathrm{msec}$ of a subcooled blowdown event, $100 \mathrm{msec}$ being the time period in the transient when acoustic effects may be very important. 


\section{SATAN}

SATAN is a digital computer program developed for blowdown analysis by the Westinghouse Atomic Power Division. The formulation in SATAN consists of a time space analysis of multi-loop PIN's in which one or two parallel loops can be employed in representing the primary coolant system. Analysis of both the early subcooled and later two-phase portions of the blowdown transient is permitted in SATAN with incorporation of terms required to determine the acoustic wave effects in considerable detail. The physical model in SATAN consists of conservation laws representing mass, momentum and energy in which the main dependent variables are pressure, enthalpy, liquid and vapor masses, and axial and radial (branch) mass flow rates. Subsidiary relationships are employed to determine auxiliary variables such as quality, density and temperature. The numerical integration of these conservation laws employs an explicit solution technique. Description of the fluid state properties includes the subcooled liquid, two-phase and superheated steam regions. Calculations at the break have provisions for variable rupture time. During the course of the calculations, flow reversal is permitted at any point in the system where it is required to satisfy the conservation laws. Heat transfer to and from the coolant is provided for in the core and steam generators respectively.

The formulation of SATAN provides for two space dimensions in the reactor core and one space dimension in the reactor coolant loops. The reactor core is treated in $\mathrm{R}-\mathrm{Z}$ coordinates. Description of the secondary coolant system is based on a lumped parameter approach. The primary coolant system can be divided up into as many as 70 spatial elements with variable meshsize based on the storage capacity of the IBM 7094 digital computer on which the program is run.

Comparisons with experimental data from the LOFT semi-scale blowdown test program have shown that SATAN is capable of representing the acoustic phenomena observed in the subcooled portion of the blowdown decompression. Moreover, these experimental comparisons generally give reasonable agreement between the predicted and observed pressure transients throughout the entire blowdown. The general trends of hydraulic 
loads on the reactor core as predicted by SATAN for a typical large PWR system indicate that a rupture time as large as $300 \mathrm{milliseconds}$ reduces loads on the core by at least a factor of two. Helmholtz type oscillatory core pressure drops have been predicted using SATAN with typical results giving \pm 400 psi amplitude at 15 to 17 cycles per second for large PWR systems.

The formulation of SATAN and its application to reactor blowdown problems are generally similar to the BURST computer program.

\section{WATER-HAMMER}

The WATER-HAMMER computer code was developed by Kaiser Engineers to analyze the initial stage of a decompression transient.

A decompression wave is started at a specified location and is followed through a linear system. Continuity of pressure and velocity across discontinuities gives rise to reflected and transmitted waves which combine to describe pressure as a function of time and position. The fluid is considered as a frictionless liquid capable of supporting tensile strain.

Frictional effects can be simulated by placing special orifices in the system.

A plotting routine is available in the IBM-7040 version.

Three special junctions are provided: exit junction, pressurizer junction, and check valve junction.

Provisions are made to account for pressure loss at the exit junction. The pressure does not drop to ambient but is maintained above ailitient by an empirical relation.

The exit orifice has a specified area and opens at a linear rate over a specified number of time steps.

Since energy balance is missing and constant acoustic velocity is assumed, only subcooled liquids can be described. When the pressure drops below the vapor pressure of the liquid, other means for investigation are required.

The code functions for zero initial velocity but has not been tested for non-zero initial velocity. 
Required input includes initial system pressure and saturation pressure, initial fluid velocity, area of rupture, time for rupture to open, rupture orifice characteristics, location of three special nodes, location of nodes for data printing, fixed speeds of propagation and pipe areas between nodes, time for wave to pass between successive nodes. Pressure and.time at specified nodes, fluid velocity and time at exit node are provided as output.

Since the program is valid only for the early transient, its use will always involve relatively short time on the computer.

\section{RELAPSE-I (FLASH)}

FLASH originated at Westinghouse-Bettis. RELAPSE-I is the PhillipsPetroleum modified version.

The FLASH computer program is primarily a blowdown code which predicts the approximate behavior of a loss-of-coolant accident in a pressurized water-cooled reactor system. Since most major reactor components are described in RELAPSE, the code also can be used to compare similar hypothetical accidents from a safety viewpoint. The effectiveness of certain design parameters, such as the location, flow rate, and temperature of an in-core coolant injection system, can be evaluated by using these codes.

FLASH contains simple mathematical models describing the major features of a reactor system. The primary coolant system description includes pumps, pressurizer, heat exchanger, check valve, and emergency fill-water provisions. The core description includes convective, nucleate boiling, and film boiling heat transfer along with void reactivity feedback for the reactor kinetics. Provisions for external reactivity control are included along with some automatic scram control options.

Two-phase fluid flow, assuming thermodynamic equilibrium is included. Separation of the steam-water mixture is treated by a constant velocity bubble rise model and leak flow is calculated by the Moody method. Physical property tables cover the range from 1 to 2400 psia and 32 to $5600^{\circ} \mathrm{F}$.

RELAPSE-I is a modified version of FLASH for adaption to the IBM7040 where the input/output provisions are different along with some of 
the programming structure. Other changes include a different reactor kinetics package based upon IREKIN computer program, Doppler and energydependent reactivity feedback, an automatic rather than an explicit time dependent heat exchanger, the provision for an air head in the pressurizer, an expanded set of scram control options, and extension of the steam tables from 2400 to 3200 psia.

Since the mathematical models describing the system are simple, care must be used in the interpretation of the calculated behavior. For instance, geometric detail in both the core and primary loop is suppressed in preference to the total system description. Also, certain phenomena such as sonic effects and core melting are not included.

Interpretation of short duration effects as calculated by the code is highly questionable since the models are insufficient to show this kind of detail. Specifically, the code does not describe fast ruptures which can produce traveling pressure waves and metastable conditions.

Both FLASH and RELAPSE-I are constructed for analysis of pressurized water reactors (PWR) and do not include provisions, such as zero core flow, for pool-type or natural-convection reactors.

The required input includes primary volumes, relative heights for pipe junctions, leak areas and locations, fluid inertias, friction factors, pump and fill system data, heat transfer parameters, reactor kinetics parameters, scram control data, and initial conditions on power, flow, pressure, and enthalpy.

The output data consist of local pressures, flows, masses, liquid and two-phase mixtures levels, fluid properties, heat fluxes and transfer quantities, reactivitles, core leiliperatures, and power.

In a blowdown calculation, the final conditions such as local watersteam inventories and core temperatures, are necessary input information for subsequent core heat-up and meltdown calculations. In some cases, transient pressures can be used to estimate the forces, neglecting sonic phenomena, generated across the core. Sometimes the transient displays important interactions between system components such as the effect of emergency fill water or inadequate pressurizer design.

The calculated pressure transients for top breaks and subcooled gasdriven cases are in good agreement with the experimental flask blowdowns 
being performed at TAN (Test Area North*). Calculated bottom break pressure transients do not agree as close as the other cases.

The predicted amount of water remaining in the flask after blowdown is in good agreement with the steam-driven bottom,breaks and the gas-driven, subcooled blowdowns. The steam-driven top break mass calculations, in general, seriously underestimate the amount of water remaining in the flask. Cyclic pressure phenomena, predicted by FLASH, have been seen in simulated reactor loop blowdowns.

The trends observed in parameter studies on leak size, initial pressure, power, etc., appear correct. For example, slow depressurizations allow more phase separation than faster blowdowns, resulting in larger amounts of water remaining in the system.

\section{LOCO}

The LOCO computer program was developed by Westinghouse APD for treatment of blowdown predictions where small breaks are involved. The method employed in LOCO involves determining blowdown behavior throughout the reactor primary system by small incremental steps in system pressure during the blowdown transient. For each of these steps the makeup in blowdown mass flows are determined from mass and energy balance considerations and also flow equations. The relative values of the makeup in blowdown flows then determine decrease in system pressure for the next series of calculations. Spatial variations in pressure throughout the primary system as they affect the coolant properties are not considered, hence, LOCO is restricted to relatively small break sizes and consequently gradual system depressurization rates. Detailed core thermal analysis during blowdown utilizes output from LOCO as used for detailed thermo-calculations in the LOCTA-R computer program.

RIP

(Reactor Internal Pressure) Computer Program

The RIP program was developed by GE-San Jose for analysis of BWR blowdown problems including the pressure vessel blowdown, the determination of pressure distribution, and forces on reactor internals. Critical liquid, two-phase or steam flow is employed to determine the blowdown flow rate. Subcooled or two-phase fluid properties are employed, together with provision for a distinct water level so that uncovering of the reactor core can be represented during blowdown.

*Phillips Petroleum Company, National Reactor Testing Station. 
The reactor vessel is represented in the RIP program by a series of constant volume nodes interconnected by two-phase flow resistances. Up to five such nodes can be provided and are typically employed to represent the reactor core, the lower plenum, the upper plenum, the mixing and downcomer reglon, and the steam dome, respectivély. Reactor power time history during blowdown is supplied as an input, with experimental data on heat transfer to the coolant employed to determine coolant enthalpy rise. The five nodes into which the fluid in the reactor vessel is divided are interconnected by two-phase frictional flow resistances. Momentum terms comprising temporal and spatial components are neglected. The pressure distribution throughout the reactor vessel system during blowdown is determined based on the above model so that pressure drops across the reactor core can be provided to determine the effects of hydraulic loads.

The rise in the liquid level in the mixing and downcomer region is treated in the subsidiary calculation based on output from the RIP code. This approach considers the time dependent pressure in the downcomer region as well as the coolant enthalpy predicted by RIP and is based on a steam separation model. Results of the water level calculation are used as input in succeeding RIP calculations by means of determining the time at which the dryer flow switches to a net quality condition. Provision is also included in RIP for a transient time delay in the steam line so that the switch in fluid conditions of the dryers is not immediately seen at the critical flow location for steam line breaks.

\section{KE Saturated Blowdown Code}

Kaiser Engineers developed the Saturated Blowdown Code. The purpose of the code is to provide a means of analyzing the pressure and thermal transients that occur during the saturated portion of a blowdown process resulting from a break in the primary cooling line of a pressurized water reactor system.

The mathematical model employs the basic mass-, momentum-, and energyconservation equations to compute transient pressure, temperature, and mass-flow conditions occurring throughout the coolant loop during the blowdown. Homogeneous two-phase flow is assumed during the blowdown and 
Fauske's Critical Flow Model is used to compute exit or break mass velocities. State properties for the two-phase water-steam mixture are provided by Steam Table subroutines. Thermodyamic equilibrium of the steam-water mixture is also a basic assumption employed in the model.

The code considers the primary coolant loop as a series of nonuniform segments whose sizes depend upon both natural boundaries and expected rates of pressure changes. The coolant loop consists of reactor, heat exchanger, pump, pressurizer, check valve, and piping. The code can be adapted to handle coolant line breaks at either the inlet or the outlet of the reactor vessel.

Heat transfer between the coolant line wall and the fluid is computed in all segments by means of forced convection equations. Temperature profiles within all segment walls except the reactor core and the heat exchanger are computed by transient conduction equations. For the reactorcore and heat-exchanger segments, lumped-parameter heat balances are employed to compute core and heat-exchanger tube temperatures. An option is included in the code whereby reactor core decay heat generation may be included in the core heat balance. If used, the decay heat generation rate is based on an assumed steady state power level of 50 megawatts.

In order to obtain computational convergence, it was necessary to preclude the possibility of coolant flow reversals in the loop. Therefore, it is necessary to assume that the initial mass velocity throuphout the loop is zero.

Because of computer core space limitations, the maximum number of segments that may be used to represent the coolant loop is 53 .

The model is limited to consideration of the saturated portion of the blowdown process. Subcooled blowdown cannot be considered.

Because of the assumptions of homogeneous two-phase flow and thermal equilibrium no effects of slip flow or separation are considered. The code input is divided into the following four basic categories with typical examples of data:

System Geometry: Number of segments, segment volumes, flow areas, equivalent diameters.

Hydraulic Information: Flow characteristics such as wall relative roughness and pressure-loss coefficients. 
Heat-Transfer Characteristics: Thermal properties of segment wall, reactor core and heat exchanger heat capacities, segment heat transfer areas.

Initial Conditions: Steady state pump discharge pressure, initial segment temperature.

For each segment in the coolant loop, the fluid pressure, temperature, mass velocity, quality, and specific volume as functions of time are supplied as output data. In addition, the mean heat-transfer coefficient and heat-transfer rate between the fluid and the wall for each segment are also tabulated in the output.

- The output quantities described above are intended to provide pressure and temperature histories for use in structural analysis.

A review of the code logic developed by the Service Bureau Corporation revealed two major errors. The first was associated with the input of total heat capacity of both the reactor core and heat exchanger. These values were supplied as input but were never used in the calculations because they were erroneously recalculated in the code. The second error was associated with storage of computed segment wall temperature profiles. Two tapes were used for storage. One tape was to store previous computation values while the second was to store current calculation values. The intent was to alternate tapes when advancing from one calculational step to the next. However, it was found that proper sequencing of the tape was not accomplished so that same values were always used for "previous time step" values. No estimate of the effect of these errors on the blowdown process has been made nor is there any assurance that other errors are not present.

It is necessary to establish convergence criteria for various computation sections in the code before reasonably accurate data may be obtained. One such item included in the criteria is maximum number of iterations to be allowed in computing certain key parameters. Another convergence criteria item is the specification of tolerances on variables such as pressures, pressure drops, mass flows, and mass flow adjustments in the iterations. 
LOCTA -R

The LOCTA-R computer program was developed by the Westinghouse Atomic Power Division for detailed thermal analysis of the reactor core response to a loss-of-coolant accident. The reactor fuel elements are treated by use of finite-difference conduction equations in the radial direction only. Description of the fuel elements consists of three fuel nodes and one cladding node. In addition, various axial sections of this radial representation are stacked to give the full core length effects including the temperature $r i s e$ in the steam flowing past the fuel elements.

Internal heat generation $c a n$ be provided as input to LOCTA-R or can be computed internally based on the decay heat (fission product, capture products, and delay neutrons). Input describing the blowdown process is required from a computer program such as FLASH including information describing the time behavior of the inlet coolant terperature, liquid level and pressure. The method incorporated in LOCTA-R includes calculation of the zirconium-steam reaction energy based on a parabolic rate law with steam limiting provisions. The zirconium oxide reaction product film is assumed to remain on the surfaces of the fuel elements and is included in determining the conductive resistance to heat loss from the elements. The zirconium oxide is assumed to contain any molten Zircaloy after the clad melting temperature is reached and up to the point where the zirconium oxide melts. After the oxide melting point is reached, the molten metal cladding remaining (if any) is assumed to drop into the bottom of the reactor vessel where $10 \%$ further $z$ irconium steam reaction is assumed to occur before the metal is cooled below the reaction threshold temperature.

Heat-transfer coefficients incorporated in the LOCTA-R program include the nucleate boiling regime where a value of approximately. 10,000 $\mathrm{Btu} / \mathrm{hr} \mathrm{ft}^{2 \circ} \mathrm{F}$ is used and the film boiling range where the film coefficient is dependent upon local pressure, quality, and flow, ranging from 100 to $1000 \mathrm{Btu} / \mathrm{hr} \mathrm{Ft}^{20} \mathrm{~F}$. After the core is uncovered, laminar or turbulent heat-transfer film coefficients are employed for heat transfer to the steam depending upon the local value of the Reynolds number. Finally, a pool boiling film coefficient in the range of $75 \mathrm{Btu} / \mathrm{hr} \mathrm{fl}^{20} \mathrm{~F}$ is used after the core is re-covered with water from the emergency core coolant system. 


\section{-TACT V}

The TACT V code was developed by GE-San Jose to treat core heatup beginning with the assumed time of the break in the reactor system. The model incorporated in TACT permits core subdivisions in both the radial and axial direction with further subdivisions within each fuel bundle to accommodate several zones of fuel rods. The total number of such nodes permitted for the complete reactor core description is 1250. Radiation heat transfer between fuel rods and from fuel rods to the channel boxes is considered. However, no net heat loss from the reactor core is provided except that convected away by the steam and hydrogen leaving the core. The program provides for a continuous calculation of the extent and current rate of zirconium-steam reaction for all surfaces within the reactor core based upon the above nodal subdivision. Zirconium-steam reaction rate calculations are performed using the parabolic rate law of Baker. The distribution of spray flow over the top of the core and the effective cooling of fuel bundles from this spray are predicted using experimental correlations developed from tests performed at GE.

NURLOC

The NURLOC computer program has been written at Battelle-Columbus for the comprehensive analysis of core-pressure vessel heat transfer during a loss-of-coolant accident. NURLOC, is based upon a generalized procedure for numerically solving the two-dimensional heat-conduction equation over several connected regions with various complicating factors specific to this application. A variable-interval rectangular mesh is superimposed upon the problem geometry which is assumed to be axisymmetric. For the reactor problem, equivalent cylindrical shells are used to represent groups of individual fuel pins and control rods. These shells are concentric with the remaining cylindrical geometry representing the pressure vessel, core support structure, thermal shield, and any other internal structure that may be present. The mesh intervals are adjusted such that the density of mesh intersections is highest in the regions of interest and region boundaries coincide with mesh intersections. The numerical procedure then consists of solving the explicit finite-difference form of the conduction equation at each of the mesh intersections. 
With the explicit form, the temperature at each mesh point is calculated in terms of the temperatures at a time earlier by a small finite time increment.

Boundary conditions and heat generation rates are set by models which characterize various complex chemical and physical processes which can occur during an accident. The processes considered in NURLOC include boil-off of residual coolant water, metal-water reactions, radiative exchange, and material transport as a result of melting in addition to the usual conditions of convection, fission product decay heating, and delayed neutron heating.

The effects of core meltdown on heat transfer are treated by assumption of the motion of the melted materials and subsequent calculation of heat transfer in the altered geometry by the general procedure described above. 'Thus the model consists of an assumed sequence of material motion (which is controlled by temperature) and a set. of general procedures which alter the geometry according to the assumed sequence while maintaining conservation of energy and mass.

$$
\text { ARC-II }
$$

ARC-II is a Phillips Petroleum Company computer code for the'calculation of the extent of metal-water reaction and reactor heatup following a loss-of-coolant accident.

ARC-II is based on an annular ring concept for the representation of the nuclear reactor system. Radially the geometric representation of this FORTRAN-IV computer program includes fuel, cladding, control rods, flow skirt, support barrels, thermal shield and reactor vessel wall. Axially the geometry extends up to the reactor outlet nozzle and down to the reactor bottom head. Important heat sinks such as core support grids, control-rod guide-tube extensions and the inlet flow baffle are included. The heat sources in ARC-II are fission product decay heat (spatial and time dependent) and metal-water reaction heat. The metal-water reaction is based on parabolic rate law and may be steam limited. Steam availability to the core may be input to the program or computed based on convective heat-transfer nodes in the bottom head. The steam available to successive axial core levels is 
determined by material balance. Axial and radial conduction within the geometric components is allowed. Axial and radial gray-body radiative heat transfer is allowed between all elements depending on visibility. The thermodynamic properties of materials are temperature dependent. Melting of fuel and cladding to include the latent heat of fusion is allowed but changes in core geometry are not yet part of ARC-II.

The number of temperature node points that may be used depends on the available computer. ARC-II is limited to approximately 350 node points on the IBM-7040. The input parameters include geometry, material properties, radiation view factors, and fission product decay heat. The output includes complete time- and space-dependent temperature profiles, heat generation rates, radiative heat transfer rates, heats of fusion, heat stored, metal-water reaction heat, and oxide growth.

MOXY - II

MOXY-II is an exploratory program developed by Phillips Petroleum Company to evaluate "lumped" model techniques for the analysis of core heatup and meltdown following a loss-of-coolant accident.

MOXY-II is used to determine core temperatures based on radiative and conductive heat transfer in $x-y$ coordinates for a quarter core representation. MOXY-II can be used to describe $n$-regions within a quarter core. Approximately 100 radiating surfaces within a region are allowed. The radiative heat transfer is based on gray-body radiation to include reflectivity which allows interchange of heat between surfaces that are not directly visible to each other. Region skipping of radiative heat from inner regions to regions not directly adjacent is included. MOXY-II has the capability of providing a fairly detailed temperature description of structural components such as filler pieces and control rods. The code allows for space and time-dependent fission-product afterheat and computes metal-water reaction heat. The metal-water reaction heat is computed based on the parabolic rate $\mathrm{law}^{\mathbf{b} 3}$ and a specified quantity of steam. MOXY-II does not account for cladding melting and changes in geometry due to "slumping" or for convective or radiative heat losses to the steam. The required input parameters are materials properties, radiative-heat-transfer view factors, fission product decay heat (spatial and time dependence), system geometry and description. The output of 
MOXY-II includes complete time-dependent spatial distributions of temperature, heat generation, metal-water reaction heat, oxide growth, rate of radiative heat transfer, and heat stored.

\section{CHEMLOC-II}

CHEMLOC-II is an Argonne National Laboratory computer code for the calculation of the extent of metal-water reaction and core heating following a loss-of-coolant accident.

CHEMLOC-II is based on a cylindrical geometric representation of the reactor core. This FORTRAN computer code takes into account axial and radial conduction in the fuel and cladding, radial radiation from cladding to cladding, and convection from cladding to flowing gas. The heat sources are fission product decay heat (space and time dependent) and metal-water reaction heat. The metal-water reaction is based on the parabolic rate law and may be steam limited. Steam availability to the bottom of the core is supplied as input with availability to successive axial levels computed according to steam consumption. A concentration gradient concept is employed as a metal-water reaction limiting mechanism. The temperature of gas in the core is evaluated. The thermodynamic properties of the system are temperature dependent. Provision for description of other components in the core such as control rods and fuel canisters has been made. CHEMLOC-II has provisions for the melting of components and for" changes in core geometry. 


\section{References}

1. J. A. Redfield and S. G. Margolis, FLASH - A Program for Digital Simulation of a Loss-of-Coolant Accident, USAEC Report WAPD-TM-534, Westinghouse Electric Company, Atomic Power Department, Pittsburgh, Pennsylvania, May 1966.

2. G. E. Gruen and K. V. Moore, Rod-Ejection Analysis Using the RELAPSE IBM-7040 Code, ANS Transactions, 9(1): 307-308 (June 1966), American Nuclear Society Annual Meeting, Denver, Colorado, June 20-23, 1966.

3. K. A. Dietz (Ed.), LOFT Analysis - Hydrodynamics Describing Acoustic Phenomena During Blowdown, Pp. 45-55, Quarterly Technical Report STEP Project July 1965-September 1965, Section III, USAEC Report ID0-17165, Phillips Petroleum Company, National Reactor Testing Station, July 1966.

4. K. A. Dietz (Ed.), LOFT Blowdown Analysis, PP. 65-69, Quarterly Technical Report STEP Project October 1965-December 1965. Section IV, USAEC Report ID0-17167, Phillips Petroleum Company, National Reactor Testing Station, September 1966.

5. Private communication, J. McAdoo, Westinghouse Electric Company, Atomic Power Department, Pittsburgh, Pennsylvania.

6. Stanislav I'abic, Early Blowdown (WATER-HAMMER) Analysis for Loss-ofFluid-Test Facility, Kaiser Report 65-28-R, Kaiser Engineers, June. 1965.

7. Stanislav Fabic, Digital Computer Blowdown Analysis for Loss-ofFluid Test Facility, Part 1: Engineering, Part 2: Programming, Kaiser Report 65-29-R, Kaiser Engineers, May 1965.

8. Private communication, D. A: Rockwell, General Electric Company. Atomic Power Equipment Division, San Jose, California.

9. D. L. Morrison et al., An Evaluation of the Applicability of Existing Dala lu the Analytical Description of a Nuclcar-Roactor Aocident, USAEC Report BMI-1779, Battelle Memorial Institute, Aug. 12, 1966.

10. K. A. Dietz (Ed.), Quarterly Technical Report STEP Profect April 1966-June 1966, USAEC Report IDO-17187, Phillips Petroleum Company, National Reactor Testing Station, January 1967.

11. K. A. Dietz (Ed.), Quarterly Technical Report STEP Profect January 1966-March 1966, USAEC Report IDO-17186, Phillips Petroleum Company, National Reactor Testing Station, November 1966.

12. R. D, Richtmyer, Difference Methods for Initial Value Problems, Intersclence Tracts in Pure and Applied Mathematics, No. 4, Interscience, New York, 1958. 
13. L. Baker, Jr., and L. C. Just, Studies of Metal-Water Reactions at High Temperatures. III, Experimental and Theoretical Studies of the Zirconium-Water Reaction, USAEC Report ANL-6548, Argonne National Laboratory, May 1962.

14. Argonne National Laboratory, Reactor Development Program Progress Report, October 1966, USAEC Report ANL-7267, October 1966. 
Appendix D

COMPANIES, INSTALLATIONS, AND PERSONS VISITED REGARDING

INFORMATION FOR THIS REPORT

\begin{tabular}{|c|c|c|}
\hline Company or Installation & Individuals Contacted & Date of Visit \\
\hline $\begin{array}{l}\text { USAEC, Germantown, } \\
\text { Maryland }\end{array}$ & $\begin{array}{l}\text { A. J. Pressesky } \\
\text { R. J. Impara } \\
\text { R. R. Newton } \\
\text { G. Arlotto }\end{array}$ & $8-9-66$ \\
\hline $\begin{array}{l}\text { Combustion Engineering, } \\
\text { Inc., Windsor, Connecti- } \\
\text { cut }\end{array}$ & $\begin{array}{l}\text { V. C. Hall } \\
\text { J. R. Parrette } \\
\text { W. K. Wilhelm } \\
\text { I. M. Johnson } \\
\text { F. Bevilacqua } \\
\text { J. M. West } \\
\text { R. L. Hoover } \\
\text { P. C. Zmola } \\
\text { J. R. Dietrich } \\
\text { A. Nelson }\end{array}$ & $9-22-66$ \\
\hline $\begin{array}{l}\text { General Electric Company } \\
\text { (meeting at ORNL) }\end{array}$ & $\begin{array}{l}\text { R. McWhorter } \\
\text { J. Smith }\end{array}$ & $9-29-66$ \\
\hline $\begin{array}{l}\text { General Electric Company } \\
\text { (meeting at San Jose, } \\
\text { Cal.iforni.a) }\end{array}$ & $\begin{array}{l}\text { J. Russ } \\
\text { O. Foster } \\
\text { R. P. Rray } \\
\text { L. Kline }\end{array}$ & $9-9-66$ \\
\hline $\begin{array}{l}\text { Phillips Petroleum Com- } \\
\text { pany, Idaho Falls, Idaho }\end{array}$ & $\begin{array}{l}\text { N. Sowards } \\
\text { J. Waage } \\
\text { S. E. Jensen } \\
\text { W. Little } \\
\text { R. P. Rose } \\
\text { G. Brockett } \\
\text { T. Wilson }\end{array}$ & $\begin{array}{l}9-5 \text { and } 9-6 \\
1966\end{array}$ \\
\hline $\begin{array}{l}\text { Battelle Memorial Insti- } \\
\text { tute (meeting at ORNL) }\end{array}$ & D. L. Morrison & $10-10-66$ \\
\hline $\begin{array}{l}\text { Westinghouse Electric } \\
\text { Corporation, Pittsburgh, } \\
\text { Pennsylvania }\end{array}$ & $\begin{array}{l}\text { R. A. Dean } \\
\text { J. D. McAdoo } \\
\text { R. A. Wiesmann } \\
\text { T. Paxton }\end{array}$ & $\begin{array}{l}11-15-66 \\
11-16-66\end{array}$ \\
\hline $\begin{array}{l}\text { Babcock \& Wilcox, Inc., } \\
\text { Lynchburg, Virginia }\end{array}$ & $\begin{array}{l}\text { J. H. Taylor } \\
\text { H. Flora } \\
\text { C. E. Parks }\end{array}$ & $11-21-66$ \\
\hline $\begin{array}{l}\text { Battelle Memorial Insti- } \\
\text { tute, Columbus, Ohio }\end{array}$ & $\begin{array}{l}\text { D. Morrison } \\
\text { S. Bashan }\end{array}$ & $1-10-67$ \\
\hline
\end{tabular}




\begin{tabular}{|c|c|c|}
\hline Company or Installation & Individuals Contacted & Date of Visit \\
\hline USAEC (meeting at ORNL) & $\begin{array}{l}\text { A. J. Pressesky } \\
\text { F. Schroeder }\end{array}$ & $4-25-67$ \\
\hline $\begin{array}{l}\text { General Electric Company } \\
\text { (meeting at San Jose, } \\
\text { California) }\end{array}$ & $\begin{array}{l}\text { L. Klein } \\
\text { R. Leffengren } \\
\text { P. O. Ianni }\end{array}$ & $8-7$ and $-9,1967$ \\
\hline $\begin{array}{l}\text { Phillips Petroleum Com- } \\
\text { pany, Idaho Falls, Idaho }\end{array}$ & $\begin{array}{l}\text { W. S. Little (PA and ET) } \\
\text { L. Schlenken (PA and ET) } \\
\text { H. Curet (LOFT) } \\
\text { J. R. Wilson (IOFT) } \\
\text { R. Jensen (LOFT) } \\
\text { G. Bright (WRSPO) } \\
\text { F. Schroeder (WRSPO) }\end{array}$ & $10-9$ and $-10,1967$ \\
\hline $\begin{array}{l}\text { Westinghouse Electric } \\
\text { Corporation, Pittsburgh, } \\
\text { Pennsylvania. }\end{array}$ & $\begin{array}{l}\text { J. Dorycott } \\
\text { R. Salvaton } \\
\text { R. Dean } \\
\text { D. Paddleford }\end{array}$ & $11-16$ and $-17,1967$ \\
\hline
\end{tabular}

